\title{
"At least I have a house to live in": Māori and Pacific young people's hopes and fears about the future
}

\author{
A thesis \\ Submitted to the Victoria University of Wellington \\ In fulfilment of the requirements for the degree
}

Master of Arts in Education

at

Victoria University of Wellington

2017

by

HINE RANGI MARIE FUNAKI 


\section{INSPIRATION}

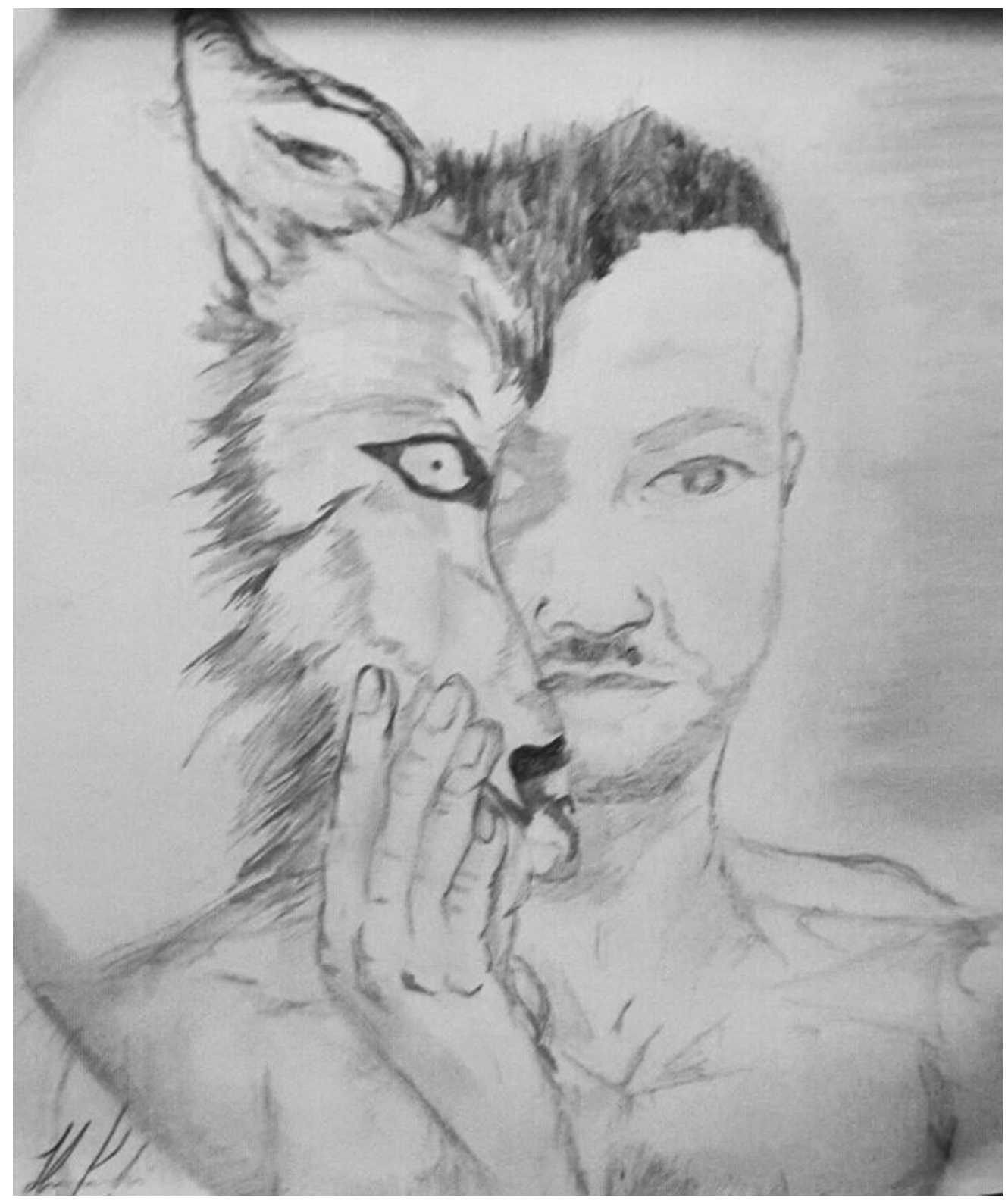

After reading Olga Ulturgasheva's (2012) book, Narrating the future in Siberia: Childhood, adolescence and autobiography among the Eveny, I was inspired by a future-focused concept called djuluchen that she uses in her study. Djuluchen refers to a 'forerunner' or travelling spirit that parts from the host (or in this case, the narrator planning their future), venturing out into the narrated future as it waits for the host to 'catch up' at the planned destination. In this current study of hope and narrating the future, I was drawn to the spiritual aspect that djuluchen encapsulates. The act of narrating one's own future is an agentive act and a powerful tool for transformative change. I drew this abstract piece representing my perception of djuluchen for my best friend Aaron to instil hope, future thinking, planning and narrating. This was at a time where he was facing uncertainty about the future. 


\section{ACKNOWLEDGEMENTS}

Ehara taku toa i te toa takitahi, engari he toa takitini. Success is not the work of one, but the work of many.

Words cannot express the gratitude that I have for those who have helped me as I make my way through my journey. I would firstly like to thank my supervisor, Associate Professor Joanna Kidman for believing in me and helping me grow as an academic. The timely feedback and feed-forward has given me hope to continue in this path to make a change in the education field. Your patience in scaffolding my learning as I journeyed through this Masters process has given me support and guidance as well as the freedom to share my own passions. There were no limits to the lengths that you went through as you mentored me and for that, I am truly grateful. Not one single piece of advice you have given has gone unappreciated. From suggesting me to simply breathe, to efficient data management strategies, I have gained a vast amount of learning from your wisdom.

I would also like to thank leaders who I have always looked up to who not only make a difference in academia, but also in a community setting. Dr Cherie Chu, Associate Professor Kabini Sanga and Dr Fiona Beals have demonstrated leadership qualities that I aspire to be able to display. I have come to stand-still moments in my academic journey where I have questioned my ability to continue, and through their mentorship, they have helped me come to realise my own potential. My resilience has grown stronger with their belief in me. I cannot thank you enough Dr Fiona Beals (Dr Phi, leading by degrees) for your wealth of knowledge and input in developing the focus group activities and walk-along questions.

This research could not have been possible without the participants who gave their time to the study. Their willingness to contribute to the body of knowledge for Māori and Pacific young people is indebted to their stories. The richness and depth of personal narratives shared have inspired me to continue further in my research. Therefore, a special thank you is dedicated to both participant groups, their families for allowing them to take part as well as the boxing gym involved. I am deeply grateful for the immense support and encouragement from the trainers and gym manager at the boxing gym. Thank you for allowing my study to take place among your members. I am inspired by your leadership and genuine hope for transformative change in your community.

I would like to gratefully acknowledge funding for this research from Ngā Pae o te Māramatanga, Māori Centre of Research Excellence and Victoria University of Wellington for the Victoria Research Support grant, the Tū Horomata scholarship, and the Victoria Masters by Thesis Fees scholarship. Without the scholarship funding managed by student finance and the scholarship office at Victoria University of Wellington, this study would not have been completed in the time it was. I would also like to acknowledge financial grants received by my iwi Ngāi Tahu and Ngā Puhi who believed in my journey. 
Often people are forgotten. However, I cannot omit administrative help from Pine Southon. You have done everything you can to make matters easier for me and have taken a vast amount of stress off my shoulders. I am truly appreciative for your support.

To Kirsten Reid from Student Learning and Support Services at Victoria University and Sean Fernandez, you have both provided timely support in helping me make sense of my own writing and format, I am forever grateful.

My appreciation for my family can never be restricted to one page. I have witnessed the strongest woman I know stand up for social justice and lead others towards change, all the while putting everyone and their needs before her own. My mother Tina Birch will even continue to help others in need as she lay in a hospital bed. Her leadership, love and support know no bounds. I am honoured to have had the privilege of being raised by my mother, a strong people leader who never backs away from a challenge, who always stands up for peoples' rights. I have had the best a mentor believing in me from day one. When times get tough and I see no hope, I hear her words "when you fall off your bike, what do you do? You get up, and you get back on again". My mother and my pops Terry Managh have supported me every step along my way. They have removed barriers to my achievements and supported me in any area of need. My siblings Tui Funaki, Piripi Birch and Christina Funaki-Randell have not doubted me once in my journey. They give me reasons to appreciate the meaning of family and unity. Although when we are all together, dysfunction is one word that comes to mind, not far from that is love.

Those who I keep close to me have literally given me their shoulder to cry on, on many occasions. Chy Edmonds and Aaron Cole, you have provided me with unconditional support throughout our friendship. You have been there through the good, the bad and the ugly, supporting me mentally, socially, spiritually, and every other way possible. Your silliness and humour keep me smiling and laughing. Aaron in particular, for the past six years, you have been the first person I consider coming to when I have exciting news, sad news, scary news or when I am struggling with adverse situations, doubt, anxiety and at times, depression. You have journeyed with me through this process, never losing hope or belief in me. I recall a time where you suggested that hope is all you need, and I argued that will was more superior. You were right. I know that now as I explore the hopes of these young leaders in this study. Thank you for seeing the hope that I could never see and showing me how to find it for myself.

Finally, I dedicate this thesis to my son Blade Williams. Watching you grow older and as our conversations get longer, I realise that you are now eight years old. We are growing together, learning together and from each other. I am reminded of the sacrifices that we have both endured for this day, and I promise you that it is not in vain. Despite shorter time together during both of our busy days, you continue to show your immense love and care for others. Coming home with flowers that you picked me, or a picture of my favourite animals you printed out are only few examples of the unconditional, thoughtfulness that you possess. Do not ever change. Be the strong person I have had the privilege to raise and call my son. I love you my darling, my number one. 


\begin{abstract}
Young people are often represented as the leaders of the next generation and much attention is given to the need for them to become more active participants in shaping the nation's future. Over the years, education policy makers, health officials, government representatives in the criminal justice and welfare systems have sought ways of involving New Zealand's youth more closely in civic society as they grapple with a daunting range of problems, many of which are likely to significantly worsen in the coming years. Despite these efforts, the views of some of the most economically and politically marginalised indigenous and/or racialized young people continue to be elusive and as a result a less nuanced understanding is available about how young people think about their lives in times ahead.

This study explores the hopes and fears that marginalised urban Māori and Pacific youth hold about the future and how they establish a sometimes fragile sense of belonging in precarious and uncertain times. In this project, Māori and Pacific young people were invited to discuss their aspirations and anxieties about the future and how these ideas are influenced by their everyday local 'places' in the present. Two participant groups were involved in the project; one included Māori youth in an urban centre where there were few opportunities for unemployed young people while the other group included Pacific youth living in a city area where many families experience high levels of economic hardship. The research tracks their views about who they are now as young people growing up in a complex and increasingly divided society and who they might become in the years ahead. Taking a place-based approach, focus groups and walk-along interviews were conducted in two New Zealand cities. As the study progressed, the participants began to talk about the significance of hope, and lack of hope, in their everyday lives. Drawing on the work of Paulo Freire, it is argued that informed hope can be a powerful humanizing force in young people's lives and the study suggests that when youth have a strong foundation of hope and belonging, they are often capable of becoming active agents of social change.
\end{abstract}

Keywords: Māori youth, Pacific youth, Belonging, Agency, Future, Hope, Place 


\section{Table of Contents}

\section{Prefaces}

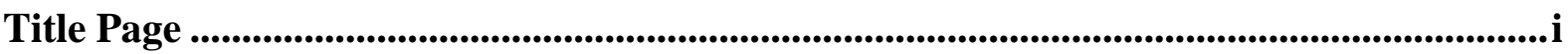

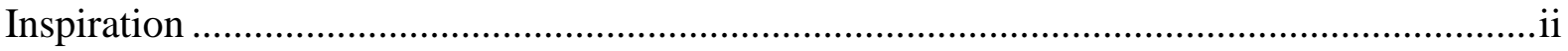

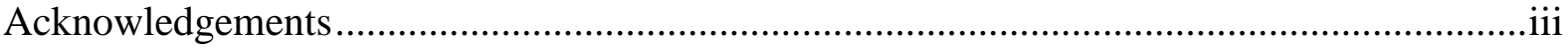

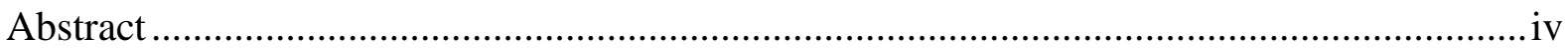

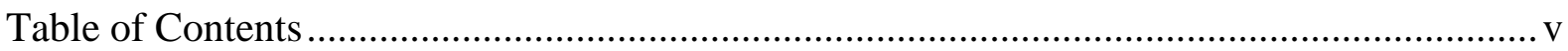

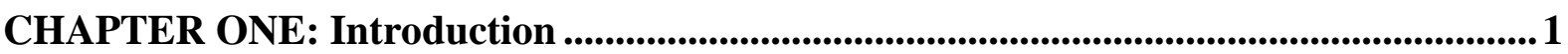

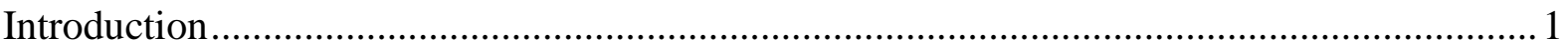

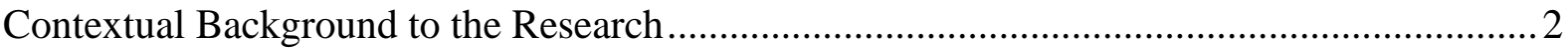

Rationale

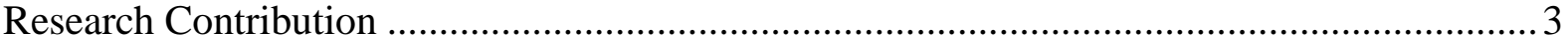

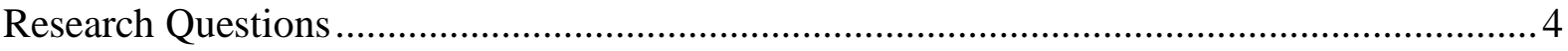

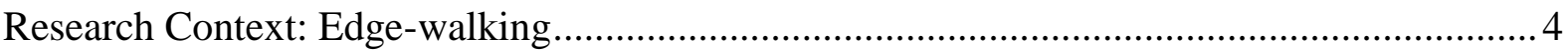

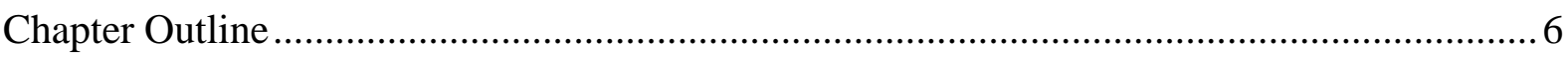

CHAPTER TWO: Literature Review and Theoretical Statement ......................................8

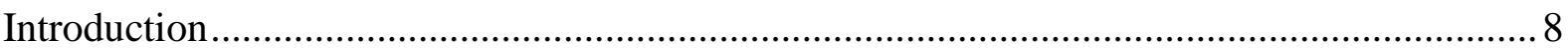

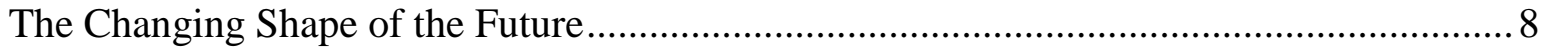

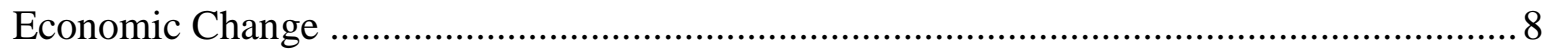

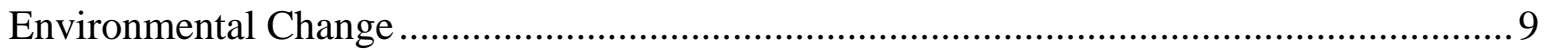

Māori and Pacific Peoples and Climate Change .............................................................. 10

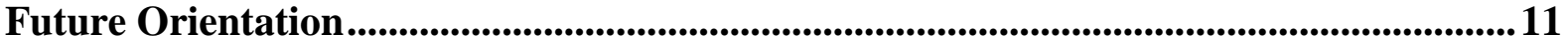

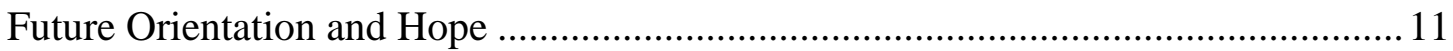

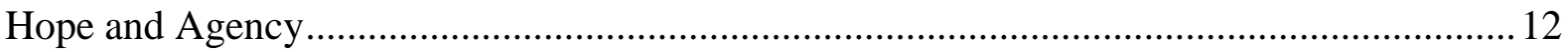

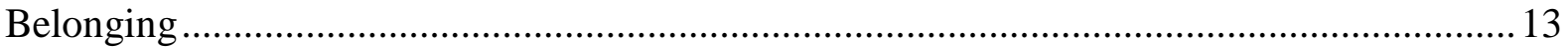

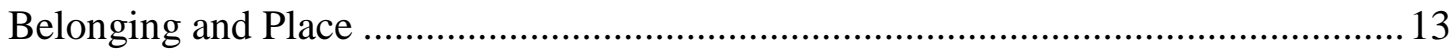

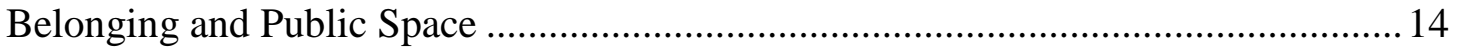

Belonging Through Group Membership and Sport ................................................. 14

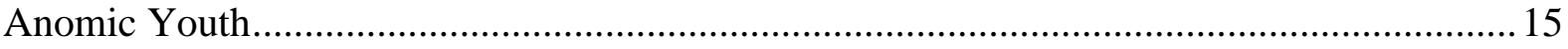


Gaps in the Literature

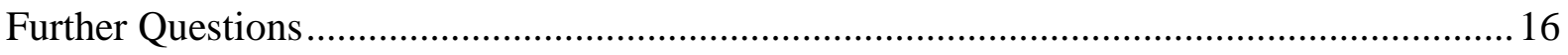

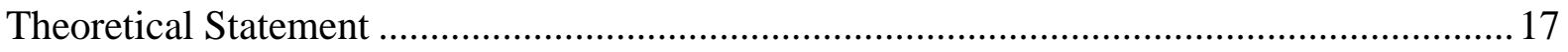

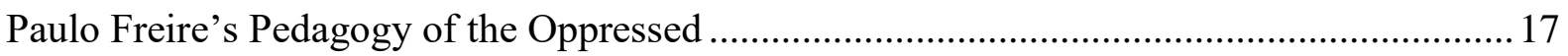

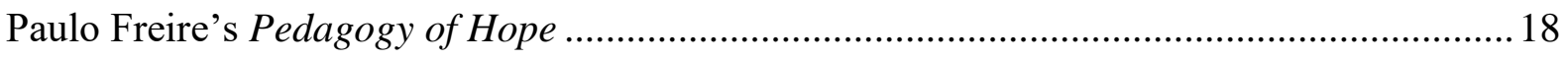

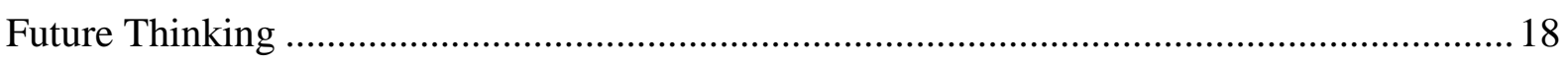

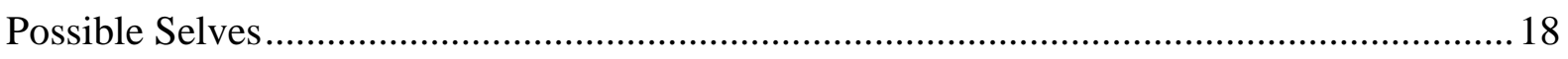

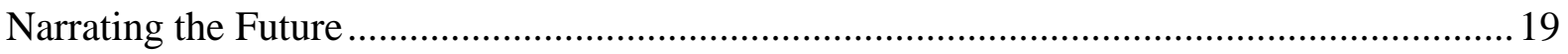

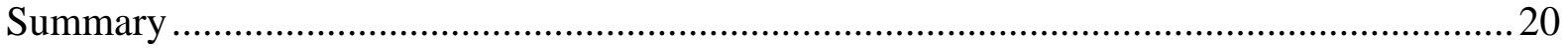

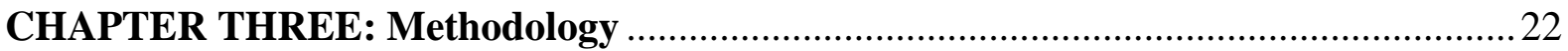

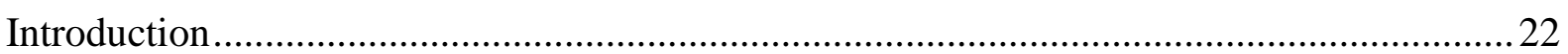

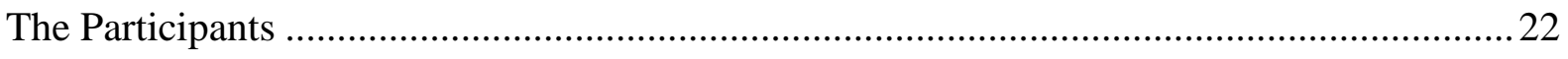

Taiohi Māori Participants ................................................................................ 23

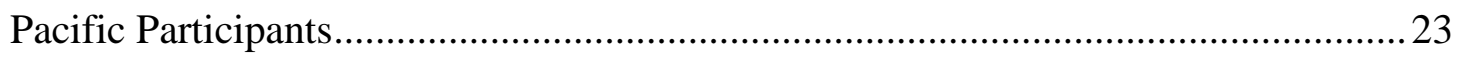

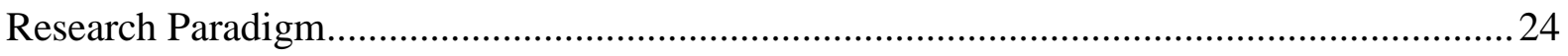

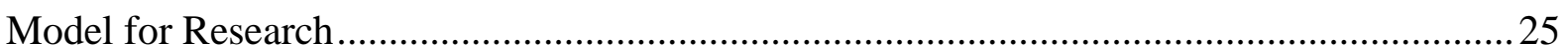

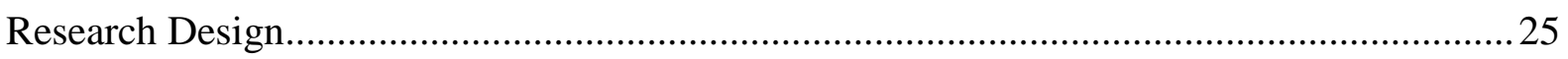

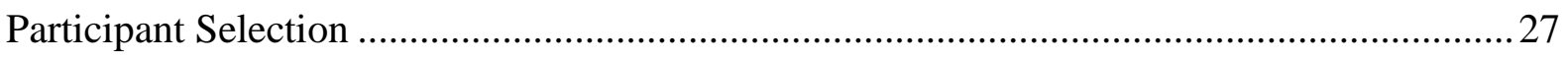

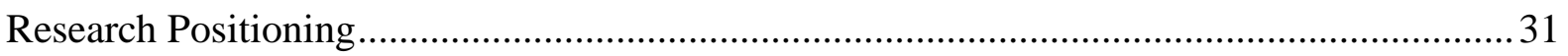

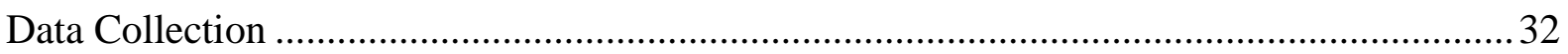

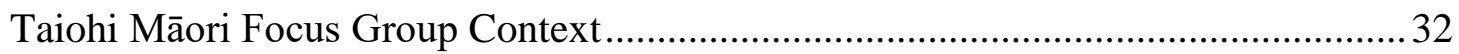

Pacific Participant Focus Group Context................................................................... 32

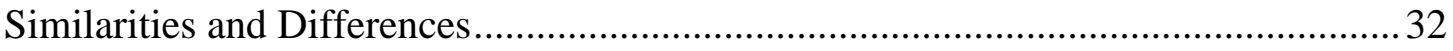

Walk-along Interview Context for Taiohi Māori and Pacific Participant Groups........ 33

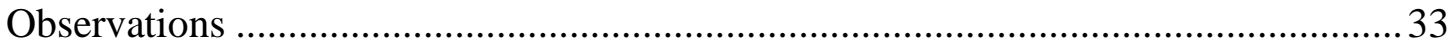

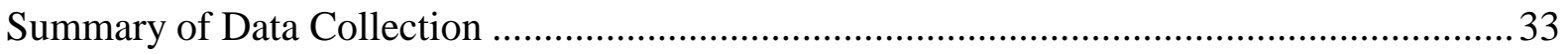

Pacific Participants’ Focus Group Hui ….............................................................. 34

Observations of Pacific Participant Group ……....................................................... 34

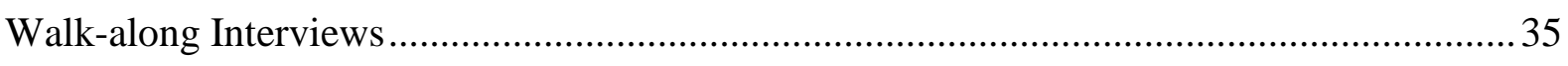


Walk-along Interviews with Pacific Participants.

Taiohi Māori Participant Group ................................................................................ 37

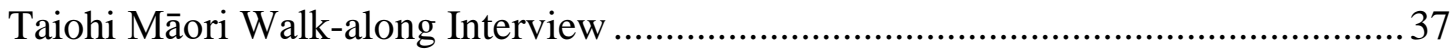

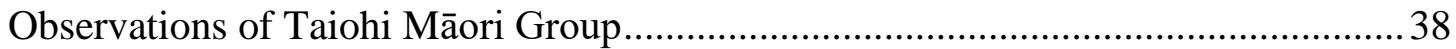

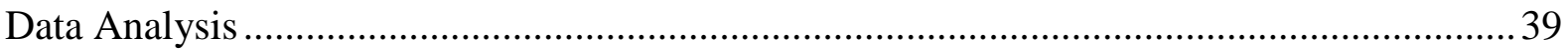

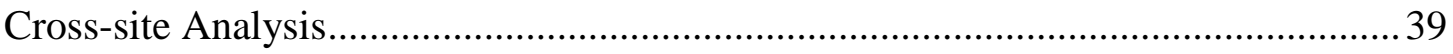

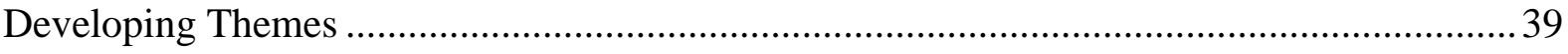

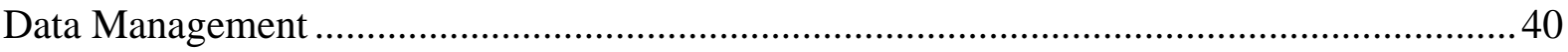

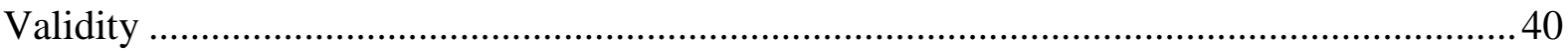

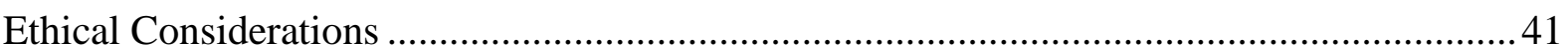

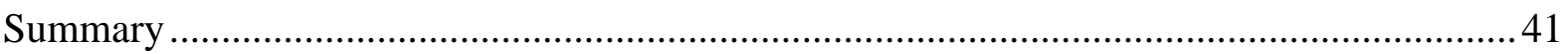

CHAPTER FOUR: Taiohi Māori-Growing up in the Gully .........................................42

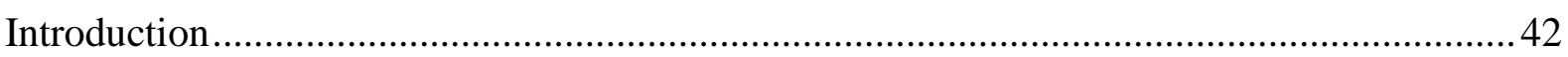

Building Research Relationships with the Participants ..................................................... 42

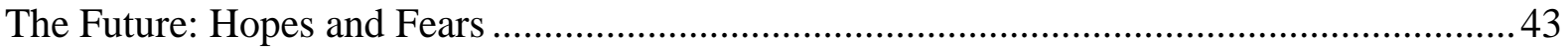

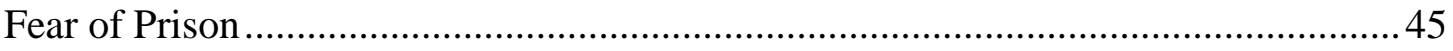

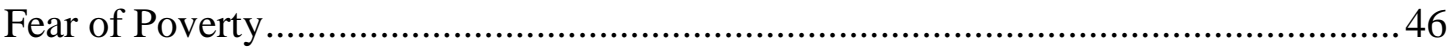

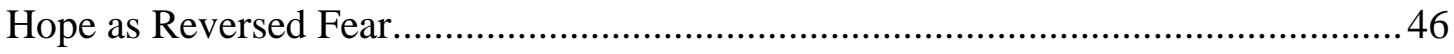

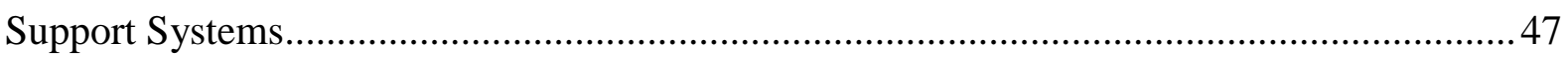

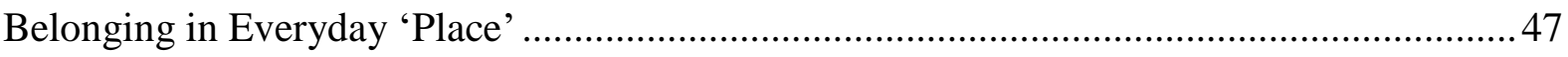

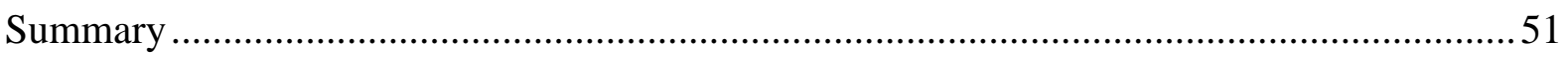

CHAPTER FIVE: Pacific Youth-Growing up in Tūmanako ..........................................52

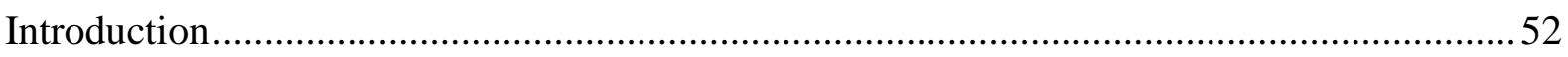

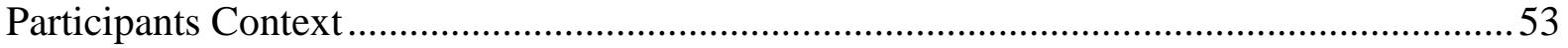

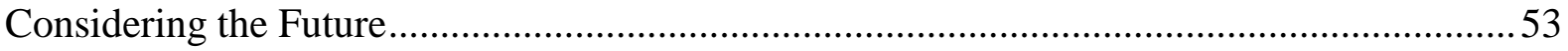

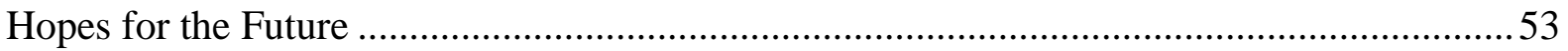

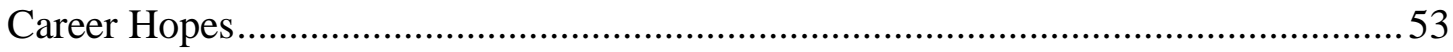

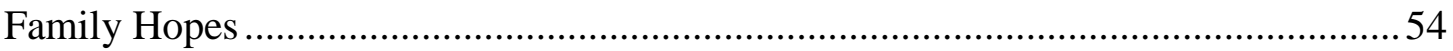


Concerns for the Future

Avenues of Support

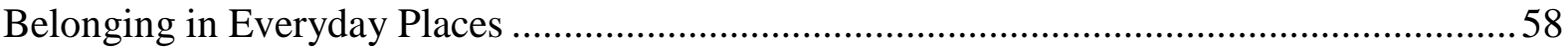

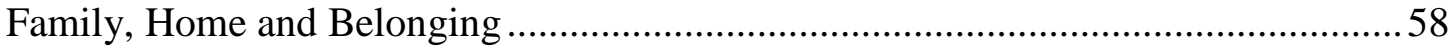

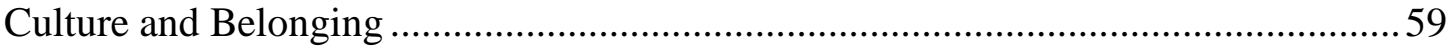

Belonging Through Faith/Religion ......................................................................5

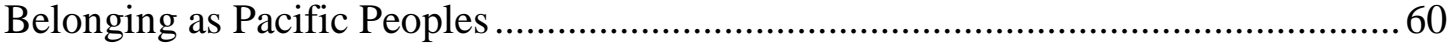

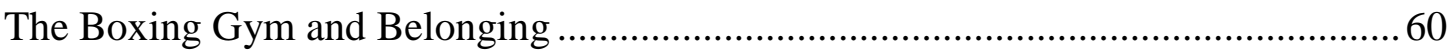

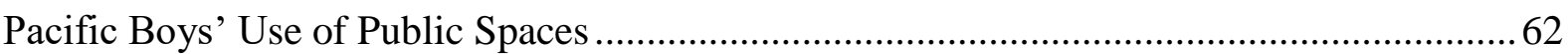

Summary

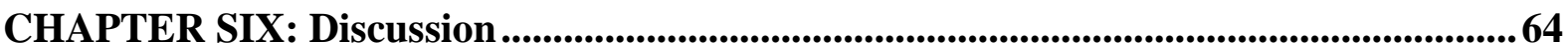

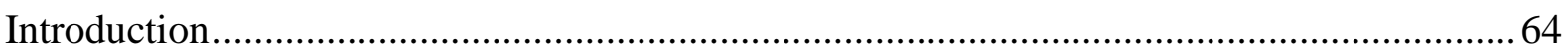

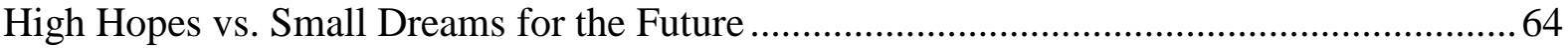

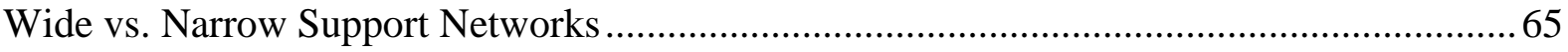

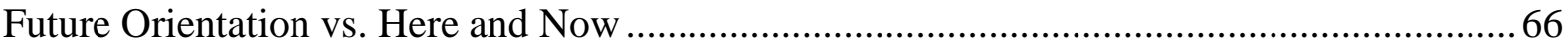

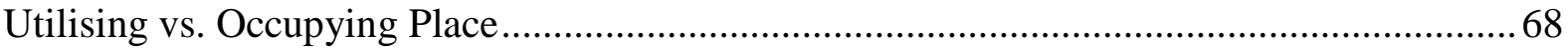

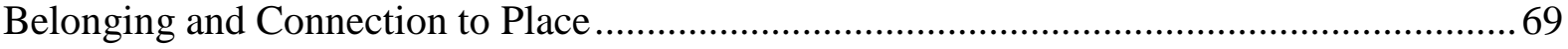

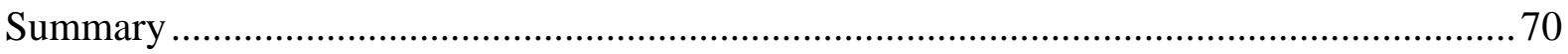

CHAPTER SEVEN: Conclusion ........................................................................................ 71

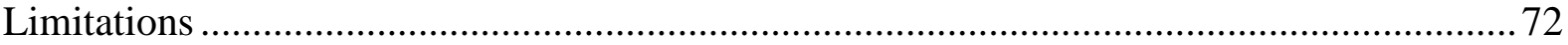

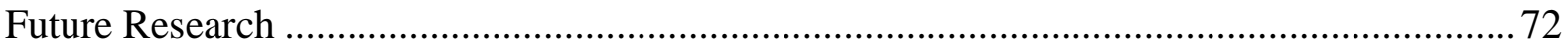

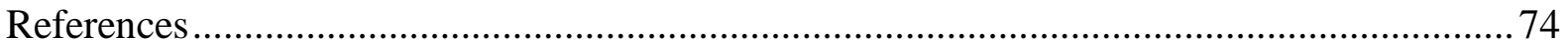

Appendix 1: Participant Information for Taiohi Māori Focus Group in the Gully .................. 82

Appendix 2: Participant Information for Pacific Group in Tūmanako ................................. 83

Appendix 3: Run Sheet for Pacific Focus Group Hui....................................................... 84

Appendix 4: Run Sheet for Taiohi Māori Focus Group Hui ................................................. 90

Appendix 5: Focus Group Hui- Prompt Questions............................................................ 96 
Appendix 6: Walk-along Interviews-Additional Prompt Questions....................................97

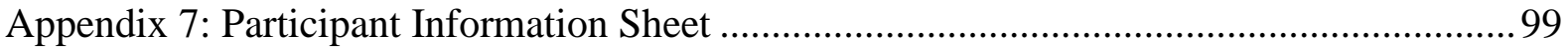

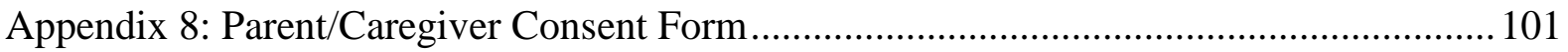

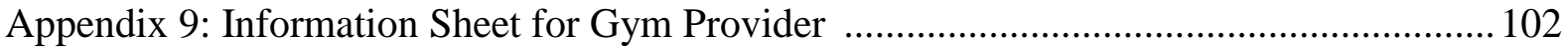

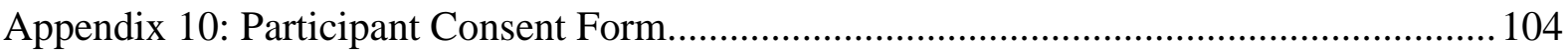

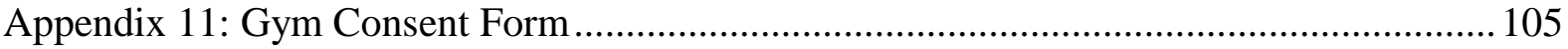




\section{CHAPTER ONE}

\section{INTRODUCTION}

He was only 13 ...Hine, what makes someone take their own life?

He saw no hope [Field research journal entry].

\section{The Rose That Grew From Concrete}

Did you hear about the rose that grew

from a crack in the concrete?

Proving nature's law is wrong

It learned to walk without having feet.

Funny it seems, but by keeping its dreams,

it learned to breathe fresh air.

Long live the rose that grew from concrete

when no one else ever cared.

Tupac Shakur (1971-1996).

What is life without hope? To some, a life without hope is a life not worth living. In Aotearoa New Zealand, indigenous youth face a challenging and uncertain future. In the coming years young people will face a range of social, political and economic issues.These include, for example, rising levels of poverty and preventable poverty-related illnesses, the impact of climate change and environment damage and social dislocation. While facing these wider societal issues, many young Māori and Pacific must deal with the impact of these tensions and challenges in their own everyday lives. For example, many Māori and Pacific families currently live in income poverty (Kawharu, 2015; Pasifika Futures, 2015). More than half the Pacific people in Aotearoa New Zealand live in the most economically deprived areas (Pasifika Futures, 2015).

Unemployment rates for young Māori are also very high; they are more likely to be unemployed than non-Māori youth (Te Pou o te Whakaaro Nui, 2015). As well, Māori have a higher rate of incarceration than any other ethnic group in New Zealand (Statistics New Zealand, 2012). Marie (2010) argues that the percentage of young Māori prisoners will likely increase as youth are offending at younger ages between 12 and 16. In education, young Māori have a lower rate of NCEA attainment than non-Māori (New Zealand Ministry of Education, 2015). Facing these kinds of challenges, many Māori and Pacific youth experience hopelessness, depression and suicidal thoughts (Ministry of Health, 2016; TiatiaSeath, 2014). This is important to note because suicide rates are consistently higher for Māori 
than non-Māori; particularly, young Māori men from economically marginalised areas (Ministry of Health, 2016). Alongside Māori, the rates of Pacific youth suicide attempts are increasing (Tiatia-Seath, 2014).

In this thesis, I argue that hope can be a powerful 'antidote' (Bishop \& Wells, 2014, p. 782) for these difficult situations. Drawing on the work of Paulo Friere (2004) I contend that a foundation of hope can help young people to adjust and cope with social changes. By focusing on youth, this study is attentive to the mechanisms of hope that create and underpin identity and belonging for young Māori and Pacific people in Aotearoa New Zealand. Young people often have rich and detailed narratives that can explain the critical consciousness that underpins their ideas about hope and the future. In line with writers such as Olga Ulturgasheva (2012), I will suggest that when youth have a strong foundation of hopefulness, they are more likely to be active agents of social change and in doing so, they become narrators of the future.

\section{Contextual Background to the Research}

This thesis is part of a wider study funded by Ngā Pae o te Māramatanga, New Zealand Māori Centre of Research. The title of the study is Ngā Moemoea ō Āpōpō: Empowering Taiohi Māori Leaders for the Future. A key aim of the wider project is to uncover the hopes and fears for the future for Māori youth and to explore how they can be supported to develop problem-solving strategies for the social, economic and political challenges ahead.

My study is a smaller scale project that is carved from the wider study. It considers the perspectives of both Māori and Pacific youth. The current study is situated in two large urban areas in Aotearoa New Zealand. In this thesis, the term 'Pacific' describes people living in Aotearoa New Zealand who migrated from the Pacific Islands as well as those who are born in New Zealand but who maintain a connection and identification with a Pacific Island heritage (Core Education, 2014).

This study is important because as Beck (2015) argues, if our future leaders cannot see hope in times of change, and cannot look past their current adversity, their futures will be at risk when faced with environment change, social, political and economic change.

\section{Rationale}

While there is an increasing body of academic literature that focuses on the concepts of belonging and the future, only a handful of researchers and authors place a lens on the needs of Māori and Pacific youth. The existing literature in this domain draws attention to the overrepresentation of Māori and Pacific communities in a range of social and economic inequalities, ranging from poor health, high crime, low educational outcomes and so on (Capital \& Coast District Health Board, 2016-2017; Holmes, Murachver, \& Bayard, 2001; Nakhid, 2003; Sanga, 2012). There is a strong focus on the role of schools in alleviating 
social and economic inequalities, as well as overcoming the challenges of complex social needs. To gain a greater understanding, as well as to fill some gaps in existing academic literature, this thesis focuses on young Māori and Pacific people's everyday lives in community contexts outside of formal schooling contexts. To that end, it is located within a critical dialogue concerning the cultural, social, economic and political issues that young Māori and Pacific peoples will face in the near future.

Some of the challenges confronting future leaders include: mitigating rates of poverty and related health, education and social issues; improving the use of indigenous languages within mainstream contexts; improving forms of indigenous leadership, which includes improved management and procurement of assets and social services and providing sustainable ways to manage the quality and supply of food and water (Hohepa, 2013). Supporting young Māori and Pacific people today and engaging them in research dialogues that provide a space where their voices are heard and their concerns are taken seriously is important. Tomorrow's leaders need to feel a sense of belonging in their communities, regions and nations if they are to understand how their leadership can initiate genuine and transformative change.

Many researchers in the field of indigenous youth studies contend that marginalised indigenous youth often consider that they have limited control or choice over their futures and that they cannot envision their life options beyond the present (Bryant \& Ellard, 2015; Chappell \& Chappell, 2015; Rua, 2015). Bryant and Ellard (2015) suggest that for these young people, it is important to identify those moments where hope is generated because these moments, even if they are fleeting, can be captured and utilised as a form of agency in shaping young people's futures. However, this requires young people to recognise those moments and make use of the opportunities. Currently, there is little understanding about how indigenous and Pacific youth in contemporary New Zealand think about hope or how it can be harnessed to create meaningful change. This thesis aims to capture those moments of hope and explore how they can be used to create social change. In line with this, I will argue that hope and belonging are critical factors in the lives of Māori and Pacific youth in Aotearoa New Zealand and that to be hopeful as Māori or Pacific young persons, can at times, be a political act. I will be focusing on hope as it occurs in 'places'; in other words, I look at how everyday hope (and hopelessness) occurs in Māori and Pacific young people's local environments. In this respect I draw on Webb and Radcliffe's notions that "[y]oung people's agency and struggles for inclusion reveal how they appropriate specific spaces and social categories in order to position themselves normatively in relation to wider society" (Webb \& Radcliffe, 2015, p. 2).

\section{Research Contribution}

This study explores Māori and Pacific youth hopes and fears about the future. Future perceptions are influenced by the ways in which people establish a sense of belonging in their immediate context. Understanding the ways in which concepts of belonging impact on youth may enable and encourage a shift in the way that local and national education, health and 
social services engage with youth. Providing support structures that encourage youth, especially those with complex needs, to carve their own pathways will go some way towards improving social cohesion. A further aspect of this research is to identify the gaps with regard to understanding the ways in which Māori and Pacific youth establish their sense of belonging in their everyday places.

\section{Research Questions}

The key research questions for this thesis are drawn from the larger study of which this project is part. The research questions that have guided the design of this investigation are:

What hopes and fears do urban Māori and Pacific youth have for the future?

How do young Māori and Pacific people establish a sense of belonging in everyday places?

As the larger study is carried out in other areas across the country, more information will come to hand about the way that Taiohi Māori (Māori youth) think about and engage with the future not only of their tribal communities but also the future of New Zealand society and the wider world.

\section{Researcher Context: Edge-walking}

I constantly reflect on my own identity, and this thesis has prompted me to think in new ways. My ethnicity, my upbringing, my aspirations and hopes for the future influence my position as a researcher and also contribute to my multi-faceted identity, all of which I bring to this research project. I consider myself to be an edge-walker. Tupuola (2004) describes edge-walkers as individuals who are able to successfully navigate multiple ethnic identities. My narrative as an edge-walker begins with my cultural background and spans my life experiences, struggles and the barriers I have overcome to get me where I am today as a researcher in academia. My mother (Mum) descends from Ngā Puhi in Hokianga and Ngāi Tahu in te Wai Pounamu. My father (Dad) was born in Tonga, giving my three sisters and me two ethnic identities, Māori and Tongan.

My parents married at an early age; Mum was 17 years old at the time. She had my eldest sister at 18 years. Dad was still maturing and instead of the domestic family life, he was attracted to the excitement of partying and experiencing things that were new to him as someone who had grown up in a Tongan village. I was eight months old when Dad left Mum. I remembered him visiting my sisters and me every second Sunday when he would take us out to the park, McDonalds or the TAB (to bet on horses). The innocent child in me at such a young age was hopeful that my parents would get back together and we could all be united as a family. Even though Dad had a new family, I still held onto this dream. As I got older and asked Mum more and more questions about why Dad left, I learned more about him and 
started to resent him. I blamed him for Mum being a struggling solo parent living in state housing. I blamed him for the poverty we lived in. I blamed him because we did not have nice things like his son did. I thought that, if he had just stayed with Mum, we would live in a nicer home, have nicer things and all round, be happier.

By the time I turned eleven, I was aware of how my family had struggled and I resented my father so much that I no longer considered myself to be his daughter. I also did not consider myself to be Tongan. I could not speak the Tongan language, I had only been to Tonga as an infant and I rarely saw my Tongan aunts, uncles and cousins. At one point, I considered legally changing my surname to my mother's maiden name. As a result of this broken relationship with my father, I grew up only identifying myself as New Zealand Māori.

While I whakapapa [connect] to Ngā Puhi, Ngāi Tahu, and Tonga, I feel a strong sense of belonging in Wellington, Aotearoa New Zealand where I was born and raised. It is a place where I have experienced economic struggle, personal development and academic success. However, this sense of belonging was only established later in life during my tertiary education. For the most of my adolescence I felt lost. By the age of 13, I was unhappy and socially disconnected from my peers.

The peer groups I associated with changed during my time at secondary school. School was not engaging for me and I began to skip classes. Mum did everything she could. She gave me curfews and tried to stop me from being around people who got into trouble and she demanded that I end my relationship with a boyfriend. She could see that my behaviour was spiralling out of control and knew that she needed to intervene before I got too far in to the newly adopted life. When I was 15 , I moved out of home to live with my boyfriend at that time. He was involved with gang affiliates and led a troubled life that involved a constant round of crime, criminal convictions and frequent spells in Police custody. During the one year I was with him, I lived precariously often drinking all night with him and his associates and then going to court to support them. I lived each day at a time because I did not know if I would live long. I carried a knife in my pocket if I walked the streets at night, always staying alert in case I was attacked by young people from other suburbs, enemies or gang affiliates. Thinking about the future was never something I seriously considered. Nothing seemed certain to me and nothing seemed hopeful.

At that time, my purpose in life was still not clear to me. School was not a place where I belonged. I did not want to be at home either. At age 16, I tried to do NCEA level 2, but I knew I was struggling. I saw no hope. I withdrew from school. I stayed lost for many years, going in and out of jobs in the hospitality industry or beauty, such as hairdressing, just to get some sort of student loan living cost or allowance. At 19, I found out I was pregnant. I was so scared and I did not know if I was ready for motherhood. So I turned to Mum. Through her support, I knew I could do it. For the first time in many years, I was hopeful. I was motivated to change my life and I knew my purpose.

I asked myself "what would I like to change about the world?" At this point, I thought about school and I believe that my life would have turned out differently had I seen my life purpose 
early on, stayed in school and completed secondary school. Education was my new area of interest. My son, Blade, began childcare when he was thirteen months old and I began to study at university for a degree in Education. Throughout my tertiary studies, I learned how to edge-walk; weaving constantly between academic and student life and motherhood. Edgewalking across multiple identities strengthened my belief that I could achieve my dreams. There were many times when I thought I would not succeed. However, when I got to that point, I reflected on my purpose, my drive and what I wanted to change in the world. These reflections showed me hope and motivated me to continue on my pathway.

As a young Māori and Pacific woman, growing up in poverty and experiencing identity issues and uncertainty about where I belonged, I had seen little hope for the future. It was not until I was faced with a big decision, my pregnancy, that I sought advice from Mum to decide on my next actions. Not everyone has this opportunity. It is my hope that this study will encourage young Māori and Pacific peoples to have these types of critical reflections now and begin planning their futures, guided by hope. My aim here is to encourage these young future leaders to find hope, even in the darkest of times and establish a sense of belonging.

\section{Chapter Outline}

This introductory chapter has outlined the background of this study. In Chapter Two, I review academic literature relating to concepts of hope and belonging. In particular, I have reviewed material that focuses on future thinking and transformative change for indigenous youth. Of note is the growing body of research relating to Māori and Pacific peoples. With this in mind, I recognise the need to add to this body of knowledge.

The theoretical ideas that underpin this study are also discussed in Chapter Two, under the subheading 'Theoretical Statement'. I draw from a range of theories and explore themes involving hopeful futures and belonging in a range of social and cultural contexts. I also draw on ideas from Paulo Freire's work Pedagogy of Hope (2004) which reinforces the need for informed critical dialogue and hopefulness as a means of effecting transformative social change.

In Chapter Three, the methodology used in this study is discussed and I describe the research methods used to gather data. These methods included semi-structured focus group hui (interview), walk-along interviews, researcher notes and naturalistic observation. In this chapter, I also outline the data analysis process and provide detail on ethical considerations in working with young people.

In Chapters Four and Five, I present the findings from this study. For the purposes of clarity, I have separated the findings from the Māori participants and the Pacific participants. In this way, a comparative cross-site analysis was formulated and this is discussed in Chapter Six. The focus of Chapter Four is Taiohi Māori. Taiohi refers to 'youth' or a condition of youthfulness. Throughout this study young Māori are therefore referred to as Taiohi Māori (Keelan, 2001). An area of focus is the participants' hopes and fears for the future. In this 
thesis, I sought to understand how this group establishes a sense of belonging in everyday 'places' around the city area that I have called The Gully. In Chapter Five, I present findings from the Pacific participants living in another city, who also discussed the same concepts of hope, future thinking and belonging in their everyday places.

In Chapter Six I explore the patterns and contrasting themes that emerged between the Taiohi Māori and Pacific youth participant groups. In particular, I consider the importance of having solid support systems and how these support systems can be related to the degree of hopeful futures. I propose that the ways that participants utilise everyday spaces, influences their ability to construct stories about place, and also grounds their connection in establishing belonging.

I conclude this thesis in Chapter Seven. Drawing on a strengths and evidence-based piece of research, the points raised in Chapter Seven remind us of the importance of protecting our young future leaders of Aotearoa New Zealand. In line with this I offer a series of recommendations. 


\section{CHAPTER TWO:}

\section{LITERATURE REVIEW AND THEORETICAL STATEMENT}

\section{Introduction}

In this chapter key concepts in the literature relating to the way that young people think about the future is reviewed and linked to the theoretical approach that has been taken in this thesis. In the first section of this chapter, young people's uncertainties and anxieties about the future are the main focus but I also explore how young people's engagement with 'place' influences their hopes and fears about the future as well as their sense of belonging (or not belonging) within their communities and neighbourhoods. Little has been written about how Māori and Pacific youth interact with their physical environments outside of formal schooling contexts and it is the intention of this study to address some of these gaps in the literature. Throughout this chapter I have identified a series of themes including; the changing shape of future, future orientation, hope, agency, belonging, place and space, and anomic youth. These themes offer insight into how in later chapters I focus my analysis of the data.

\section{The Changing Shape of the Future}

In later chapters of this thesis I will discuss the uncertainties that Māori and Pacific urban youth living in economically marginalised communities have about the future. Other studies about marginalised youth tend to focus on the need for young people to adapt to a world that will change dramatically in the course of their lifetimes. These changes include economic and environmental shifts. During this study, the participants also raised concerns about future income and job security as well as rising sea levels and global warming. For this reason, I have focused this section of the literature review on economic and environmental change, particularly with regard to climate change.

\section{Economic Change}

The shape of the future and how we think about it is changing (Beck, 2015; Claisse \& Delvenne, 2015; Eichler, 2015). Previous research shows that many young people are worried about future economic hardship and unemployment (Mason, 2012; Means, 2015) and these concerns were certainly echoed by the participants involved in the present study. But worries about economic recession not only affect young people's hopes and fears about the future, they also influence how effectively they establish a sense of belonging in everyday places. Black and Walsh (2015) suggest that in times of global economic recession, young people become frustrated by a lack of employment opportunities in their own communities. Often they have little choice but to leave their communities to seek economic opportunities elsewhere. Those who do not have the means or opportunities to do this are often 
"condemned to geographic and socioeconomic immobility" (Black \& Walsh, 2015 p. 188). Mason (2012) shares similar concerns noting that when young people live in environments where economic, political and social conflict is rife, it is almost impossible to engender a sense of long-term belonging or establish a long-term commitment to 'place'. A sense of belonging that is anchored in physical environments cannot therefore be achieved when disconnection to place is present. Thus, economic recession has a clear impact on how young people plan for the future.

\section{Environmental Change}

I did not initially anticipate that climate change and associated environmental destruction would emerge so strongly as a theme for this study. Prior to undertaking this thesis I had a rather romanticised view of the hopes and fears that young people have about the future. Through the research conversations that took place in the course of the fieldwork, however, it became clear that environmental change and global warming is an issue that has a strong influence on the way some young people consider the future and this was particularly the case for the Pacific participants.

Beck (2015) contends that climate change has the potential to modify the social and political power dynamics of the world on an almost unimaginable scale. The threat of radical environmental change in the future causes anxiety and concern for many youth (Woodman 2011) and this is not surprising given that climate change is one of the most significant issues that the world is facing (Beck, 2015; Eichler, 2015; Manning, Lawrence, King \& Chapman, 2015). Furthermore, climate change is already being experienced in different parts of the world (Crate \& Nuttall 2016). As Beck notes, "[c]limate change has already changed the world, our way of being in the world, our way of thinking about the world, and our way of imagining and doing politics" (Beck, 2015, p. 76).

Global warming is therefore "a serious and increasingly urgent threat to human health and wellbeing" (Bennett, Jones, Keating, Woodward, Hales, \& Metcalfe, 2014, p. 16) and it is one that requires a multi-faceted response. Bennett et al. (2014) note that poor communities are especially vulnerable and at a significant disadvantage in planning or preparing for what lies ahead. As the impact of climate change takes effect, young people of today can expect to face food insecurity, greater strain on economic markets, weather damage to natural and built environments, changes in air quality and water supply, amongst other challenges (Bennett et al. 2014; Ruth, Bernier, Jollands, \& Golubiewski, 2007) and as I discuss later, many of the participants in this study were well aware of this.

The participants in this study were also aware that the means of addressing these concerns lie with high-level decisions that are made in the present. They were also aware that many critically important decisions are not being made partly because powerful corporate interests, which are financially invested in the status quo, are highly resistant to making the necessary changes for human survival (Beck, 2015; Crate \& Nuttall, 2016). 


\section{Māori and Pacific Peoples and Climate Change}

Within Māori society, various individuals and groups possess the knowledge and skills to mitigate at least some of the impacts of climate change (King, Penny, \& Severne, 2010). King et al. (2010) argue that Māori groups are particularly vulnerable to climate-sensitive impacts because nearly fifty percent of Māori economic, social and cultural assets are invested in natural environments such as agriculture, fishing, and forestry. Production rates will be seriously affected in the agriculture sectors as the effect of floods, greenhouse gas emissions and storms wreak havoc on ecological systems. As well, climate change will affect the fisheries sector as fluctuations in water temperatures change the chemistry of the ocean. Forestry sectors will also be impacted as the quality of wood declines and an increase in pests will lower production rates (King et al. 2010).

Māori therefore need to find ways of coping with climate change but this becomes more difficult as time goes by. At some point in the near future the option to simply relocate to a more comfortable or less climate-affected environment will no longer exist. As well, many Māori live in vulnerable communities with complex social and economic needs and either will not have the resources to move away from the worst effects of climate change or will be required to maintain a kaitiakitanga [stewardship] role in tribal areas where the forests and seas are dying (King et al. 2010).

Pacific populations are also greatly affected by climate change and this can already be seen today with rising sea levels. Low-lying atoll islands such as Tuvalu, Kiribati and the Marshall Islands are vulnerable to even the smallest change in sea levels. As Burns (1999) notes, "a one-meter rise could result in the loss of 80 per cent of the Majuro atoll in the Marshall Islands, home to half of the nation's population" (p. 235). Burns' article was published almost two decades ago and climate change is an even greater concern now.

Pacific peoples living in Aotearoa New Zealand with ties to families and communities in the Pacific Islands are well aware of these matters and know about the environmental damage that is already taking place. In the longer term, climate change refugees from the Pacific will need to find ways of maintaining cultural identities in increasingly difficult diasporic conditions. For those communities already under threat, identity construction and people's sense of belonging in both Aotearoa New Zealand and their Pacific Islands homelands (Mackley-Crump, 2015) is ever more precarious and as shall be discussed in a later chapter, several participants talked at length about these matters during the walk-along interviews.

Climate change affects different groups of people in different ways. Māori iwi [tribes] and hapū [clan groups], for example, have stewardship over natural resources that may be lost or damaged beyond repair. At the same time, many Māori and Pacific peoples are overrepresented in statistics relating to poverty-related illnesses (Bennett et al. 2014). These populations in Aotearoa New Zealand will be greatly affected by environmental and climate change and poor health will continue to be a significant factor in their quality of life. With this in mind, Māori and Pacific young people need to establish informed strategies for the future if they are to live well. It is for this reason that future-thinking on these matters needs 
to begin now. In the next section, I discuss how future-thinking or 'future orientation' has been conceptualised in the academic literature.

\section{Future Orientation}

This study applied ideas about 'future orientation' or forward thinking during fieldwork as a tool to encourage dialogue about the challenges that young people face now and in the future. In line with this approach, I have drawn on Woodman's (2011) study about youth and the future which shows that young people both "shape the future and engage in the present" (p. 125). The findings suggest that future planning is a pursuit that is best shaped collectively rather than individually as young people discuss their uncertainties about the future. To that end, Woodman applied the notion of 'future orientation' to respond to the concerns that were raised by young people. This involved engaging participants with the future as part of an exercise in autobiographical narrative; goals were set, plans were established and commitments were made to future action (Seginer, 2008). Future orientation strategies can also help young people to develop a sense of direction (Hamilton, Connolly, Liu, Stange, Abramson, \& Alloy, 2015) which allows them to engage as active social and cultural agents during times of social upheaval and change (Crivello, 2015; Hardgrove et al. 2015), meeting challenges responsively rather than reactively.

\section{Future Orientation and Hope}

Hope and future orientation are key concepts for this study. Bishop and Wells (2014) refer to hope as "the ability to perceive positive futures" and suggest that "hope plays a key role in people's quality of life and well-being in the present" (p. 781). To have hope, they argue, a person must have three things: firstly, a goal to work towards; secondly, agency, or a way to self-assess and change outcomes through planning; and, thirdly, the ability to identify realistic ways of achieving these goals (Bennett, Wood, Butterfield, Kraemer \& Goldhagen, 2014).

While it is important to embed hope in young people's thinking about the future, the reality for many is that they may experience periods of uncertainty, anxiety and doubt (Best Practice Journal, 2010; Bishop \& Willis, 2015; Seginer, 2008; Jacobs, 2005). A positive futureorientation is desirable but social, economic, environmental, and political change often leads to a deep-seated unease for youth, and a subsequent loss of future direction. The effect of this can manifest in a number of ways including feelings of hopelessness, depression and suicidal ideation (Chenhall \& Senior, 2009; Wexler, 2006).

In Aotearoa New Zealand, suicide is a significant cause of death for young people. In 2007, Māori made up thirty-five per cent of deaths by suicide (Best Practice Journal, 2010). More recently, the Ministry of Health (2016) has reported that suicide rates for young Māori are consistently higher than for non-Māori. In particular, young Māori men have higher rates of suicide than females. Among males, Māori suicide rates were reported at almost twice the 
rate for Pacific youth. Suicide rates for youth living in lower socio-economic areas were four times as high as young people who lived in wealthier communities (Ministry of Health, 2016).

Risk factors for suicide include but are not limited to, past traumatic physical or sexual abuse, social and educational disadvantage, a past history of suicidal behaviour, dysfunctional living situations, and identity issues (Best Practice Journal, 2010, p. 37). At the same time, "[p]rofound hopelessness is a strong risk factor for depression and suicide" (Best Practice Journal, 2010, p. 37). Seginer (2015) explains that hope can strengthen resilience amongst young people and needs to be incorporated in an informed way into their conversations about the future. As Hamilton et al. (2015) argue,

Young people cannot work towards outcomes that they have no ability to imagine in the future, nor will they be motivated to direct their efforts towards imagined futures if there are no (perceived) viable routes to get to them (Hamilton et al. 2015, p. 169).

A possible future then, needs to feel possible and if young people are to take ownership of their futures they need to feel connected and hopeful, as is discussed below.

\section{Hope and Agency}

I have argued here that hope has an influence on how people think about the future. DuncanAndrade (2009) extends this idea contending that while hope is important, false hope can be highly destructive. In schooling contexts, false hope can manifest itself in three ways; 'hokey' hope, 'mythical' hope and 'hope deferred' (Duncan-Andrade, 2009, p. 182). 'Hokey' hope is the idea that good outcomes will happen if someone simply tries hard and is a 'good' person. This can be a form of wishful thinking if no effort is then put into establishing strategies and actions that will secure the desired outcomes (Duncan-Andrade, 2009, p. 183). 'Mythical' hope occurs when the reality of social and economic inequality is ignored and it is assumed that a meritocratic society will always reward individual effort equally. Lastly, 'hope deferred' refers to a type of false hope that is deeply invested in the belief that good things will happen in the future regardless of whether action is taken to bring about these goals. In line with this, Duncan-Andrade contends that some teachers merely hope that their students will have positive lives in the years ahead without actively helping them to achieve change, arguing:

When they figure out that the teacher is unwilling and/or unable to close this gap, their hope is deferred. And just as Martin Luther King Jr. foretold of justice, hope too long deferred is hope denied (p. 185).

Duncan-Andrade argues that false hope must be replaced with true hope or 'critical hope' (p.185) and this requires students and teachers to enter into genuine and authentic dialogue about their hopes and fears about the future. I took these arguments on board in this thesis as I listened to the hopes and fears young urban Māori and Pacific peoples have about their own 
futures and at the same time I encouraged them to begin narrating their future pathways. My aim was that by discussing hope and the future, these young participants could reflect on their own lives and what they imagine is possible and desirable for them.

\section{Belonging}

There are many ways of conceptualising the notion of belonging. In this section I discuss some of the literature on belonging in relation to place, public spaces and sport. Yuval-Davis (2006) suggests that belonging is often associated with one's position of power within a group as well as the physical locations in which social attachments are formed. A sense of belonging to a community or neighbourhood, then, may translate into increased civic engagement (Harris, Battle, Pastrana, \& Daniels, 2015). Moreover, Cohen and Garcia (2008) argue that the notion of belonging is part of the social identities that people form as part of their affiliation with family, community, ethnic or religious groups.

Cuervo, Barakat and Turnbull (2015) suggest that the quality of family and community relations is highly influential in the kinds of decisions people make about their future particularly during periods of rapid social and economic change. This is an important consideration in relation to indigenous young people who are often faced with difficult choices about maintaining cultural values in environments where these are not valued. As Cuervo, et al. contend, "to deny indigenous youth the possibility of embracing a different pathway than their traditional one is as discriminatory as denying them the opportunity of belonging and embracing their own culture(s)" (p. 28). Young Māori and Pacific peoples in Aotearoa New Zealand draw their sense of belonging from various contexts, including friendship networks and peer groups, church or religion and sports clubs amongst other things, and in this study many of the participants talked about the role of these factors in their own lives. Some of the literature on these aspects of belonging is discussed below.

\section{Belonging and Place}

Māori and Pacific young people's engagement with their local places is a key focus in this study. In the social sciences, 'place' is not viewed simply as a physical location, it also encompasses the emotional, social and cultural dimensions that people attribute to particular spaces (McCreanor, Penny, Jensen, Witten, Kearns, \& Barnes, 2006). In this respect, 'place' involves emotional attachments, or detachments, that link to people's sense of belonging to physical territories (McCreanor et al. 2006). In other words, as McCreanor et al. (2006) suggest, "we often say we feel 'at home' to mean that we feel comfortable and that we belong somewhere" (p. 198). Similarly, Crath (2012) asserts that an understanding of place offers insights into the way that marginalised youth establish social relations within physical locations, describing 'place belonging' as an 'intimate...feeling of 'being at home' that are negotiated in everyday practices..." (p. 45). 
For many Māori, the concept of 'home' is connected to history, tradition and ways of life, while many Pacific young people experience 'home' as a diasporic condition in relation to Pacific homelands as well as to Aotearoa New Zealand (McCreanor et al. 2006). Place and a sense of 'home' or belonging are therefore deeply entwined and this was experienced in different ways by the indigenous Māori and diasporic Pacific participants in this study. In this respect, place is never neutral. In particular, it became clear that when young people are provided with spaces where they can act according to their own priorities, a sense of belonging can be fostered (Kidman, 2012).

\section{Belonging and Public Space}

Van Hecke, Deforche, Van Dyck, De Bourdeaudhuij, Veitch, \& Van Cauwenberg (2016) have conducted studies with young people using walk-along methodologies and their work has informed the methodological design of this study. They found that young people more often visited public spaces such as parks, playgrounds, town squares, sports areas and vacant lots when they are in close walking or biking distance. Young people were also drawn to public areas where there are sports facilities or where there are good facilities that are clean or where there is an attractive natural landscape. They found that young people avoided public areas where there were conflicts over the use of space, for example, where there were gangs, homeless people or drug users who engaged in 'turf wars'. It has been found previously that these factors have an influence on young people's level of civic engagement (Wood, 2011) and this was also the case in the present study. Thus, as Kidman (2012) points out, public spaces can become sites of tension between different groups of young people and negotiation often needs to take place before public spaces can be shared (Panelli, Nairn \& McCormack, 2002). These tensions also emerged during the fieldwork for this thesis and are discussed further in Chapter Four.

\section{Belonging Through Group Membership and Sport}

As will be discussed further in the next chapter, the Pacific participants in this study were members of a community boxing gym and they described their involvement with the gym in terms of a 'family-like' connection. Studies show that membership or affiliation with sports teams, clubs, and groups offer many young people a sense of connection and relationship (Allen, 2003; Cnaan, Gelles, \& Sinha, 2004; Maxon, Whitlock, \& Klein, 1998; Newman, Lohman, \& Newman, 2007). The desire to be part of a group where social bonds are established and maintained are therefore an important motivating factor for young people to engage in sporting activities (Allen, 2003).

Newman et al. (2007) suggest that belonging to peer networks and groups can offer young people "a sense of definition, purpose, meaning, worth, and social control, all of which contribute to positive mental health (p. 259). Peer group membership may include keeping in touch through sport, e-mails, social media, 'hanging out', clubs, or after-school activities and 
these can have a positive influence on youth well-being especially during times of change (Newman et al. 2007). Overall, Newman et al. concluded that youth who placed importance on peer group membership were more likely to have a positive sense of belonging and had fewer behaviour problems than those who did not see peer group membership as important.

Mynard, Howie and Collister (2009) contend that involvement with team or club sporting activities can engender a sense of belonging amongst young people especially when teamwork promotes responsibility and commitment which enhances their self-esteem and confidence. However, the reality for many young people in economically marginalised communities is that there are often fewer recreational resources in their local areas and this limits their opportunities to participate in team sports (Van Hecke et al. 2016). Additional barriers for low income families may also include increased family responsibilities for young people, such as needing to care for siblings, as well as the financial costs associated with many team sports (Van Hecke et al. 2016). The benefits of belonging to sports teams or clubs is therefore evident but not all young people have the same level of access to these facilities. In the present study, for example, the Māori participants were very interested in sport but did not belong to any teams or clubs and financial barriers played a part in this. The Māori participants therefore established connections with peer networks in different ways from the Pacific participants, as will be discussed in a later chapter.

\section{Anomic Youth}

Later in this thesis I refer to "anomic" youth. This term originally comes from Emile Durkheim's argument that when societies become more complex the social bonds between individuals and their communities begin to disintegrate (Durkheim, 1951). To that end, the concept of 'anomie' is used as a "tool to understand the relationship between social structure, culture and deviant behaviour" (Bernburg, 2002, p. 729). Accordingly, young people who do not meet societal goals and norms are subject to "powerlessness, alienation and confusion regarding rules" (Zhao \& Cao, 2010, p. 1211) and are often perceived as living in a state of anomie or "normlessness" (p. 1212).

More recently, 'anomie' has come to refer to a condition of late modernity where the traditional structures, values and norms that previously guided young people have effectively dissolved under capitalism and young people subsequently have little guidance as they enter into the worlds of adulthood (Côté, 2014). James Côté (2014) suggests that the dissolution of traditional and non-secular societies under capitalism has radically affected the life courses of many people who,

find themselves (1) with little guidance from their families of origin or an organized religion; (2) compensating for fragmented institutional contexts (e.g. disjunctive education-to-work contexts); (3) coping with decoupled and erratic life-transition options (e.g. creating a family of orientation entirely different from their family of origin); or (4) struggling to meet the requirement to individualize their life plans without a sense of purpose rooted in stable values. (Côté, 2014, p. 41-42). 
Consequently, anomic individuals often feel isolated and disconnected from wider society. Their options are consequently frequently very limited and resources are sometimes obtained through illegal means (Nakhid \& Shorter, 2014; Zhao \& Cao, 2010). As will be discussed in chapters four and five, the young people involved with this study were looking for meaning and structure in environments that were exceptionally challenging. Members of the two participant groups dealt with this in different ways but as will be seen later, when strong family and ethnic community support systems are in place, the search for meaning and belonging was considerably less fraught (Nakhid, Tanielu \& Collins, 2009). When these networks were not available, the disconnection from wider society intensified and this sometimes led to the participants obtaining the resources they needed to survive in ways that are not socially accepted or endorsed.

\section{Gaps in the Literature}

Little work has been carried out with young people from indigenous Māori and diasporic Pacific communities in Aotearoa New Zealand that explores their hopes and anxieties about the future. While the broader reach of this study will encompass youth voices from rural and provincial centres, this thesis focuses on urban youth and their everyday communities of place and in many ways it is unique in the education literature in Aotearoa New Zealand. Much education policy research, for example, focuses on the needs of Māori and Pacific youth as students in schools but few studies investigate their lives outside the formal structures of education and this is where a great deal of rich data is overlooked. At the same time, many studies in education about Māori and Pacific youth are conducted by people who are outsiders to struggling urban communities in economically marginalised areas. Outsider researchers do not always have access to some of the most marginalised members of these communities and frequently identify these groups as "hard to reach." As a result, the voices of these young people do not often figure in the academic literature in the field of Education.

\section{Further Questions}

As a way of addressing some of the gaps in the current literature, this study explores the hopes and fears that young Māori and Pacific have for their future and seeks to understand how 'place-belonging' is established. However, this highlights further questions that have yet to be fully addressed, such as: How can youth workers, adults, community leaders, coaches/trainers and other adult leaders encourage marginalised young people's aspirations for the future? How and why do young people maintain connections to neighbourhood places in environments of severe economic precarity? This particular study does not have the scope to address these gaps. Rather, it aims to create awareness about groups that are often overlooked or who are invisible to many researchers within the broader education domain in Aotearoa New Zealand. With this in mind, I outline below the theoretical approach that informed the design of this thesis study. 


\section{Theoretical Statement}

This study draws from several theoretical sources spanning young people, place-belonging, and aspirations and worries about the future. In particular I have referenced many of Paulo Freire's ideas about hope, agency and change. As well, my theoretical conceptualisation about indigenous and diasporic youth and the future draws heavily on Hardgrove, Rootham and McDowell's notion of 'possible selves' (Hardgrove et al., 2015); and, Olga Ulturgasheva's work with the Eveny people of northern Siberia (Ulturgasheva, 2012; 2016). These ideas are discussed below.

\section{Paulo Freire's Pedagogy of the Oppressed}

Freire's ground-breaking work, Pedagogy of the Oppressed (1993), proposes a pedagogy that is located in the political, cultural and social struggles and experiences of people's daily lives. This is not pedagogy of the oppressed, however, but rather it is a pedagogy for the oppressed whereby leaners engage critically with the world in which they live and consider ways in which transformation can be effected. In line with this, Freire (1993) proposes a critical pedagogy, forged in praxis, as a means of liberating oppressed groups. He argues that oppressed or marginalised peoples must do more than reproduce existing social relations and forms of knowledge that reflect the values and biases of the oppressors. Instead, they must actively engage with reality on their own terms and through their own lived priorities. However, simply becoming aware of oppression is not enough to create change. Freire contends that a critical consciousness of the forces that shape and maintain oppression is also needed. This kind of consciousness is one that questions the political status quo and seeks new understandings of the social and political structures that oppress different groups of people. Ultimately, it unleashes a desire to begin a fight for liberation that carries throughout one's life (Freire, 1993; Freire \& Shor, 1987).

Importantly, Freire (1993) argues that the struggle for liberation begins with an awareness of the role of oppression in people's own lives. Reflection and dialogue with others who experience similar encounters informs deeper reflection and understanding that can lead to critical consciousness (Freire, 1973). Becoming critically aware of the problems that maintain oppression has the power to initiate political action. This combination of reflection and analysis creates 'praxis' a cycle of reflection and action geared towards generating transformative change (Freire, 1973). The key idea here is that those who are oppressed need to take action for themselves.

Freire's work frames much of my own thinking about this study. In particular, the notion that reality is not static nor a closed narrative delivered to marginalised peoples by oppressive interests. Rather, I begin with the Freirean notion that political and social change in a dynamic and vibrant present is possible, desirable and necessary for indigenous and diasporic youth. Furthermore, and in line with Freirean thinking, I 
consider that for effective change to happen, an awareness of the history that has created oppression must also be explored and named. Pacific youth who are part of the diasporic movement of peoples around the region and indigenous Taiohi Māori who live the settlercolonial nation of Aotearoa New Zealand have different histories of oppression and injustice that have a direct bearing on their present circumstances and because of this they will engage with the future in very different ways. Despite this, their futures will play out in the shared space of the New Zealand nation-state and in this respect there are moments, even if fleeting, where alliances and resistance can, potentially, be forged.

\section{Paulo Freire's Pedagogy of Hope}

Twenty years on from writing Pedagogy of Oppressed Freire returned to his original ideas and reflected on them further. His book Pedagogy of Hope (2004) was the outcome of these deliberations and in this work Freire turns his attention to the significance of hope in bringing about social and political transformation. He begins by arguing that hope is both an "ontological need" (p.2) and a driving force in overcoming the structures that maintain oppression. Writing about his own experiences, Freire discusses the salience of hope in times of struggle, noting that "hope is necessary, but it is not enough. Alone, it does not win. But without it, my struggle will be weak and wobbly. We need critical hope the way a fish needs water" (2004, p. 2).

The relationship between hope and agency can be described as follows; agency is the vehicle by which change comes about but hope is the driver. Thus, when young people are faced with acute social problems, hope takes on particular importance. Freire (2004) suggests that during these periods of upheaval, the oppressed need to nurture moments of hope because they can act as an important trigger for transformative change and liberation. He writes,

When it becomes a program, hopelessness paralyzes us, immobilizes is. We succumb to fatalism, and then it becomes impossible to muster the strength we absolutely need for a fierce struggle that will re-create the world. I am hopeful, not out of mere stubbornness, but out of an existential, concrete imperative. (Freire, 2004, p.2).

I have taken these words very seriously in the course of this study.

\section{Future Thinking}

\section{Possible Selves}

Hardgrove et al. (2015) apply the concept of 'possible selves' to explore how young people develop their thinking about their future trajectories and their transitions between adolescence and adulthood. While their study focused on young men in the United Kingdom who were transitioning into the workforce, the notion of possible selves "can encompass any aspect of 
envisioned future identity or experience" (Hardgrove et al. 2015, p.165). They argue that asking young people to talk about their possible selves and their "'imagined possibilities' in the future" (p.165) can throw light on their "'motivation' to act in the present" (p.165). Their findings show a connection between the imagined futures of young people, and their societal position in the present. Of interest here is the notion that the future is not linear or unidirectional but rather that there are multiple possible futures and therefore multiple possible selves which can be drawn on by young people at different times. This concept drives elements of the methodological approach of the present study which is discussed in the next chapter. As will be seen, the idea that young people may have many possible futures as well as many possible future selves is embedded in the research design.

\section{Narrating the Future}

The work of Olga Ulturgasheva (2012) had a particularly strong impact on the early stages of the design of this thesis project. Ulturgasheva is a cultural anthropologist who has worked in indigenous Eveny communities in North-eastern Siberia. These communities have experienced rapid social and cultural change in recent decades and Ulturgasheva has conducted ethnographic research with young people in these areas. She argues that indigenous Eveny youth are able to narrate their future in ways that hold considerable cultural significance for them in the present. In particular, she writes about the Eveny concept of djuluchen 'a spirit that travels ahead' (Ulturgasheva, 2016. p. 56). Here, instead of asking participants to imagine a possible future as was the case with the Hardgrove et al. study discussed in the previous section, Ulturgasheva claims that young people need to narrate their own future, as an agentic act in the present and they did so in uniquely interesting ways. Two participant groups were included in her study; young Eveny people living in the forests and young Eveny people living in Siberian villages. Using a narrative design, she captured the stories that these young people shared about their way of life and how they planned their future. Paying special attention to the way that her participants imagined and narrated their future, Ulturgasheva looked closely at how they viewed themselves, their culture, their history and the connections between these aspects with time; past, present and future.

One particularly interesting concept that Ulturgasheva drew from the Eveny people is djuluchen. This term translates as 'forerunner' and it is one that I took inspiration from as did the participants in my own study. The djuluchen is a spirit that is released into the future when the host makes future plans or narrates their future. This can be carried out through wishing, hoping and planning their next steps in their future trajectories. The Eveny people understand djuluchen as a spirit that parts from a person and travels ahead to a planned temporal destination. The spirit waits at the designated destination in time until the host or the individual catches up. When the host is reunited with the spirit at the intended destination, that individual is believed to have reached full personhood. In doing so, individuals narrate their own future biographies, telling their djuluchen how their future will pan out. This notion of 'becoming' was important to Ulturgasheva's participants as they underwent a series of 
radical cultural and social transitions through their adolescence and into a future that was entirely different from that experienced by their parents and grandparents.

The young Eveny participants in Ulturgasheva's study narrated their future, describing what they expect they will be doing in terms of employment and where they would reside. Six years later, Ulturgasheva returned to Siberia to follow up on her research. She found that all but one participant had fulfilled the imagined steps as stated when narrating their autobiography and she notes that "the futures they were narrating emerged as a strikingly predictive blueprint for their possible actions in the future" (p. 2). Here, she makes a purposeful note to resist what narrative researchers may dismiss as merely negotiating versions of self, to actually distinctively stating that participants were sharing "an actual glimpse of their lives in the future" (p. 3). To explain this notion, she uses reversed memory as an example from Alice in Wonderland, specifically an episode of 'The Looking Glass' where Alice reflects on a memory that is yet to occur, or a memory that only works in reverse. Her Eveny participants narrated their futures in a sequence that contradicts the orthodox order of linear or chronological memory. Instead of carrying out the experience and then recounting the lived experience through story-telling, these young people were generating the narrative and then carrying out the experiences. In short, autobiography allowed them to tell their own stories of past events or experiences that have already occurred and then discussed or retold (Ulturgasheva, 2012).

From the djuluchen position, however, the travelling spirit is described as a back to front autobiography, where the future is planned, and the event occurs only after the narration (Ulturgasheva, 2012). Instead of reflecting on a memory after an event has occurred, a prememory is planted before the event. It was not until Ulturgasheva's return to Siberia, however, that she came to understand this. Through further analysis exploring the process and what came after as participants' lives unfolded, Ulturgasheva relied on the element of djuluchen to present the future autobiographies of the young Eveny participants in her study.

A key idea that is used in this research is how young people are the agents of their futures, they are the narrators of their stories and by foretelling their future biographies, they are capable, active agents of their lives. Although this study involves indigenous groups living in small villages and forests, the concept that underpins the future narratives (djuluchen) is "open and accessible to any ordinary person" (p. 170). Approaches of this nature tend to resonate and reflect well the cultural nuances of indigenous peoples.

\section{Summary}

The aim of this thesis is to explore the hopes and fears that young urban Māori and Pacific peoples have about the future. In this chapter, I have identified key concepts in the youth studies literature that have contributed to the design of this thesis project and I have outlined my theoretical approach. In particular, I have indicated that Freire's ideas about informed hope and its significance in transformative social and political change have informed my thinking. The research design of this thesis takes these ideas and centres them in a series of 
theoretical concepts on the notion of possible selves and multiple non-linear futures. In line with this I have highlighted indigenous notions of temporality that have underpinned the way the methodology was developed. This is discussed further in the next chapter. 


\section{CHAPTER THREE}

\section{METHODOLOGY}

\section{Introduction}

In this chapter the research design, the methodological approach and the ethical considerations that were taken into account are outlined. Throughout this thesis pseudonyms chosen by the participants are used and all place names have been changed. Two groups of participants based in two urban regions were involved with this study. These urban centres are referred to in the thesis as Tūmanako and the Gully. In both these cities there are suburbs that score very highly on the New Zealand Index of Deprivation (Ministry of Health, 2013) and the participants in both groups resided in these areas.

\section{The Participants}

Two very different groups of young people were involved with this study. One group of participants included Taiohi Māori (Māori youth) living in an economically depressed urban centre which is referred to in this thesis as the Gully. These young people were struggling with a range of issues including unemployment, economic precarity and family dysfunction. They saw few opportunities to move beyond their immediate situations and this had a significant impact on how they viewed the future. As well, there are only a limited number of public spaces in the Gully where unemployed young people can meet socially. In their own neighbourhoods, there were few public parks, safe communal gathering places or free recreational facilities available to them nor was it always possible to stay in their family homes during the day. These young people, therefore, spent a lot of time working out where they could go to 'hang out' together. This also had an impact on the way that interviews were conducted as I discuss later in this chapter.

The other group of young people who participated in this study were Pacific youth. This group included adolescent males who identified closely with their Pacific heritage. These participants were heavily involved in a boxing gym in a city that is referred to in this thesis as Tūmanako. In Tūmanako, as is the case in many economically precarious urban areas, boxing gyms and martial arts centres provide many young people with a structured, safe environment where they can socialise together and in this case, the gym had become a focal point for the participants, their peers and their families.

Like the Taiohi Māori group, the Pacific participants were growing up in extremely difficult economic circumstances. However, their lives were patterned in very different ways. This was partly because the social structure of the gym and the close involvement of extended family members in the gym 'community' provided the Pacific young men with a way of thinking about the future that was considerably more hopeful than that of the Taiohi Māori participants. 


\section{Taiohi Māori Participants}

This group included five males and one female, aged between 16 and 18 years, all of whom identify as New Zealand Māori. Not all of the participants were able to identify their tribal affiliations but those who did traced their links to Ngāti Kahungunu and Ngāti Porou; two large tribal groupings with ancestral bases in different parts of the North Island. The participants are a group of friends who live in state housing estates in various suburbs across the Gully. The suburbs they live in are listed as deprivation ten by the Ministry of Health (2013) placing them in the top 10\% of the most economically deprived areas in New Zealand. For the most part, households in these areas are headed by single parents and this was the case for the participants in this group.

None of the participants were enrolled at secondary school at the time the study took place. The male participants had all been expelled from secondary schools and each of them had attended an alternative school at some point. One participant had been expelled from alternative schooling after also being expelled from secondary school. The female participant was working full-time in a fast-food outlet. At the time of the study, she was pregnant and trying to earn as much as she could as she prepared for the arrival of her baby. The other participants, one of whom is her partner, are not currently in paid employment.

Most of the participants in this group are or have been under court ordered tresspass notices that prevent them from being in certain places in the Gully. One of these places was the shopping centre which is a central gathering place for many young people in the Gully. The participants talked openly with me about their frequent clashes with the law and told me about various activities they were involved with that have drawn them to the attention of the Police. These activities included, for example, car theft, burglary and marijuanna and underage alcohol use. Each of these participants have had first-hand experience of the criminal justice system; a system they fear deeply but one which is a constant presence in their own lives as well as those of many of their family members.

In research terms, this group of young Māori is considered 'hard to reach' (Faugier \& Sargeant, 1997). These populations are rarely included in qualitative research. Often, it is difficult to gather groups of highly marginalised young people together for research purposes as well as connect with them on a level where they are willing to share stories about their lives. I knew that creating a positive, trusting relationship with members of this group was imperative. With the help of a close friend who knew the participants personally and was willing to introduce me to them, I was able to bring the Taiohi Māori group together to talk to them about the study. I discuss how this took place in further detail later in this chapter. Participant details including age and tribal affiliation are provided in Appendix 1.

\section{Pacific Participants}

This group included nine males aged between 14 to 17 years who identify as Pacific, including those of Samoan, Tongan, Tokelauan, Cook Island Māori, Tuvaluan, and Kiribati 
heritages. All these participants were enrolled in secondary school at the time the study took place and all reside in Tümanako, generally in two-parent or extended family households. Some of these participants had immigrated with their families to Aotearoa New Zealand from homelands in the Pacific Islands. The reasons their families brought them to New Zealand varied although the most common explanation was for educational and economic betterment. Other Pacific participants were born in New Zealand.

These participants are all members of a community boxing gym in Te Ana Kore, a suburb in Tūmanako. The gym was selected as a site of data collection because a key question for the study is to explore how young Māori and Pacific establish a sense of belonging in their everyday places. In contrast to the Taiohi Māori participants, who struggled to find communal spaces where young people can safely and legally gather, the boxing gym provided the Pacific participants with an environment where young people could meet and where family members were also welcomed. These contrasting experiences offer insight into how different young people engage with place and space and its impact on their social identities, as will be further discussed in later chapters. The boxing gym is located in an economically depressed area with high crime rates. At the time the study took place, membership of the boxing gym was open only to males aged between nine and 18 years. For this reason, all the boxing gym participants were male. Participant details, including age and ethnicity, are provided in Appendix 2.

\section{Research Paradigm}

Qualitative research approaches were used in this study. There is no single theory or paradigm that specifically belongs to qualitative research and it means "many things to many people" (Denzin \& Lincoln, 2005, p. 10). This type of research does, however, provide participants with a voice that may not have otherwise been heard in a more quantitative inquiry (Marvasti, 2011). The research was designed within a constructivist paradigm (Guba \& Lincoln, 1994). Constructivist theorists argue that people construct their social realities in relation to and in connection with one another (Jackson \& Sorenses, 2006). Reality is shaped by a mutual uncovering of collective meanings in a range of social practices and situations. In this respect, Glaserfeld (1989) argues, social reality is subjective, experiential and highly fluid as it is created and recreated anew by people interacting with each other. Constructivist paradigms therefore posit an ontological position whereby multiple realities inform the lifeworlds of the self, rather than one reality with multiple conceptions (Denzin \& Lincoln, 2005).

Peter Berger and Thomas Luckmann, leading proponents of these ideas, argue that everyday life is an "ordered reality" (Berger \& Luckmann, 1991, p. 35) that is shared by others in different ways. They contend that individuals come to know and understand the social world through their interactions with others and it is in these moments of connection, or sometimes, disconnection, that they come to recognise, comprehend and typify the patterns and flows of the world they share. As Berger and Luckman write, "[t]he social reality of everyday life is 
thus apprehended in a continuum of typifications" (p.47). In this study, the participants drew on interactions in their everyday life-worlds not only to find ways of understanding their social environments but also to find patterned (typified) and shared meaning within them. It is these small, everyday moments that I have tried to capture in the design of this study.

\section{Model for Research}

Feagin, Orum and Sjoberg (1991) define a case study as "an in-depth, multi-faceted investigation, using qualitative research methods, of a single social phenomenon." (p.2). As discussed in the introduction chapter, this project is part of a larger multi-site case study of young Māori hopes and fears about the future. In this thesis, the phenomenon of investigation has been broadened to include Pacific youth and to further distinguish it as an original piece of work I have also introduced a focus on young people's sense of belonging in their everyday places. The unit of analysis here is youth in urban communities that rank highly on the New Zealand Deprivation Index.

Yin (2003) suggests that a case study approach should be used when there is a focus on contemporary events that do not require controls for behavioural events. Case studies often include interviews with people as well as the researchers own observations. An advantage of using case study inquiry is that it relies on data triangulation to uncover common themes (Yin, 2003). Data triangulation aids in the analysis of the data, lending some strength to the findings (Altrichter, Fieldman, Posch, \& Somekh, 2008) and as will be discussed further in this chapter, this approach has been used in this thesis.

\section{Research Design}

This study was guided by two qualitative research designs; ethnography and narrative inquiry. Ethnographic research is the study of human social life and as such it describes, analyses, and interprets shared patterns, behaviours, and beliefs within cultural groups (Creswell, 2013). As Van Maanen (2011) argues, "[e]thnography is written representation of a culture (or selected aspects of a culture" (p.1). Accordingly, this type of design is focused on 'writing about groups of people' (Creswell, 2013, p. 489) and usually involves some degree of participation by the researcher in people's daily lives (Atkinson \& Hammersley, 2007). By participating in the daily lives of the research participants, the researcher is able to consider how participants view their own situations and experiences, how they consider others and how they view themselves (Atkinson \& Hammersley, 2007). Ethnography then, "tells stories about real people in real places" (Knowles \& Cole, 2008, p. 530), and situates the researcher in these real 'places'. Knowles and Cole (2008) add that ethnography research is needed to challenge our existing theories and "find the stories we didn't know we were looking for in the first place" (p. 530) because often, ethnography research is exploratory and 'open-ended' (Atkinson \& Hammersley, 2007, p. 3). However, over time, the focus becomes clearer, identifying specific research questions, seeking understanding of phenomena. 
Ethnographic researchers seek to understand phenomena from participant views and observe participant behaviours by engaging in their activities (Creswell, 2009). Ethnographic approaches were selected for this study as I explored detailed events that the focus groups experience in their everyday places. Data were gathered through group brainstorming exercises, field notes, observation and semi-structured interviews collected over several months. By semi-structured, I refer to what Kvale (1996) describes as an interview that is partially structured rather than rigidly organised. The purpose is to establish a clear sense of direction and to gather focused data whilst still allowing for fluidity in the course of research conversations.

Ethnographic strategies such as observation and interviewing were also used in a walk-along interview method that was adapted for this study. Kusenbach (2003) suggests that when people are in their everyday environments they do not normally comment on what is happening around them unless explicitly asked to do so and it is therefore difficult for the researcher to rely solely on an observational approach. In addition, stationary interviews may constrain natural movement when participants are relating everyday experiences especially those that involve a degree of physicality. Stationary interviews can therefore interrupt participants' 'natural activities' by requiring them to limit their physical activity (Kusenbach, 2003, p. 459). A walk-along approach was used in this study because it connected participant observation with in-motion interviews (Kusenbach, 2003). In this study I used an ethnographic walk-along interview approach that involved accompanying participants' as they walked around their local communities. The design of the walk-along interviews is discussed later in this chapter.

A narrative inquiry research design also aligns well with a constructivist paradigm and qualitative design as stories are a natural form of communication. Narrative inquiry involves creating micro-stories about individual participants' lives as opposed to a wider view of cultural norms that ethnography achieves (Creswell, 2014) and in this respect, the two approaches complement each other. This approach draws on the lives of participants, as well as the researcher, to retell a story (Creswell, 2009). Creswell (2013) argues, "[s]tories reported in a qualitative narrative research enrich the lives of both the researcher and the participant" (p. 529). In line with this, the history and past experiences of individuals and how these past experiences influence their present and future lives are a central focus.

Telling a story in detail; reporting experiences and discussing the meaning of the experiences can offer practical insights into the lives of individuals. In telling their stories, the participants in this study were able to reflect on their experiences, recreating themselves within the research context from the inside out (Freire, 1993). As the researcher, I listened to the participants use of the story-telling process to establish a bond with them. Also, during walkalong interviews when I recounted my interpretation of what the participants had said, I was able to check for validity and this was how I managed the fact-checking process. 


\section{Participant Selection}

As noted in the introduction to this thesis, this study is part of a larger project that focuses on young Māori and their hopes and fears about the future. As a smaller part of the wider project, I have focused this study on young urban Māori and Pacific people in Aotearoa New Zealand. It was not originally planned to collect data from two groups in different cities. Initially, I intended to focus on one urban youth boxing club in a low income urban area and participant selection was to include Māori and Pacific girls and boys. However, at the time of research, a female class had not yet been established at the gym that was involved with this study. The focus of participant selection then shifted to young Māori and Pacific males. Other sampling problems also arose, as I discuss later in this section, but of note here, is that a common characteristic of the participants was that they ranged in age between 13 and 19 years.

Locating an established gym with members who fit the participant election criteria, being Māori and or Pacific between the ages of 13 to 19 , required me to turn to my own networks in the first instance. Prior to conducting the research, I had not met any of the participants and this meant that I needed to establish relationships with gym members, the trainers and parents at the boxing gym.

Cohen and Arieli (2011) advocate snowball sampling as a way of recruiting participants and this is the process I also used. Kidman, Chu, Fernandez and Abella (2015) describe snowball sampling as a non-probability convenience sampling method, "whereby a research participant is asked to recommend or name another prospective participant, who then offers the name of another prospective participant and so on" (p.26). An advantage of snowball sampling is that it allows 'outsider' (p. 47) researchers who have difficulty locating or gaining access to marginalised groups to connect with potential participants. The snowball method begins with someone who knows both the researcher and potential participants, who can reach participants and who has access to these groups. Referral through a trusted source reduces uncertainty or distrust from potential participants.

The snowball sampling sequence was initiated through my own social networks with the aid of social media, such as Facebook and Messenger, which allowed me to identify and reach out to a boxing gym. I began the process by posting a status to my Facebook profile that briefly explained my research focus, aims and participant selection criteria, and I asked for referrals of possible gyms or contact details of people who might be able to assist me. I have affiliations with several boxing and Muay Thai gyms and I knew that my Facebook post would reach a wide range of potential participants. Several people subsequently contacted me and provided me with details of gyms, including website information, Facebook pages, names of the owners/coaches/trainers and phone numbers.

One person in particular linked my Facebook page with the head trainer of the selected boxing gym that was eventually recruited to this study. A friend of mine sent my profile picture with details and a link to my profile page to the head trainer at the boxing gym. This 
sharing method is called 'Linked'; a form of introduction that can be initiated through the social media application (Facebook) Messenger.

This referral led me to contact the head trainer and I spoke with him by phone about the research project and arranged a meeting with both the manager and the trainer. At the meeting, they agreed to allow me to propose my research to their young members, the majority of whom are young Māori and Pacific males in the age range I was seeking. Before proposing my study to the gym members, I wanted to ensure I was visible to members, staff and parents because I knew that this was an important part of establishing the research relationship (Fua, 2009). Accordingly, I began attending senior classes and spent time talking to family members and trainers. My son was seven years at this time, and membership age begins at nine years but with the permission of the gym managers, I took him to some classes and trained with him one-on-one by copying what the others did. In this way, we spent time in the environment and became affiliated with the club and as such we were no longer complete strangers.

There were 28 gym members in the seniors' class which ran twice a week and I hoped to recruit at least ten to 12 participants. I realised that there was a possibility that some participants might only be able to take part in one phase of the data collection such as the focus group hui or the walk-along interview. I also had to factor in that parental consent would be needed by all members for ethical purposes, including those over age 16 years, as this was a condition that the gym manager proposed. In addition, there was a possibility that participants might take part in the study and then withdraw. Voluntary participation and the right to withdraw were conditions of the human ethics approval I received from the University so I knew I also had to factor this into my plans.

I observed the senior classes over three sessions. After each session, the trainers gave me time to introduce myself and talk about the research project. At that point I arranged a time to discuss the research proposal with the gym members. I provided pizza during this meeting, and this was greatly enjoyed. It is customary within my own Māori and Tongan cultures to share food with others as a way of creating and maintaining relationships and providing food during these discussions helped to establish relationships with prospective participants who shared these cultural values.

On the day of the first meeting, I told the participants something about my own experiences. I told them about my educational journey and the pivotal moments that led me to this research. Brendtro and Du Toit (2005) suggest that those working with youth and expecting them to share their stories are more likely to gain trust and respect when they, themselves, share their own stories. In telling the young people something about myself allowed me to connect with many of them. Their nods, laughs, questions, comments and facial expressions confirmed this. Then I explained the purpose of the study, the rationale and explained how their participation would contribute to the wider issues under investigation.

Consent forms were required from both the participants and their parents/caregivers/whānau and I gave these out during the initial meeting. A tally of participants was then taken to come 
to an agreed time for the initial hui. Questions were asked and answered and a blessing was given before concluding the night with kai (food).

A date was set for the return of the consent forms but the trainers had advised me that the members tend not to be punctual with returning any forms and might need encouragement and reminders. I attended all the training sessions over the next two weeks as I waited for members to return the forms. This was important because the only form of contact I had with the members was through seeing them in person at the gym. By the due date, few parental consent forms had been returned. The head trainer, Brown Sensei [a pseudonym], sent out several reminders to the members to return the forms if they were interested in participating. Brown Sensei was my point of contact with the participants and he was very supportive of the boys participating in the project. He reminded them about the consent forms before and after each training session and even contacted members who were not at training those nights. Without this assistance, participant numbers would have been significantly lower.

I did not request participants' phone numbers nor did I think it would be appropriate to be linked with participants through Facebook or Messenger so Brown Sensei's support was extremely helpful. Had I not taken the time to build relationships with the gym staff, parents and members from different classes, fundamentals, juniors and seniors, I would not have been comfortable seeking help from the trainers to encourage members to participate and return forms so the relation-building process within the gym community was critical to the success of the project.

After three weeks, seven forms were returned, signed by themselves and their whānau. The day before phase one, the initial hui, Brown Sensei contacted me to say that ten participants would be present and to bring additional forms to sign on the day, as several parents would be in attendance. On that day, eight young men arrived. One parent with whom I had built a friendly relationship during my visits to the gym also attended. She also stayed for the duration of the hui and kept the trainer company, sharing the snacks and coffee that I provided. The inclusion of family members was important in this environment not only as a cultural courtesy but also because family is accorded high value in the inclusive environment of the gym.

One participant, Mighty, arrived late, bringing the total to nine individuals. Another participant who had returned a consent form did not arrive on the day. These nine participants make up the Pacific participant group of this study.

Initially, I only intended to work with one group of young Māori and Pacific boxing members. However, the nine participants who were recruited identified with Pacific ethnicities and only one member identified as Māori as well as Cook Island Māori. Therefore, I had to adapt my approach to meet the needs of the wider project of which this study is part. This meant that I needed to locate additional participants either within the same gym and carry out the same interviews or locate a new group who identified as Māori, preferably in the same area, who were part of the same social networks. The reason why I wanted them to 
know each other is because I wanted to ensure that they felt safe to share their hopes and fears within a group environment.

Another matter I needed to consider was time. Having to find a new group and carry out more interviews and complete transcriptions and data analysis affected the completion time of submitting this study by the due date and other deadlines were looming for the larger study of which this thesis is part. There was no time to build relationships over a period of several months as I did with the boxing group. The introduction of the new group of Taiohi Māori participants ultimately provided important comparative data that offered insights that I would not have otherwise acquired and in this respect, what at first seemed to be a crisis eventually proved itself to be an asset to the project. Thus, data in this study reflect two groups of participants; namely, adolescent Pacific boys who are members of an urban boxing gym in Tūmanako and Taiohi Māori who live in various suburbs in different parts of the Gully. The comparisons and contrasts between these groups are discussed further in Chapter Six.

Instead of using a Facebook post to make network connections in seeking a Māori participant group, I discussed my options with my academic mentors and my supervisor. My mentors gave me email contacts to reach out to people who may have been able to assist me to locate participants, unfortunately, to no avail. I was anxious that I had little time to secure a new group of participants and time was running short. After checking the conditions of the ethical approval given by the University's Human Ethics Committee, I called on my own social networks for help in much the same way as I did when I began snowball sampling with the gym members. Subsequently, I connected with the younger sister, aged 16 years, of a friend. This young woman fit the participant selection criteria and agreed to bring members of her own social group along to discuss participating in the study. Once again, snowball sampling methods allowed me to identify prospective participants and I was able to do so within the ethical parameters set down by the University's Human Ethics committee.

The criteria for this participant group was that participants were urban Māori, aged between 16 and 19 years, living in a low socio-economic area (so they were comparable with the Pasifika participant group) and, who were members of a friendship network. In order to meet ethical requirements, the participants needed to be slightly older than the majority of the gym members because parental consent was needed for anyone under the age of 16 years. Several of the participants in the Taiohi Māori group were living semi-independently or independently and were making their own major life decisions as young adults.

The participants who make up the Taiohi Māori participant group chose their own pseudonyms. Information about their ages and tribal affiliations is provided in Appendix 1. This group of Taiohi Māori were part of a friendship group that included friends and family. They reside in an area that I have named the Gully, a region that spans several low-income suburbs. They do not belong to a boxing gym like the initial group, however, several of them expressed a strong interest in kickboxing. 


\section{Research Positioning}

In this part of the chapter I explain how I positioned myself as a researcher during the fieldwork phase of the project. I will discuss my positioning with each group in turn beginning with the Pacific participants who were members of a boxing gym.

As someone associated with martial arts myself, I aimed to connect with the boxing gym participants at that level. Through my discussions with the Pacific participants in the early stages of the research, it became clear that we had all experienced family environments where money was often a problem and that had a levelling influence on conversations that took place later during the interviews. At the same time, our common interest in martial arts provided us with a space where we could talk about mutual values and ethical frameworks that are shared by martial arts practitioners.

In order to make these connections with this group of participants, I needed to develop trusting relationships. I will elaborate on specific strategies that I used to establish these relationships later in this chapter but note here that the connections that I made with participants granted me greater 'access' (Kusenbach, 2003) to their everyday lives (Unluer, 2012). Importantly, my connection with the Pacific participant group developed prior to interviews when my son became an unofficial member at the boxing gym. As the participants and their families got to know my son and me, I gained a deeper understanding of the boxing culture of the gym in ways that reflected the natural flow of the everyday experiences of its members (Unluer, 2012).

Making cultural connections was important with both participant groups and as someone who identifies as both Māori and Tongan I was able to make links at that level. Despite many shared understandings, values and ways of life within these groups, there are also significant in-group differences (e.g. different tribal or national affiliations) and members of ethnic groupings should not be considered as homogenous. Thus, my connections are made broadly in a context of fluid commonalities.

Although I gained greater understanding of participants' lives and access to the participants' site, I do not consider myself an 'insider' researcher (Kusenbach, 2003) because although I share many commonalities with the research participants, I also have many contrasting differences that separate me from the participant groups. Instead of taking an insider position, I consider my research position as an 'edge-walker'. Tupuola (2004) describes edge-walkers as individuals who are able to weave in and out of different cultural and ethnic identity domains while still maintaining a solid sense of self. In this respect, edge-walkers are people who bring together different identity positions and in doing so can throw new light on the way cultural or ethnic worldviews are perceived (Stewart-Withers, 2016; Tupuola, 2004). In this respect, edge-walking provides a 'bridge for crossing' (Stewart-Withers, 2016, p. 28) between the roles and positions I identify with. I am neither an outsider, nor am I an insider researcher. As an edge-walking researcher, I was able to weave in and out of cultural and social contexts between both groups, exploring their narratives (Burke Johnson, 1997). 


\section{Data Collection}

The focus group activities and walk-along interview questions were developed with the advice and guidance of Dr Fiona Beals. Dr Beals teaches in the Bachelor of Youth Development at WelTec and has extensive experience with the activity-based methods I used in this thesis.

\section{Taiohi Māori Focus Group Context}

As I will discuss in later chapters, the Taiohi Māori group lacked access to many public spaces so I had to arrange the initial meeting in an educational facility [in order to protect confidentiality, I have not named the facility] that the participants $(\mathrm{N}=6)$ had never been and which was unfamiliar to them. Two family members, a sister and a niece of one of the participants, also attended this hui. The participants were very hungry when they arrived so kai was provided before I began the interview activities. A range of activity-based questions were developed for the data collection process. This included, for example, asking participants to use maps to indicate areas they like to go and places where they do not feel safe. On another identical map they were asked to chart how these places might look in the future. The run sheets for these hui are in Appendix 4.

\section{Pacific Participant Focus Group Context}

This focus group was noisily interactive. There was a lot of discussion and I needed two voice recorders to ensure that no conversation was left out. The head trainer and a parent were also present at the hui. The focus group interview took place at the boxing gym which was an environment with which the participants $(\mathrm{N}=9)$ were familiar. Kai was provided at the end of the interview activities.

\section{Similarities and Differences}

The main similarities in the focus group interviews in both groups were that family members were present and food was shared. Both groups responded to the same set of interview activities and questions although the Taiohi Māori asked me to adapt the interview process in order to shorten the hui. This was because these participants felt closed-in in the room where we met and they wanted go outside and take breaks. Hosting this group in an environment that was not familiar to them proved very challenging. They did not immediately feel comfortable and it took time for them to get settled. As well, I had established relationships with the Pacific participants, their trainer and many of their parents prior to the hui. In contrast, a prior relationship had not been established with the Taiohi Māori participant group and while the interview went well, the wairua [spirit] of the hui was affected. 


\section{Walk-along Interview Context for Taiohi Māori and Pacific Participant Groups}

The walk-along interviews were attended by a smaller number of participants between two to four participants in a group at a time. However, as there were more participants in the Pacific group who took part in the study, three walk-along interviews were carried out. Only one walk-along was needed for the group of four Taiohi Māori. The locations of the walk-along interviews differed for each participants group. The Pacific participants did the walk-along interviews in their own community, whereas Taiohi Māori chose not to and their reasons for this will be discussed further in a later chapter. Because they were scattered across the Gully and did not have money for public transport, assistance in travel was also needed to ensure that Taiohi Māori could participate in the walk-along interviews and the focus group hui, whereas Pacific participants made their own way to each interview.

\section{Observations}

I recorded field observations in my field journal notes after each interaction with the participants. However, the majority of naturalistic observations occurred during the walkalong interviews. Naturalistic observation is a term that refers to an unstructured observation by the researcher who witnesses participants' behaviour in natural settings without disrupting a natural flow of discussion (McLeod, 2015). This type of observation is useful in generating new ideas or shaping one's reflections on data analysis. Notes from my field journal are included throughout this thesis.

\section{Summary of the Data Collection}

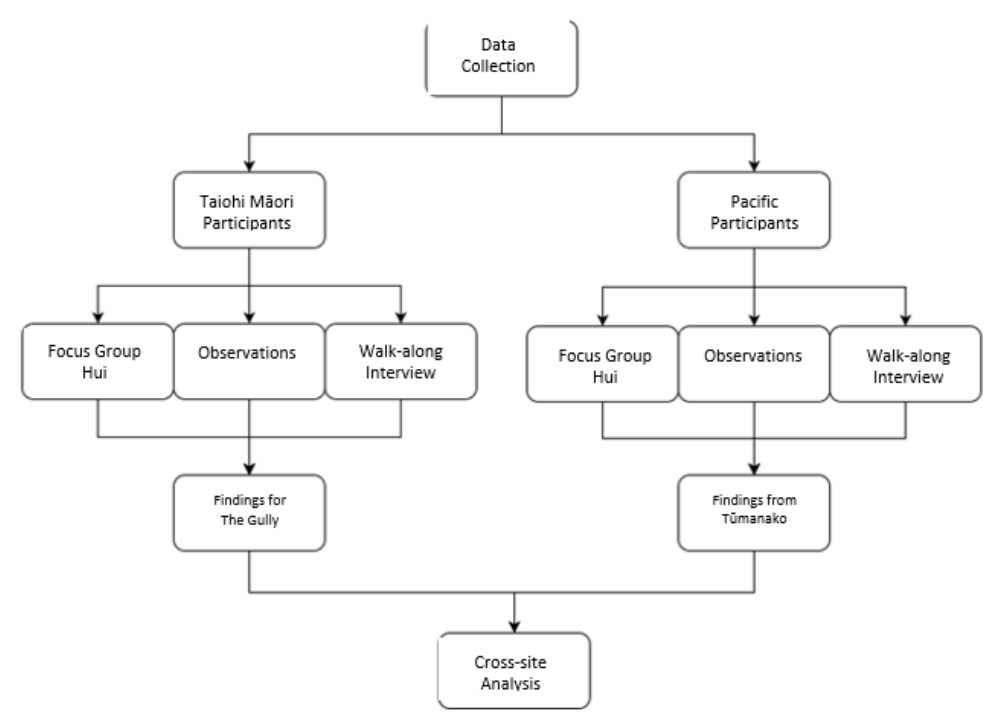




\section{Pacific Participants' Focus Group Hui}

Nine participants, one parent and the trainer, Brown Sensei, were present at the focus group I conducted with the Pacific participants. The participants helped me set up the tables and lay out the kai. Snacks were provided at the start and I arranged for pizza to be delivered after two hours of the hui. The aim was to complete the focus group hui and then conclude over pizza. However, the activities took longer than expected and the pizza arrived much before the scheduled finishing time, which made the participants hungry. We carried on until the end of the activities, having adapted some along the way to suit time constraints and reading the body language of participants. Refer to Appendix 3 for activities carried out in the Pacific focus group hui.

During this session, the boys each chose a pseudonym. To ensure that these names aligned with the ethical considerations of the study and would not be deemed inappropriate to others, they were asked to choose a name that could be a fighter name, or stage name, in a boxing match. Fighting names are important in the boxing community, for example, the fighting name of a female martial arts champion is The Preacher's Daughter (Holly Holms, UFC champion Mixed Martial Arts fighter) and the participants took seriously the opportunity to name themselves.

During the focus group hui, the Pacific participants engaged in a range of activities relating to the guiding questions of the research that were similar to those in the Taiohi Māori group (for example, activities involving maps of their city and poetry tasks) but slightly adapted to better fit the cultural context. The focus group activities included a mix of group and individual participation and required that they did some group brain-storming of ideas. Props were also used in activities such as a boxing glove to pass around and share our dreams for the future, activity cards that displayed images of possible outcomes in the future that elicited discussion around future orientations, among others. Refer to Appendix 3 for a list of activities and resources used in the focus group hui. At the completion of the focus group, feedback was given and thoughts shared about the hui. One participant blessed the kai and offered a prayer. Over kai, we discussed the next phase of data collection, the walk-along interviews.

\section{Observations of Pacific Participant Group}

The Pacific participants were clearly comfortable in their community and felt an attachment to it. They knew the best places to go and eat, they knew where they wanted to walk and they often spoke to people they knew as we walked through the area. I could see the connections they had in their community, even those who lived a little further away from the area where we did the walk-along interviews expressed a sense of comfort and neighbourliness. 


\section{Walk-along Interviews}

As previously mentioned, the walk-along interview is a qualitative method where participants take the researcher on a tour through their lived experiences. A walk-along or go-along interview provides ethnographers with privileged access to participants' everyday experiences that would not have otherwise be attainable by other means (Van Hecke et al. 2016). Walk-along interviews take place in their neighbourhoods or places that participants are familiar with (Carpiano, 2009; Kusenbach, 2003; Van Hecke et al. 2016). These walkalong approaches enable researchers to do more than "'hang out' with participants, rather, ethnographers establish a coherent set of data by simultaneously observing participants in their spatial environments and while assessing their experiences" (Van Hecke, et al. 2016, p. 463). Van Hecke et al. (2016) suggest that a productive timeframe for conducting a walkalong research method averages between 60 to 90 minutes.

In most cases, walk-along interviews take place outside of participants' neighbourhood context (Kusenbach, 2003) and this was the case for the Taiohi Māori participant group. I will discuss the reasons for this later in this chapter. Of note here, however, is that the walkalong interview method offers an in-depth understanding of the experiences of the research participants in their local contexts (Carpiano, 2009). In this study, I sought data about how the participants engaged with their local contexts on a daily basis but I also wanted to understand the social and cultural meanings they attached to them.

The walk-along interviews allowed conversation to flow more naturally than it would have in a formal one-to-one interview situation. At the same time, many of the participants have had interactions with the 'system' (e.g. the New Zealand Police, the Ministry of Justice, social welfare agencies, teachers) and have been in situations where formal one-to-one interviews usually mean that some form of punishment or reprimand will be forthcoming. Attempting to collect data from the participants in a similar manner may not have uncovered the rich and detailed tapestry that the participants shared and in this respect, the walk-along interviews were a productive way of initiating discussion.

\section{Walk-along Interviews with Pacific Participants}

Three separate walk-along interviews took place with the Pacific participants. The first walkalong interview was scheduled with Wolfie, Siracha and Bullet Boom Security. They had arranged to meet me at the boxing gym after school where they would decide where we would walk. In the end, only Wolfie showed up as one participant had travelled out of town and the other participant also had a change of plans. We planned to reschedule when they were all available.

The first walk-along interview that took place was with brothers, Iron and Security. As we walked through their neighbourhood they told me stories about things that had happened in these places. They led me to the city centre which was full of people and then we walked through an area where crowds had gathered around a community hall where a Cook Island 
festival was taking place. Loud music, children playing and the smell of food added to the cultural atmosphere of this neighbourhood. As we walked through the swarms of people Iron and Security decided to head to their old primary school. On the way to the school, I asked prompt questions, such as "why did you move? How did you feel when you had to move?" The neighbourhood was familiar to them and they pointed out houses in the street where their friends live and recounted a story about a local person they knew who ran past us as we walked. It was at the school, an environment they knew well, that Iron and Security began to tell me more about their memories of growing up in the area and the plans they had for their future. In addition to planning their future, discussions about 'street kids' or what I refer to as 'anomic youth' emerged.

The second walk-along interview was with brothers, SOK and Coco. It took place on a Monday at lunch time on a public holiday. The research and prompt questions were the same as those asked in the previous walk-along interview with Iron and Security (refer to Appendix 6). However, there were additional prompt questions that occurred naturally as part of the flow of conversation, such as, if you could change anything about Te Ana Kore or the community, what would you change? We met at the boxing gym and walked from there. On the way, they pointed out the "best" bakery and as arranged previously, I purchased food for them. They chose to sit down and eat in the city centre. We had initially agreed to walk around the neighbourhood after we had eaten but this plan was set aside as an easy flow of conversation had begun and I did not want to interrupt it. We remained seated in the city centre and then walked back to the boxing gym towards the end of the interview. This pair shared their plans for the future and discussed the things they like to do in their community.

I met with Barboza, Mighty and Siracha outside the boxing gym on a Thursday after school, before their training session that evening. We walked to the local shops and bought food from the bakery. They decided to walk to a nearby duck pond and find a spot to sit down and eat, away from the wind. Shared community spaces, such as parks, were utilised in this interview which is something that was less discussed in the previous walk-along interviews.

The remaining participants from the focus group, Wolfie and Bullet Boom Security were unable to complete the walk-along interviews. Wolfie was very busy with the end of year exams at school and also works part time after school and during the weekends. Bullet Boom Security also had commitments that hindered his availability to participate. However, the stories gathered from this group are rich and both answers the research questions and brings light to important themes that I explore in the following chapters.

Due to conflicting schedules, the walk-along interviews occurred across a span of two months. As previously mentioned, my contact with the participants was limited to attending their training sessions and hoping to see the participants there to arrange available times to carry out the walk-along interviews. However, this was not always successful, as some participants were not always present at training sessions. As part of my agreement with the gym managers who wished to maintain confidentiality around their members contact details, I did not have access to messaging the participants via social media and only two participants 
had mobile phones. The head trainer, Brown Sensei, offered to keep in contact with the participants through Facebook to remind them about their meeting times with me.

A number of factors need to be taken into account when conducting walk-along interviews with young people. Working around their school, family, work and social schedules is one major consideration. Another factor is that parental consent forms often take time to be completed and this can hold up research schedules. As well, these kinds of interviews are weather-dependent. Factors to consider during the walk-along interviews are; weather conditions, wind, background noise in the audio-recordings such as sea gulls, cars, music and noise made by passers-by and the difficulty of hearing what was said when participants moved away from the recorder. These factors became most evident during the transcribing process as at times, the sound quality of recordings was affected.

\section{Taiohi Māori Participant Group}

I had called on members of my own social networks to help me bring together the Taiohi Māori group to discuss their participation in the study. There were five males and one female who made up this group aged between 16 and 18 years. They all resided in various suburbs in the Gully. Consent forms were given out at the first meeting and a time for the focus group hui was organised. The focus group hui took place at an educational facility because the participants did not have access to safe public spaces where we could meet with any degree of privacy. Food was provided at this and subsequent meetings. At the initial briefing, they all agreed to take part in the focus group hui and the walk-along interview.

The same activities that were used for the Pacific participant group were carried out for this group of Taiohi Māori, with minor adaptations made according to time restraints and context. Refer to Appendix 4 for research questions and prompting questions asked during Taiohi Māori focus group hui. At the completion of the focus group hui, we arranged to meet for the walk-along interviews the following day.

\section{Taiohi Māori Walk-along Interview}

By the time the walk-along interviews were conducted with the Taiohi Māori group the number of participants had dropped to four people. I arranged to pick up the participants in their own neighbourhoods around lunch time. Each participant arrived early to the designated meeting place ready to take part in the interviews and looking forward to being fed. This group chose not to do the walk-along interview in their own neighbourhoods but instead chose a more central location.

Two participants were not able to go to the locations that I originally suggested. The reason for this was that 48 hours earlier, they had been issued with Court-ordered trespass notices that prohibited them from being in central urban areas in the Gully. Instead, Onepu beach [this is a pseudonym] was chosen as a place where they could safely and legally gather for 
the walk-along interview. It was also a location that did not favour one neighbourhood in the Gully over another. This was important because the participants lived in different suburbs but also, none of them wished to do the walk-along interviews in their own communities. The participants discussed stories and themes around the urban spaces they generally utilise, even though we were walking in an area in which they were less familiar.

The questions in this walk-along interview were semi-structured and designed to work with the flow of the participants' conversation. This allowed me to retain some fluidity in the discussions that took place while still maintaining a steer toward the key research questions (Kvale, 1996). The walk-along interview questions are in Appendix 6. However, the walkalong interviews in the Gully were conducted under very different circumstances from the gym members' groups in Tūmanako and I had to adapt the key interview questions accordingly.

\section{Observations of the Taiohi Māori Group}

The Taiohi Māori were initially rather apprehensive about being in environments that they did not know well. I noticed them constantly checking out what was going on around them as they entered unfamiliar places, such as the educational facility where the focus group hui took place and the beach where we did the walk-along interview. To begin with, they kept a careful and wary eye on people they passed and it took time for them to feel settled.

During the walk-along interview, we saw a noisy and potentially violent domestic dispute taking place not far from where we were walking. A man was behaving aggressively towards a young woman, and we saw him standing over her as she sat cowering at a park table. The participants and I were unsure what to do. Two of the male participants wanted to go over to the couple and physically remove the man as they were concerned for the woman's safety. Another member of the participant group urged them not to take matters into their own hands (some group members had already been in trouble with the police in the hours leading up to the walk-along interview and there was a concern about potentially drawing themselves to police attention again) and suggested we keep an eye on what was happening from a distance and take action only if the situation got worse.

We decided to remain visible to the couple who were having the argument so that they could see that witnesses were nearby. I did not want to put the participants at risk of any harm or have them arrested for assaulting the man who was behaving aggressively to his partner so eventually, when the dispute ended and the man left, I approached the woman who had been involved in the argument and told her that I had taken notes about what I had seen and offered to help her if she wished to notify the Police. She declined this assistance and after discussing it with the participants, the walk-along interview was resumed.

Despite the fact that the woman was a stranger to these participants, they showed deep empathy and concern for her situation. They were not concerned about their own safety but responded in line with their own ethical beliefs about standing up for someone at risk of 
being harmed. I note these observations here as I point out the risks of conducting walk-along interview methodologies in areas where there are many complex social problems.

\section{Data Analysis}

Data were analysed thematically in this study and I focused closely on emerging patterns of group behaviour (Aronson, 1995). Data were collected through several sources including my research journal notes, field notes and interviews. Tesch (1990) recommends that qualitative researchers become fully immersed in data and read materials many times over to allow new insights to develop. It is suggested that in doing so, they will gain a deeper understanding of what participants recount during data gathering activities (Tesch, 1990). In line with this, I read and re-read data, coded themes as they emerged, formulated connections between codes and themes and related themes to relevant literature in the field.

\section{Cross-site Analysis}

As there were two sets of data from two sets of focus groups, Māori participants and Pacific participants, I separated each group into two piles; the focus group hui data; and, the walkalong interview data. Both focus group hui involved group brainstorming, audio recordings and other activities. These sets of data needed to be structured into a coherent format and then transcribed. I organised each activity in order from the beginning to the end of each focus group hui. Data from the walk-along interviews were kept separate for Māori and Pacific. Observations were noted in a journal. Together, these data provided the means for a cross-site analysis where I could compare and contrast each data set and establish themes (Khan \& VanWynsberghe, 2008).

\section{Developing Themes}

After each walk-along interview was carried out, but before transcribing, I drew concept maps to reflect on what I had learned from the interviews. Then I turned to my research journal and described what had taken place and my thoughts about each interview. By the end of this process, I had a stack of one page summaries of my learning that I later organised into the themes that had emerged from the data.

I repeated the same process of 'coding' (Hsieh \& Shannon, 2005) for the walk-along interviews as coding the focus group hui. I separated the Taiohi Māori data from the Pacific participant group data ensuring that transcripts were stored in separate folders in both electronic and hard copy. I read the transcriptions then re-read them, highlighting key points or any other material I found interesting and useful for the study, regardless of whether their statements directly answered the research questions or not. Once the highlighted sections 
were collated, I added notes so that sorting the data into themes would be easier in the next stage.

Bryman (2008) suggests researchers should begin reading data with minimal notations to minimise researcher bias and misinterpretation and I did not begin to identify themes until I had transcribed all interviews and highlighted all interesting findings. Once these steps were complete, I could then begin locating themes that emerged across the entire walk-along interviews and both focus group hui. There were many paper piles by this stage and to keep data manageable I used colour-coded post-it notes to distinguish quotes I could use for each theme. I then created a skeleton draft of the findings for each participant group, organising each section into key themes and added bullet points of examples that illustrated each theme. During this process I began to see how the findings chapters could be structured. Once the skeleton outline of the findings chapter was filled in, bullet points became full paragraphs. These paragraphs were split into sections, firstly answering each research question and then exploring additional themes that emerged through discussion. A coherent story format started to form.

\section{Data Management}

For security purposes, audio-recorded data were immediately transferred from the recording device to my pass-worded personal laptop and an online secured drive. This was part of my ethical obligations but it also ensured that data could not be inadvertently wiped. Hard copy data were photocopied after each interview, then scanned and saved on a pass-worded online drive, for insurance against any data loss. Paper-based data were transcribed and stored. In line with my ethical obligations, all these data were stored in a locked cabinet, inside a room that was locked, inside a building that had security controls in place.

The focus group hui and walk-along interviews were audio-recorded and these data were saved to my laptop and the online drive for each separate walk-along interview. In some cases, two recording devices were operating simultaneously in case one recorder failed to capture conversations. Each walk-along interview was transcribed and saved to the online drive and sent to my supervisor for additional safe storage.

\section{Validity}

This study combined multiple methods and strategies such as naturalistic observation, theories, and empirical materials. By combining a range of methods and strategies, as opposed to a single method or single theory study, I hoped to overcome intrinsic biases. Triangulating the data was necessary to ensure validity and overcome the weaknesses in the study (Altrichter, et al. 2008). Strategies used to maintain the defensibility in this study include reflexivity, descriptive and interpretive validity (Burke Johnson, 1997). Although I was granted privileged access as an 'edge-walker' researcher, to observe and examine the participants' environments, I needed to ensure that I was not only focusing on my own 
interests. Reflexivity ensured that I was continuously challenging my own research biases and positioning myself in the worldviews of the participants. This was achieved through ongoing critical self-reflection and discussions with the Principal researchers and my research mentor, Dr Fiona Beals, who works in the field of youth development. Knowledge systems that were embedded in the participants' narratives also needed to be protected. Thus, I drew from a descriptive validity strategy, situating myself through the eyes of the participants, reporting descriptive data such as settings, places, behaviours, among others (Burke Johnson, 1997). Lastly, I carried out interpretive validity checks whereby I asked the participants during the interview whether my understanding of what they told me was correct. I did this several times during the interviews to ensure that I had interpreted their stories accurately.

\section{Ethical Considerations}

This study had approval from the Victoria University of Wellington Human Ethics Committee. To protect the identities of the participants and others involved in the data collection, pseudonyms have been used. Place names have also been changed. All participants were given participant information sheets outlining the aim of the research and their contribution and I discussed these in person before data were collected. Those who took part in the Pacific participant group were also given a consent form for a parent or guardian to sign to allow their participation in either the focus group hui, or the walk-along interview or both. See Appendices 7-11 for these forms.

The manager of the boxing gym requested that each participant have parental consent to participate in the study, regardless of whether they were over the age of 16 or not and I complied with this request. I also ensured I provided the boxing gym management with its own information sheet and consent form to carry out the research with their members and to carry out the focus group hui in their vicinity.

\section{Summary}

In this chapter I have outlined the methodological approach that was taken in this study. To that end, I have discussed how participants were selected and how relationships were established and some of the challenges, limitations and constraints of the methodological approach have also been described. In the next chapter the Taiohi Māori findings are showcased and their hopes and fears for the future and their sense of belonging in everyday places are explored. 


\section{CHAPTER FOUR:}

\section{TAIOHI MĀORI: GROWING UP IN THE GULLY}

\section{Introduction}

This chapter presents the findings from the focus group and walk-along interview with young urban Māori from the Gully region. The chapter is organised into two main themes. The first theme explores the hopes and fears these young people have about their future. Their most deeply held fears relate to being incarcerated, poverty and losing custody of their children. The second theme focuses on belonging and how these participants establish a sense of belonging in the Gully; an area where in many places there is significant economic deprivation and families struggle to make ends meet. During the interviews, these participants talked about 'place' and how their networks of friends and family shape who they are. To protect the identity of the participants, place names have been changed and participants selected their own pseudonyms. In interview extracts, the initials HF refers to me as the researcher.

\section{Building Research Relationships with the Participants}

In this section I provide some contextual information about these participants. The reason for this is to give insights into their everyday lives, what is 'normal' for them, and to establish the background against which their hopes and fears about the future are shaped. Their past and current circumstances provide important clues about their view of the futures so it is important to provide some detail about this.

This group of young urban Māori live in single-parent households in low socio-economic areas around the Gully. They have grown up in families who have experienced severe, longterm financial pressure. All the participants live at home with one or more members of their families, with the exception of one young woman, who at the time the fieldwork took place, was pregnant and living precariously between several homes, going between her partner's home and her sibling's homes.

Lack of money is a major issue for these participants. For example, while transporting participants to the venue of the walk-along interviews, the topic of food came up and the young people told me that they were "starving". It transpired that this was not an exaggeration, they were literally very hungry. Consequently, they all looked forward to eating the takeaways that I told them I would provide. I had invited them to choose what kind of food they wanted to eat while we went on the walk-along interview and their excitement about this was not only because the food was paid for (they rarely had enough money to purchase takeway food), but as I discovered later, after the interviews, they were excited about eating a hot meal and having a choice about what they could eat. At that time, Breach1 had gone several days without a full meal. He told me that there is often little food in his 
house and his mother spends most of the household food budget on alcohol. He eats instant noodles if they are available or eats at his friends' homes if they happen to have enough food to share with an extra person. Financial struggle was a recurring theme for this group of young people and as this chapter shows, it had an impact on nearly every aspect of their lives.

The stories these young people had to tell touched on some challenging issues including crime, poverty, and times of deep hopelessness and despair. I had not met the participants prior to conducting the fieldwork and I was aware that trust had to be built quickly. As well, I knew their stories were likely to be personal and could leave them feeling vulnerable so establishing trust was paramount. I began by telling them a little about my own life as someone who grew up in a single-parent household in a poor community not far from where they live. I provided food during my meetings with them and as we ate and talked together about our experiences of growing up in the region, the participants became increasingly open to sharing parts of their lives with me.

Trust not only needed to be established for the safety of the participants but also for myself as the researcher. On the first day we met, two participants were under the influence of either marijuana or alcohol and their behaviour was somewhat unpredictable. While I was able to maintain an atmosphere of safety and respect I decided, in the interests of everyone's comfort, to conduct the walk-along interview the following day without them. I did this discreetly in a way that maintained their dignity and acknowledged my genuine appreciation for the time they gave to the first set of interviews.

The walk-along interviews took place the following day. Normally, these interviews would take place in the neighbourhood where the participants live. However, these participants reside in various suburbs across the Gully and did not have access to their own transport nor money to pay for public transport. I provided them with transport because without the means of getting to and from the area where we did the walk-along interview it was unlikely that they would have been able to participate. As a researcher, as part of my ethical obligations to the participants and also to my university's human ethics committee, I had to ensure that the participants and I were safe from any danger, especially when walking together in a public place. This required some thought because as mentioned in the methodology chapter, the participants decided that they did not want to go to their own suburbs, which were not especially safe environments for a walk-along interview and instead suggested a central location that they were all allowed to occupy without breaching trespass notices that had been served on two participants the previous day.

\section{The Future: Hopes and Fears}

The Taiohi Māori expressed high levels of anxiety and concern about the future. They had little optimism and thought about the years ahead in terms of negative realities, such as going to court, getting criminal convictions or being incarcerated. In addition, the findings highlighted their expectation that the severe financial pressures that they and their families 
currrently experience would continue throughout their lives. Breach1 told me that he only considers the future when his fear of going to jail becomes a likely possibility.

I sometimes think about the future when I'm in a complicated situation. Like when I'm going through court I'd think, what's gonna happen in the future. Cos I dunno if I get locked up or something [Focus group hui].

One participant, Dubz Up, explained that he felt happier when thinking about the past because the present holds few positive or enjoyable experiences and this affects how he thinks about the future.

Dubz Up: I just wanna go back to the old days you know. When I was just young. There's nothing around right now [Focus group hui].

During the focus group Dubz Up reflected on the "old days" when his closest friends lived in the same neighbourhood. Due to the lack of stable, long-term housing in poor communities in the Gully, many families have little choice but to relocate fairly regularly and this fractures a sense of community that is tied to particular neighbourhoods or 'places'. In these neighbourhoods, many families are just 'passing through' and over time this semi-nomadic existence has become the norm. Dubz Up spoke of his sense of loss and isolation as friends and relatives have moved away from the area where he lives and the disruption to his social and familial stability as a result. He has few support networks around him in his immediate environment and sees his present circumstances as being so bleak that he cannot fathom the future without experiencing extreme anxiety.

As these interview extracts show, the future is a source of great worry for these young people and during the interviews they rarely expressed any hopefulness about the years ahead. Two of the participants, aged 16 and 17 years, were in a relationship and about to become parents. The couple were living apart but at the time the interviews took place were looking for accommodation where they could live together as a family once their baby was born. Unsurprisingly, their hopes and fears centred on the future of their child. Both participants knew of children who were removed from their families and their greatest hope was not only to be able to provide financially for their child but also maintain custody. In this respect, hopefulness and optimism about the future took on particular significance. They deeply feared the kinds of struggles they knew they were likely to face in years to come and much of their lives were spent looking for ways of avoiding these risks and hazards. In other words, these Taiohi Māori fear the future, and thus, their primary hopes are to avoid these fears becoming a reality. Hope is therefore largely expressed as the reverse side of the negative life situations and circumstances that they most fear. I have called this form of hope, 'reversed fear' which describes the young people's articulation of hope in terms of successfully avoiding frightening possibilities. In the sections below I expand on the kinds of anxieties that these young people experience such as the fear of poverty and prison. 


\section{Fear of Prison}

Getting permanently caught up in the justice system was a common concern for these participants. For those who were on a Court-ordered curfew at the time of the interviews, being required to be at home at specified hours was highly problematic. During curfew, the Police are permitted to enter people's homes up to three times during the night to confirm that young people are in residence. This constant attention from authorities had created tensions with the participants' families but had also disrupted the sleep of the entire household and often their neighbours as well. Families who live in difficult economic circumstances often have to work very long hours at unsociable times and sleep is important. As well, many families in the Gully live in overcrowded housing with many people sleeping in a single bedroom. Houses and apartment blocks in the Gully are built close together so a late-night Police visit is likely to wake the neighbours. The arrival of authorities at unspecified hours of the night can therefore break up sleep patterns in several households where sleep is often already deeply disrupted. In my fieldnotes I recorded that these participants also feel stigmatised when they are served trespass notices that prevent them from gathering in public spaces such as the Gully city centre and the shopping malls. Their activities bring them to the attention of the Police fairly regularly and this often leads to Court appearances, which they describe as a place that they do not want to be.

Breach1: You just don't wanna be in there. Sometimes you can get good ones [judges], you get bailed, but sometimes you can get custody. Locked up. It depends. It's all up to the judge though [Walk-along interview].

Being in Court and facing legal penalties reinforced the participants' sense of having little or no control over their future. Most of these participants were aged 16 and 17 years at the time the interviews took place so at this stage going through the court system resulted in punishments such as curfews, trespass notices or fines, rather than imprisonment. But they feared having their future being decided by a Judge or jury and as they get older, their fear of prison increases because they know that once a minor turns 18 years, they are tried as adults. For example, when discussing social activities, Ekin talked about being old enough to legally purchase his own alcohol (previously family members or older friends provided him with alcohol). This led to other participants within the group highlighting the vulnerability that Ekin now has as an 18 year old.

Breach1: 18 straight... Herehere [A pseudonym is used here in place of the name of the prison]

Blazer: Off to lock up [Focus group hui].

Now that Ekin is 18 years old, his fears have moved beyond the consequences of curfew and fines, to worrying more about incarceration. Breach1 simply states his hope, "Just be a free man, no court" [Focus group hui]. Similarly, Ekin states his dream "to stay out of jail. Not to end up in [Herehere]." In many respects, the criminal justice system is a major presence in 
the lives of Māori young people and their families in the Gully and much time is spent calculating how to evade the attention of the Police as well as avoid the threat of prison.

\section{Fear of Poverty}

Among the fears noted during the focus group hui, were anxieties about whether or not these participants would be able to pay for basic essentials. Growing up in poverty and knowing the struggles their families experience on a daily basis contributed to their fears about how they would survive in the future. Thus, the participants listed employment as a key hope as well as a primary source of worry. These young people do not have secondary school or tertiary qualifications, nor do their families and they come from low income households. Thus, they worry about the difficulty of finding employment that will allow them to pay their bills knowing that they are at a disadvantage in the economic field, having to compete for jobs against those who have educational and occupational qualifications. Also, as noted earlier, growing up in state housing areas does not provide them with community stability and often results in the need to relocate, as was the case of those who were close to Dubz Up.

Dubz Up: Theres nothing around [Rāwāhi] anymore because it's always... nah, just all my mates are moving and stuff. It's just... I'm the only one around there [Focus group interview].

Anxieties about having stable, affordable accommodation also worries these participants. They are familiar with the high demands and very long waiting lists for state housing and are aware of many families on these waiting lists who are already homeless. There is a clear link between the concerns that these young people have for the future and the factors that influence their present including their experiences of growing up in economically precarious environments. Their first-hand experiences of poverty and associated anxieties about getting suitably paid long-term work therefore closely shapes their view of what they think their future will be like.

\section{Hope as Reversed Fear}

There is a relationship between the hopes that the participants have, and their fears. For example, they fear not having enough money in the future to pay their bills. Their hope, which addresses this particular fear, is to find employment that will allow them to pay the bills. Similarly, they have concerns about finding suitable accommodation in an area where there are lengthy waiting lists for housing, much of which is substandard. They know this will be difficult with little money and limited emplyoment prospects. Accordingly, their hope to address this concern is simply to find somewhere to live that they can afford. In other words, their hopes are reflected in their fears and I described this kind of hopefulness as 'reversed fear'. 
I point out this observation because during the focus group hui, the participants were invited to explore their hopes and dreams about the future through a series of activities that were devised for the project. The activities promted discussion around the hopes and fears for the future. However, despite aspirations being forefronted in the data gathering process, the concerns of these Taiohi Māori were considerably more prevalent and these were directly mirrored in the way they discussed their hopes. They subconsciously linked their hopes and fears together and in relation to each other. I will discuss this further in Chapter Six but note here that utopian visions of the future and creative expressions of optimism about life in times ahead are more readily adopted by those who already carry a sense of stability and certainty about the future. Those who are in circumstances where it is difficult to exercise active agency in matters relating to food and income security or acquiring safe and affordable housing or jobs that pay a living wage perceive the future in dramatically different ways.

Meanwhile, the Taiohi Māori involved with this study did not state what kind of employment they hoped for, nor whether they wished to own their own home. These matters seemed very remote to them. In contrast to the Pacific participant group (discussed in the next chapter), rather than dreaming of long-term stability and wealth in terms of careers and dream homes (as the Pacific participants did), the Taiohi Māori simply hoped to relieve their concerns with immediate solutions to the problems they know they will soon face. This finding will be returned to in the discussion chapter, further exploring possible reasons for the limited scope that this group displayed in their hopes for the future.

\section{Support Systems}

During the focus group hui, when asked to list the types of support avenues that Taiohi Māori can utilise to assist their hopes and dreams for the future, few systems were identified. In contrast to Pacific participants who, as I discuss in the next chapter, listed multiple internal and external support avenues, these Taiohi Māori did not.

Breach1: All I know is family and friends [Focus group hui].

There was mention of individual coping mechanisms and motivation such as sports, music and art. However, friends and family were seen as the most important sources of support and at times, these could be unreliable. There appears to be a link between the scope of their aspirations and the degree of support avenues they see are readily available for them. This will be discussed further in the discussion chapter.

\section{Belonging in Everyday 'Place'}

This group of young people did not feel particularly 'anchored' or 'at home' anywhere in the Gully. They are in constant motion between various suburbs in the area and as Breach1 noted, they "go all the way around the motu [region]" [Breach1, focus group hui]. Accordingly, they do not occupy or utilise these spaces in ways that firmly connect them to 
those places or provide them with a sense of belonging or stability. This also means they do not engage much with recreational spaces in their neighbourhoods, such as playing basketball at the basketball courts, or spending time at the park with each other. Rather, these young people tend to be intermittently present in various places or merely passing through. When asked to share stories about places where they spend time, I had assumed they would discuss memories of things that occurred in those places or activities that they enjoyed. However, this was not the outcome. The following discussion took place during the group walk-along interview.

HF: I had all these questions but they're not really working. It was meant to be questions like, "tell me a story about places" but...

Breach1: Most of them came up about butts [picking up used cigarettes on the streets when cigarettes were too expensive]...

Ekin: ... And most of them came up with 'on it' [consuming alcohol]

Preece Dawg: That's basically what it is for them...

Breach1: ... Getting drunk.

Ekin: That's our life [Walk-along interview].

Their stories, although rich and told in a way that even what is missing was made visible, were fragmented in structure. I was still able to capture the essence of what participants were telling me throughout the interviews but I had to ask multiple probe questions to uncover more about what they were trying to share. These fragmented responses had to be linked with more questioning and thus, interrupted a natural story flow. As I will discuss further in the discussion chapter, a possible reason their stories were so fragmented could be due in part to their deep disconnection with the Gully as a place to live and consequently, their ability to construct meaning in these places was constrained. I will later elaborate on a possible link between place-disconnection and young people's identity narratives. The reason I point out these fragmented stories and place-disconnections here is because in comparison, the Pacific participants shared stories about place and place-belonging in ways that this particular group does not. There may be a link between the ability to construct identity narratives in places of belonging, and in contrast, the telling of 'broken' stories in places where 'unbelonging' occurs.

Rather than telling me about their place-based memories in different parts of the Gully, the participants spoke mainly about where they go to get drunk with their friends. They spoke of how they spend time in the Gully and Beeton [another large centre] either consuming alcohol in the city centres or driving around with their friends.

HF: Talk me through your typical weekend.

Ekin: Meet up with one of the bros... get on the piss [consume alcohol] and then on Sunday... rest day [Walk-along interview].

This statement represented how these Taiohi Māori spend their typical weekends as a group, as they are often, inseparable from each other. 
During the focus group hui, the participants were invited to locate places on a map of the Gully where they like to go, detailing what activities they enjoy in those places. They responded that they like to go "everywhere". However, during the walk-along interview, aside from Dubz Up, the other group members made it clear that Rāwāhi [a suburb in the Gully] is a place where they will not go. They do not get along with residents of Rāwāhi and there appears to be a rivalry between residents of Rāwāhi and Rāta which goes back many years. Dubz Up was living in Rāwāhi at the time the interviews took place and he said he is comfortable going all over the Gully region except for Rāta where Breach1 resides. Rāta is a place of uncertainty for Dubz Up and he does not wish to risk being in a territory where many local youth share negative feelings towards those from Rāwāhi. Thus, Dubz Up avoids Rāta, despite his friends being residents there. Instead, they often meet somewhere else, such as Pāka, where the other participants live and where rivalries are less evident.

In addition to avoiding these places, these participants would not normally associate with people from the avoided areas, unless they happen to be family members. For Dubz Up, this exception is made as he not only spends time in the Gully, where the others also socialise; he also has family connections with the other participants. The extract below illustrates that being family is a "different story" in that it creates exceptions to rules about safe and unsafe spaces. Territorial boundaries then, are a factor when it comes to belonging in place. A barrier to their sense of belonging in these locations is the fear of being attacked by local youth from that area who share the same negative feelings towards 'outsiders' as they do.

HF: Why not Rāwāhi? [Why would you not go there?]

Breach1: It's cos we never get along with them.

Ekin: Cos we not from that 'hood [neighbourhood].

Me: But you get along with (Dubz Up)?

Breach1: Yeah cos he's a cousin. He's family.

Preece Dawg: He goes to the Gully.

Ekin: Yeah, family. Different story [Focus group hui].

Adding to their discussion about territory and boundaries, these participants also think carefully about their personal safety when navigating different areas of the Gully.

Dubz Up: Yeah, but you don't need to be scared of anybody.

Breach1: Bro, that's what you said about Rāta.

Despite trying to reassure one another that they will be safe if they cross into a rival suburb, these participants tend to gather in places where they do not feel threatened. For the majority, these places are located throughout the Gully and Beeton, and not in Rāwāhi.

As the Gully is a central location, close to where they all reside and a place where they all tend to spend time, I asked them about local activities and whether they were involved in them. During the focus group hui, I provided a map of the Gully and invited the participants 
to describe activities that are run in the area that young people enjoy. The river is somewhere members of this group enjoy when the weather is good. They like to swim there and "do bombs" (Ekin, Focus group hui). "Bombs" or "manus" is the act of jumping into a body of water, causing a big splash. Bearing in mind that several participants have trespass orders that prevent them from going to certain areas such as the Gully city centre and the shopping mall, the only other places that this group enjoy spending time with each other is either at their homes when this is possible or the central library.

Dubz Up: I just go to the library. Just go on the computers...just read books. Breach1: Facebook.

Belonging, then, is more about who these participants spend time with, instead of where. For these young people, their neighbourhood 'places' are filled with risks and danger which they must navigate carefully and become knowledgeable about territories and boundaries. These include boundaries between places of safety and places of risk. Thus, instead of establishing their sense of belonging through place, they find their social and emotional 'anchors' in friends and family and it is through the comfort and familiarity that these participants share with each other in their semi-nomadic wanderings around the Gully that they come to understand the notion of being 'at home'. Members of this group are often together; in fact, one participant said that Christmas is the only time that they are not all together because they are with their families. The rest of the time, they spend their days going to one another's home and spending time there, 'kicking back'.

Although this group do not currently have a strong sense of place-based connection and belonging, they did once know what it was like to feel anchored in a social environment where they were welcomed, valued and able to gather without a sense of risk. This was a time two years prior to the interviews taking place. The discussion emerged when I asked the Taiohi Māori what activities they enjoyed and the places they liked to go. As we spoke, it became apparent that there were not many places where urban Māori youth could spend time socialising together and where they were not prohibited by the courts or reliant on the weather. When I pointed out this observation to the young people, stories began to unravel about a local youth space in the central Gully that had a significant impact on their lives. It had been run by the Gully Council and it offered young people a range of free activities such as online computing, table tennis, and pool among many others. Unfortunately, the youth space was shut down and no longer runs today.

Ekin: It's not there. It's not in the Gully no more.

HF: What happened to it?

Ekin: It shut down cos of the Gully council.

Breach1: Yeah, they don't wanna fund the money anymore.

HF: And how did that make you guys feel?

Ekin: Ratshit! Cos we can't kick back,

Breach1: That's where all the bros went.

Dubz Up: That's where I'd always go to [youth space] aye [Focus group hui]. 
These participants reminisced about this space as a place where they all met, socialised and interacted with other local youth. They spent most of their time here and felt a strong sense of belonging with other young people from across the Gully. They also spoke of their feelings of loss and social and emotional displacement when it was closed.

Breach1: But then once [youth space] got shut down, that's when everyone just... Ekin: ... Split...

Breach1: ... Split up and went their own way and just didn't come back. I think that was the place that we all met up.

Ekin: No spot to kick back with all the bros anymore [Focus group hui].

Losing a place where they felt comfortable welcomed and valued, impacted on their connections with other youth in the Gully. As stated above, they lost not only a space to socialise, but they lost contact with many others who they considered friends. As the young people talked about this space and its importance to them, the way they talked changed. They spoke fluently with fewer pauses and they met my eye as we talked. This indicated their enthusiasm for the youth centre and the pleasure they took in being there. When they told me about the closing down of the youth space, however, they reverted back to speaking in disjointed sentences with many pauses and breaks.

\section{Summary}

In summary, this chapter has firstly provided contextual information about the participants in this group and identified the hopes and fears that these Taiohi Māori have for the future. The findings show that their fears are centred on employment, income, housing, parental custody and becoming entangled in the criminal justice system. The scope of their hopes for the future was focused on addressing these concerns as opposed to any wider aspirations that might lead towards hopeful future trajectories. Secondly, this chapter has explored how this group of Taiohi Māori establish a sense of place-belonging. Through the fragments of the participants' stories, it emerged that belonging is achieved by the connections made between people, their friends and family rather than place. For this group, friends and family are the most important aspects of belonging. The only place that brought about stories of belonging is no longer accessible leaving these young Māori feeling socially and emotionally disconnected. The next chapter presents the findings from the Pacific participant group and also discusses placebased belonging and hopes and fears about the future. 


\section{CHAPTER FIVE:}

\section{PACIFIC YOUTH: GROWING UP IN TŪMANAKO}

\section{Introduction}

In this chapter I present the findings from a group of Pacific participants. These participants are members of a community boxing gym in Tümanako and their involvement with this project throws light on how young people think about the future when they are part of broader cultural, ethnic and social networks. Firstly, I provide background information about the participants' everyday lives. Secondly, I explore their hopes and fears about the future. I also discuss the avenues of support this group have identified to assist them in achieving their aspirations. Lastly, I explore the factors that shape their sense of belonging. To protect the privacy of the participants, place names have been changed and pseudonyms are used. Where the initials HF are included, this indicates the researcher asking the participants questions.

\section{Participant Context}

Most of the participants in this group live in large, two-parent family households in Tūmanako and all are members of a local boxing gym. Most of them reside in Te Ana Kore, which is a suburb in Tümanako. This is an area that carries a strong public stigma and is the subject of much negative labelling. There is significant economic under-privilege in this neighbourhood and many families have severe financial struggles. At the same time, many homes are over-crowded and in poor condition and there are comparatively high levels of poverty-related childhood illnesses that affect many children and young people in the area, most of whom are of Māori or Pacific descent. Alongside this, there is an ongoing media discourse of anxiety about Te Ana Kore. Crime levels are high and over time various gangrelated conflicts have created an environment of heightened public fears about being attacked or killed.

Some of the participants' parents had relocated out of Te Ana Kore due to concerns for the safety of their children but Te Ana Kore is where the boxing gym is located and where these participants train and have a sense of belonging. The manager and trainers at the boxing gym told me that the reason they set up the boxing gym in this location was to offer a safe space for young men in the area to gather. In this respect, the boxing gym is a place where an ethical framework of 'brotherhood' could be engendered through the medium of boxing and the philosophies of martial arts practitioners.

Four of the participants in this group were born in Pacific nations and later immigrated to New Zealand with their families. The remaining five participants identify as New Zealandborn Pacific peoples. Those who were born in the Pacific have left behind many of their extended family members as well as ways of life. These kinds of migrations are common 
amongst the residents of Te Ana Kore and have had a significant impact on many families in the area. For Pacific youth, the act of parting from their Pacific homelands has had a profound effect on their sense of place. In line with this, I observed their strong desire to maintain their languages and cultures as a way of keeping their Pacific heritage. They did this by speaking their mother tongue, attending cultural events with their families and practising their faith through church and religious activities.

All the participants were enrolled at secondary school at the time of the study and most of them were senior students. The majority were studying for the National Certificate of Educational Achievement (NCEA), which is New Zealand's main secondary school qualification. As such, they were at a point in their lives where their success or failure at school would directly affect their future pathways through tertiary education and employment.

\section{Considering the Future}

When asked how often they consider the future, the majority of the participants said that they 'sometimes' consider the future but some of them said that thinking about what might happen in the future was "stressful" [SOK, focus group hui]. A few participants, however, said that they 'always' consider the future, for example:

Barboza: [I always consider the future] so that I always have that plan and know my next step.

Bullet Boom Security: I have to look forward to the future for my family and church [Focus group hui].

Barboza and Bullet Boom Security believe that by thinking carefully about the future and actively planning their next steps they will be well-prepared to look after those they care about in times to come. They told me that being prepared for future change is an advantage and preferable to being taken by surprise by sudden change or issues that require them to adapt quickly.

\section{Hopes for the Future}

The hopes that these participants have for the future relate mainly to their future careers, their family and the wellbeing of their community and this is the focus of this section.

\section{Career Hopes}

During the focus group hui, the participants talked about their dream careers and the types of jobs they see themselves doing. The types of jobs they envisioned include becoming doctors, professional sports athletes, marine biologists and mechanics. Few had planned how they 
might enter tertiary education or progress through to postgraduate study, however. They hope to be working in their 'dream jobs' and they wanted jobs that would impress others in their family and social networks. The following extract is from a conversation between brothers, SOK and Coco who discuss their future career aspirations.

SOK: Like, does it look good when you go out and say, "Oh, I do that for a living" Wow!

Coco: When people say, "What do you do for a living?", like, you say that (tell them your job) and then they'll be in shock.

SOK: Like, "oh that's cool!"

Coco: Yeah, "how much do you get paid?"

HF: So, something that impresses others?

Both: Yeah.

Coco: ... And you like doing. [Walk-along interview].

In these discussions about their future careers, the participants said that they want jobs that will earn them enough money to be comfortable and also allow them to provide financially for their families. At the same time they wanted work that was enjoyable. It was not enough to merely be good at a job, they also dreamed of life-long employment stability and financial security.

\section{Family Hopes}

These participants placed enormous emphasis on the importance of family and talked about how one day they want to have families of their own. Importantly, they want to be able to provide financially for their future families and ensure they can live in suitable housing with basic necessities, such as having enough food. The following extract comes from an activity carried out in the focus group hui. The participants were encouraged to select from a range of cards that displayed illustrations and concepts of what they see themselves doing or hope to be doing in the future.

Barboza: My first card is Family. Gotta work hard for my family. My other two is Children and Lifestyle.

HF: What would your lifestyle be?

Barboza: Just to support the children [Focus group hui].

As this group considered their future families they also talked about the sacrifices that their own parents had made to give them the lives they currently live. They are aware that life in the Pacific Islands is very different from New Zealand. To show their appreciation of growing up in a country where they are able to get an education and stand a better chance of earning a good salary, they spoke of needing to work hard to show their gratitude to their family, perhaps by one day buying their parents a comfortable home. The following extract is an example of their family's central place in their lives. 
HF: How come you guys moved over?

SOK: I think my mum just wanted us to grow up with like a better future for us.

HF: Did they come over for your education?

Coco: Yeah.

SOK: Yeah I think that's the main reason aye, to get a better future when we grow up

[Walk-along interview].

The extract below is an example of the hopes that these participants have to repay their family in the future through caring for them financially and emotionally in their old age.

Bullet Boom Security: I want to buy my Mum and Dad a house and to look after my family.

Coco: I want to be able to provide support, security, love, food and shelter for my family and my future family [Focus group hui].

The following conversation between Tuvaluan brothers, Barboza and Mighty gives insight into what life was like for their families before immigrating to Aotearoa New Zealand. These participants discussed the struggles their families went through and their appreciation that they do not need to endure these same struggles.

HF: What's [life] like in the islands?

Mighty: No money.

Barboza: Not as much money as other countries.

HF: What kind of work do they have to do?

Barboza: They gotta hunt for their food like fishing. They don't have proper houses.

Rising sea level...that'll affect all the islands, especially the ones that are low. [Walkalong interview].

Barboza and Mighty were born in Tuvalu, an island that is often referred to as a 'sinking island'. Global warming and rising sea levels have threatened the very existence of the Tuvaluan people. Thus, when Barboza spoke of the struggles that his family faced in Tuvalu, he also shed light on the experiences of the other participants who were born in the Pacific Islands. Climate change affects many of these participants because they come from places that are already dealing with the devastating effects of climate change. Many Pacific nations are increasingly vulnerable to cyclones, drought and the spread of climate-sensitive diseases, such as malaria and typhoid. This has affected their ways of life in the Pacific as well as their homes, jobs, and access to food and clean water sources. These participants, particularly those born in the Pacific were therefore well aware of wider global issues that directly affect their families and this influences their anxieties about their own futures. 


\section{Community Hopes}

When discussing Te Ana Kore and the Tūmanako community, I asked the participants to consider what they would change about their community if they had unlimited resources. They responded that if they had their way young people in the area would no longer have to beg on the streets or commit crime. In line with this, they thought the boxing gym could provide support and direction to other young people in their community who were struggling.

HF: If you could change anything about Te Ana Kore or the community, what would you change?

SOK: Just those kids on the street to get a direction to life. But beside that, nothing, just leave Tūmanako as it is. That's what's cool about our place [Walk-along interview].

Coco: Yeah. Find a place that you can connect with people who can understand you and like, build a bond with them I guess [Walk-along interview].

The concept of anomie or anomic youth was not one I had considered at the beginning of this study and these ideas only began to emerge during the walk-along interviews. This group refers to anomic youth as 'street kids' and 'beggars'. They see these young people as being enmeshed in the social stigma that is attached to Tümanako and Te Ana Kore. Barboza explains his views of anomic youth:

When kids move here from the islands, they know the struggle. So when they first get exposed to having money and stuff, they never save anything and like smoking weed (marijuana) and all that, it's new to them and they just try everything new and they don't know what it does [Barboza, walk-along interview].

These participants held very negative views about anomic youth in Te Ana Kore and were not especially sympathetic to the circumstances of young people living in even more straitened circumstances than themselves. In line with this, they made clear distinctions between street beggars, drug users and themselves and in this regard, the participants can be seen as wanting to establish a sense of difference from those in other low-income groups in Te Ana Kore. Anxiety about poverty, however, was a recurring theme in the interviews. The participants thought it was important to address poverty in the area. For example, Barboza and Siracha commented:

HF: If money wasn't an issue and you could change anything about Tūmanako, your community, what would it be?

Barboza: Kids with no lunch.

Siracha: Yeah. Make anything that parents need accessible to them like for whatever price [Walk-along interview].

When I asked the participants to tell me about the people in their community, aside from their own families they talked about how they appreciate their neighbourhood and emphasised the 
natural beauty of parts of Tūmanako. However, they also talked about the financial struggles that people in their neighbourhood experience. The following extract reflects the views that these participants shared about their extended families and the families that they will have in the future.

Barboza: I want to end the struggle my fam [family] went through. I want my future family to live without the struggle I went through [Focus group hui].

This group talked about their desire to end the cycle of poverty that they and their families have experienced. They hope that in the future they will be financially secure enough to alleviate these pressures as well as ensure that later generations do not have the same hardships. They see this as being achievable by being successful in education and in their careers.

\section{Concerns for the Future}

During the focus group hui, I ran a group brainstorming activity where the participants noted their concerns about the future. They spoke of a broad range of issues including political change, climate change and death. Several participants talked at length about the impact of climate change on family members and villages in the Pacific.

Barboza: [...] Rising sea levels...that'll affect all the islands, especially the ones that are low [Walk-along interview].

Wolfie also talked about his fear of earthquakes during the focus group hui. At the time the study was taking place there had been a great deal of seismic activity so these concerns stemmed directly from current events.

The other major topic of discussion was the American presidential elections which were attracting news headlines at the time. Donald Trump and Hillary Clinton were in a race for the American presidency and some of the participants expressed fear and concern that Donald Trump would win the election. They worried about the impact of a Trump presidency on life in New Zealand and other parts of the world. In particular they feared that the world would dramatically change if Trump was elected; becoming more corrupt in the future. One of the participants, Security, told me that his main concern was that Trump's policies might exacerbate racism towards ethnic minority groups, not only in America, but other parts of the world as well.

\section{Avenues of Support}

During the focus group hui, the participants were asked to list resources (such as local people, groups or organisations) that they might access as a way of supporting their future aspirations. The most common avenues of support they listed were family, friends, church or 
faith-based groups and their coaches/trainers at the boxing gym. However, they also considered support avenues outside of their immediate environments such as seeking inspiration from famous people who they consider to be role models. They included reading autobiographies of people they find inspirational or watching YouTube videos. The participants also noted that the local Police and the YMCA are sources of support in their neighbourhood and in this respect they were aware of some of the support systems within their reach and were willing to access them if needed.

\section{Belonging in Everyday Places}

This group of urban Pacific participants have an established sense of belonging that encompasses relationships with family, their cultural and ethnic identities, church and faith, and the boxing gym. As well, many public spaces in Te Ana Kore and the wider Tümanako area were also significant to them.

\section{Family, Home and Belonging}

Tūmanako is referred to as 'home' by these participants regardless of where they were living at the time or where they were born. Iron and Security, are Samoan brothers who grew up in Te Ana Kore but had moved to Wairua, a nearby suburb. Yet, Te Ana Kore still felt like home to them because it is where they spent most of their lives. They know the area and their neighbours and they spend most of their time there. Iron spoke of his sense of belonging in Te Ana Kore as follows:

Iron: Basically, our life is here. We go there [Wairua] to sleep and stuff and then we come out here ...

Security: ... eat and go back...

Iron: ... and our life's here [Walk-along interview].

When I asked SOK where home is, either back in Kiribati where he was born, or Wairua where he also now lives, or Tūmanako, he said:

SOK: I can't think because I'm not that fussy aye. I don't mind... at least I have a house to live in. That's home. [Walk-along interview].

His brother Coco adds that home is "wherever I live. Wherever my family is" [Walk-along interview]. Thus, 'home' is not so much about where they reside but where their families are. 


\section{Culture and Belonging}

The majority of the Pacific participants were fluent speakers of their Pacific languages and spoke them at home with their families. Maintaining their native tongue is an important part of maintaining their culture and sense of belonging in their communities. Although English is the dominant language in Aotearoa New Zealand, the participants retained fluency in their native languages by speaking with other members of their cultural communities at church and at community cultural events. The following extracts illustrate how participants are able to maintain fluency in their first language.

Mighty: Yeah we all speak... at home we speak our language. Outside, we don't speak it. [Walk-along interview].

SOK: Cos, our Dad. Our Dad is still...

Coco: ... Like, he encourages us...

SOK: ... He hardly speaks English. [Walk-along interview].

Kiribati brothers, SOK and Coco explained that their parents and other family members encourage their children to speak Kiribati when they are at home and Tuvaluan brothers, Mighty and Barboza, also told me that they speak Tuvaluan at home.

\section{Belonging Through Faith/Religion}

Church and Christian faith was an important part of life for this group of young people. God, prayer, faith and religion emerged throughout discussions about the future as touchstones for navigating the uncertainties of the future. Most of the participants attended church every week, both youth church and Sunday church, and this also served the purpose of connecting with others from their cultural and faith-based communities. The participants who belong to Pacific community churches were very active in the life of their churches. As well, the Pacific languages of those communities are spoken during these gatherings so the participants and their families hear their language spoken in these contexts. For this group, culture and faith are closely connected and this is another avenue through which the participants established a sense of belonging within a community.

SOK: You know how I was telling you how coming to New Zealand was a hard thing? Cos, like, all the money and stuff? Well my Mum, she has a strong faith and stuff, like, religious. She just prays every dawn. They [parents] would wake up and wake us all up and we'll just keep praying and praying. That's how we got here, through prayer. We still pray. [Walk-along interview].

Faith and prayer is what helped this family manage the migration from the Pacific to create a new place of belonging in Aotearoa New Zealand. 


\section{Belonging as Pacific Peoples}

To understand what belonging means to this group, participants were asked to put together a poem about belonging. The outline of this activity can be found in Appendix 3. The following poem was composed by SOK, Barboza, Iron and Coco to reflect what belonging means to them as Pacific peoples who identify as Samoan and Kiribati.

Belonging to us means: Being a Pacific Islander.

Belonging to us means: We look like "coconuts"

Belonging to us means: We feel "pressure" from high expectations from parents.

Belonging to us means: We taste fish, as we eat it every day.

Belonging to us means: We smell salt water, from ocean nearby.

Belonging to us means: We hear waves, from the sea nearby.

We ARE PACIFIC ISLANDERS!

By SOK, Barboza, Iron and Coco [Focus group hui].

The following poem was written by Security, Wolfie and Siracha, who identify as Cook Island Māori/Māori, Samoan, and Tokelauan.

\section{BELONGING!!!}

So belonging to me means: What I or you belong to.

Looks like: Family/friends/loved ones are.

Physical fun. Being included.

Sounds like: Laughter, Poly [Polynesian] people having fun.

Talking to friends or family. Fun.

Tastes like: Food, drinks, what we love to taste.

Feels like: Warm, comfortable emotions.

Smells like: Food/home and whatever you can't get anywhere else. It smells like home.

By Security, Wolfie and Siracha [Focus group hui].

Cultural markers such as landmarks and food serve as components of identity and belonging for these participants. As well, markers such as the ocean, coconuts and fish highlight the collective nature of Pacific peoples coming together and feeling comfortable with friends and family.

\section{The Boxing Gym and Belonging}

Belonging for these participants is linked to culture, family, church and home. But home is not only a literal place where the participants live with their families. Home was also 
considered in a figurative sense as being around people who care about each other. These participants felt a strong sense of belonging at the boxing gym with their 'brothers'. The gym provides them with a range of new experiences, including camp and youth development programmes which are run by their trainers.

SOK: No other gyms can be like, what Brown Sensei's doing. The gym is my second home now. Like, hard, aye...that's where I would prefer to go if I didn't have places to go. I'd just go there.

HF: What's the [gym's] biggest impact [on you]?

SOK: Bond with each other ... and the brotherhood. I just feel like people are just like family. [Walk-along interview].

The boxing gym is run by trainers who are committed to working with young people in the area and they bring a particular philosophy that is underpinned by a set of core values drawn from the martial arts. These values are respect, responsibility, compassion, consideration, kindness, duty, obedience, honesty and truthfulness and all gym members are expected to abide by these values at all times. When considering the impact that the gym has had on this group, Coco commented on these core values.

Coco: When you're with someone who teaches you good values and he sticks to them. Most people don't do that. Like, respect. [Walk-along interview].

The participants spoke at length about how they had made significant behavioural and attitudinal changes since they adopted the core values promoted by the boxing gym trainers. A booklet outlining these values has been produced by the gym management and distributed to the membership. After each training session, the gym members discuss one of the core values using the booklet as a guide. In the extract below, Siracha and Mighty talk about the positive impact that the gym has had on how they handle difficult social situations at school.

Siracha: School has changed.

HF: Did you used to fight?

Siracha: Na, just used to like get bullied in school and be naughty.

Mighty: Yeah.

Siracha: But then the booklet thingy helped [i.e. the gym booklet of principles and core values] [Walk-along interview].

Mighty added that since joining the gym at the beginning of the year, he has stopped fighting at school. For Siracha, bullying is no longer an issue and his behaviour towards his teachers is more respectful. In this regard, the core values practised inside the gym are carried through into other parts of their lives. 


\section{Pacific Boys' Use of Public Spaces}

During the focus group hui, participants listed activities they enjoy doing in Tūmanako. The basketball courts were important places for all of them. When they are not at home, school, church or training, they are usually at the basketball court or at a nearby public park, both of which are spaces they utilise for recreational and social purposes.

Coco: ... The only time I come home is like after school 'cos I usually just walk and I go to the park...we just play tag and that. And sometimes I don't come home till after training 'cos we just stay at the park and then we come to training [Walk-along interview].

HF: Tell me about the [basketball courts].

Siracha: Oh it's just somewhere we kick back [socialise] with the boys. Play a bit of basketball.

HF: Is that the court $[\ldots]$ ?

Siracha: Yep. And on training days, I just walk up to the gym after I play with the boys.

HF: How long would you hang out at the $[\ldots]$ ?

Siracha: Maybe like 4 hours a day [Walk-along interview].

In this way, social networks are maintained on a daily basis through the use of these public spaces and as such they are very important to young people in the area. Connection to everyday place for SOK is also made when he runs around Tümanako for fitness and training purposes. During his runs, he discovers things about Tūmanako that interest him. He knows Te Ana Kore well and made a point of describing its uniqueness when discovering a waterfall that he did not know was there.

SOK: I always go for an explore. Like whenever I go for a run, I just explore like I know my way around Te Ana Kore but I don't spend time there. I just need to know where, like, places are. [Walk-along interview].

Among some of the social problems SOK notices while out running, is what he calls 'beggars'. He often sees people on the street asking strangers for money. This saddens him and the other participants also made similar comments when discussing their concerns for the future of their community although as noted above, they were not always especially sympathetic to 'street beggars'.

In contrast to the Taiohi Māori participants, the Pacific participants had a much stronger sense of connection to their everyday places, particularly local recreational spaces. The boxing gym and church also provide safe, structured environments where social and community networks can be maintained. Unlike the Taiohi Māori group, these participants have safe, legal gathering places where they can establish a sense of community and belonging as part of a group. 


\section{Summary}

In summary, this chapter has presented findings from the Pacific participant group from Tūmanako about their hopes and fears about the future. Their hopes relate mainly to gaining good employment, being able to financially provide for their future families, repaying their parents for the sacrifices made to give them a better life and addressing the social needs of their community. Their fears for the future cover a broad range of national and global issues including anxieties about natural disasters and local and international politics.

These participants have strong primary connections to their neighbourhood community which give them a clear sense of place-belonging. The most important everyday places for these participants are a local park, the basketball courts, church and the boxing gym. Belonging in these places is activated through their relationships with the people around them including family, peers and trainers. In the next chapter, I reflect on the findings from the Taiohi Māori and the Pacific participant groups. 


\section{CHAPTER SIX:}

\section{DISCUSSION}

\section{Introduction}

This study explores the hopes and fears that young Māori and Pacific have about the future and how they establish a sense of place-belonging in the present. As well, this study provides a cross-site analysis between Taiohi Māori participants from the Gully and Pacific participants from Tūmanako. In this chapter, I identify five key ideas that emerged as I looked for similarities and contrasts in the findings from Tümanako and the Gully. These findings relate to hopes for the future, support networks, future orientation, use of space, and connection to place. I argue in this chapter that when place-belonging is not achieved, neither is the ability to construct stories of those places and this ultimately affects how young people think about the future.

\section{High Hopes vs. Small Dreams for the Future}

A striking contrast that emerged from the findings was the different ways that the young people involved with this study constructed their hopes for the future. Members of the Tūmanako participant group talked hopefully about the future in terms of their dream jobs, which included aspirations to become doctors, marine biologists, mechanics and professional sports athletes. They also talked about their desire to financially support their parents and their future families. In this respect, they had long-term plans and aspirations that involved mitigating poverty but also living comfortably as part of a wider community.

The participants in the Gully framed their hopes for the future in very different ways. They expressed them almost entirely in terms of being able to alleviate specific problems in their current circumstances. Accordingly, much of their thinking was directed towards finding short-term solutions for the serious long-term difficulties they faced. Unlike the participants in Tūmanako, they did not 'dream big' rather they positioned their future selves in terms of what they saw as being possible, realistic and achievable given the extremely limited support and resources they were able to access. Their current situation, which was marked by poverty, unemployment and the looming presence in their lives of Police and the criminal justice system, significantly shaped the way they think about the future. However, while they experience many economic struggles in the present, they still articulate hope. Mostly they hoped for the stressors to go away and to escape from their difficult, and at times, unbearable present circumstances. Thus, their hopes were focused on finding a level of financial and emotional relief from their current difficulties. These are different kinds of aspirations from those expressed by the participants in the other group but they are nevertheless a form of hope that is as real and important to them as dreams of important jobs and good incomes are to the young people in Tūmanako. 
As noted previously in Chapter Two, Duncan-Andrade (2009) contends that false hope can have a detrimental effect on young people's future goals. In particular, the notion of 'hope deferred' gives insight into why young people sometimes give up on their aspirations when they seem impossible to achieve. Often it is the case that the adults surrounding young people, such as teachers or parents, do not consider their aspirations to be realistic and do not put time into supporting them to achieve their aspirations. In this regard, significant people in the lives of young people can either encourage or tarnish critical hope (Duncan-Andrade, 2009). In turn, when young people do not have access to those who can support their dreams and help them plan for the future, they may defer their hopes, sometimes indefinitely.

The findings suggest that this was the case for participants in the Gully. Hope, for these young people, is grounded in the present and linked to what they believe is realistic, practical, and within reach, and thus, possible. Their priority was to make their current circumstances more manageable. The Tūmanako participants, on the other hand, expressed hope in terms of retaining aspects of the present that were enjoyable and important, such as relationships with family, whilst generating new ways of living that took them beyond their current circumstances into an upwardly mobile future. Unlike the Taiohi Māori group, these participants had people around them who actively encouraged them to think in these ways. These people also provided the participants with access to structured support systems, networks and resources that allowed them to consider the future as more 'porous', fluid and subject to imaginative construction and reconstruction; a story with many possible and desirable endings, all of which they considered were plausible. Thus, the way that hope was articulated by the Tümanako participants can be seen as a collective enterprise whereby young people draw on the people around them to create narratives about their future lives and possible selves. The Taiohi Māori participants, on the other hand, expressed their hopes in terms of finding ways of living in the Gully in the future with a level of safety, security and comfort that they were not experiencing in the present.

\section{Wide vs. Narrow Support Networks}

The next contrasting finding highlights the gap between support avenues identified by both participant groups. During focus group hui, participants were asked to consider as many support networks as they could that they could tap into to help them achieve their hopes for the future. The participants in Tūmanako listed multiple avenues of support, including social, religious and community networks. In contrast, the participants in the Gully identified two main sources of support, which were friends and family. While other support networks and resources are available to young people living in severe economic hardship, participants in the Gully did not know where or how to locate them. Friends and family therefore featured prominently as trusted people who they turn to in times of need. It could also be the case that they do not feel the need to go outside these groups for support and that friends and family fulfil their primary needs in this respect. Due to time constraints, I was not able to follow up during the analysis stage to ask them for further information. 
When examining the experiences of the participant groups, I saw a clear difference between the level of support they can call upon in their daily lives and this has a significant impact on how they think about the future. Hamilton et al. (2015) argue that there is a connection between the level of social support available to young people and their future orientation and opportunities. As well, Cuervo et al. (2015) argue that social, familial, and community relations influence the decisions young people make about their futures.

With these decisions in mind, it is important to be aware that there is severe economic hardship in Te Ana Kore, crime rates are high and many people struggle with limited employment and educational opportunities and access to healthcare. Many children in the area suffer from a range of poverty-related childhood diseases and housing conditions are often cramped and in poor condition. The participants living in Tümanako, however, had close connections with ethnic, cultural faith-based and place-based communities and this helped them to formulate ethical frameworks in the present that connected them to a range of possible futures, some of which would take them outside Tūmanako in the future.

The socially dislocated suburban environments in parts of the Gully mirror many of the economic conditions in parts of Tümanako but the participants in this group were not able to access the resources they needed to connect with their wider communities. When the community youth centre closed down they lost an important space where they could gather safely as a community of young people. These findings suggest that community-based organisations play an important role in providing young people with resources, networks and support to address problems they experience in the present and this in turn affects how they orient themselves to the future.

\section{Future Orientation vs. Here and Now}

As noted in the literature review section of this thesis, the cultural anthropologist, Olga Ulturgasheva (2012) has explored how indigenous Eveny youth in Siberia consider the future in narrative terms. As an indigenous researcher, Ulturgasheva draws on the concept of djuluchen or spirit 'forerunner' as one way of understanding how young indigenous Eveny people narrate their future. She suggests that when young people map out their future plans, they send out their djuluchen into the future. The djuluchen then follows the paths laid out by the host and await their host at the planned destination.

While I am aware of the risks of culturally appropriating symbols and metaphors from other indigenous cultures, I would like to use the concept of djuluchen in relation to this study to show how the future can be conceptualised in a variety of ways. For example, one of the Pacific participants from Tümanako, SOK, described his plans for his future during a walkalong interview. He told me that he plans to complete secondary school and then undertake tertiary education to become a marine biologist. He intends to begin his studies at Certificate level then enrol in other undergraduate degrees and eventually undertake postgraduate studies. By applying the djuluchen concept to this participant's future plans, one could argue that SOK has sent his djuluchen out to wait for him to reach each step that he has carved out 
for his future. His djuluchen will travel a year ahead and wait for SOK to complete his secondary schooling. His djuluchen will then move on to wait at the beginning of the Certificate course in Marine Biology. This process continues as long as the host continues to set goals and plan their future.

Similarly, the young couple in the Taiohi Māori participant group were awaiting the birth of the child with great anticipation, and in a manner of speaking, they have also sent their own djuluchen out into the Gully ahead of them. Although she is currently technically homeless, the young woman has taken work in a fast food outlet to try and earn money before her baby is born and she and her partner have also set plans in place to find suitable accommodation where they can raise their child as a family.

Ulturgasheva (2012) argues that in times of social upheaval and change, young people need to act as agents of the future by narrating their next steps in the present. Hamilton et al. (2015) also discuss the importance of young people being able to imagine their futures and in doing so establish narratives around their 'possible selves'. Both groups of participants had begun to develop a sense of multiple possible futures but they did it in very different ways and this raises another issue, namely the purpose of hope in creating change or maintaining the status quo. Having high hopes can be critical to imagining different kinds of futures but in themselves 'big dreams' can also have unintended and less desirable consequences. Lauren Berlant (2006) writes about how hoping for the 'good life', without sufficient regard for the material circumstances in which people live, can tie people to the status quo. It is a form of setting people up to fail and she calls this 'cruel optimism' which she describes as "a relation of attachment to compromised conditions of possibility" (Berlant, 2006, p.21). In other words, cruel optimism is "the condition of maintaining an attachment to a problematic object in advance of its loss" (p.21).

In the field of youth studies, the notion of cruel optimism has been used to describe, for example, how young people in the European Union are given strong messages by educational authorities that increased access to education will better prepare them for the labour market (Bessant \& Watts, 2014). Yet keeping these young people in education for longer periods of time has not addressed problems of "persistent youth unemployment, poverty and exclusion" (p.126). Bessant and Watts argue that this kind of thinking is a form of 'cruel optimism' because education is presented as a solution for all manner of social problems as well as a ticket to the 'good life'. In fact, this all too often remains an unfulfilled fantasy as large numbers of educated young people find themselves unable to get jobs. This is also a risk in Tūmanako and to a lesser extent in the Gully. Young people in Te Ana Kore genuinely believe what they have been told by teachers and educational authorities about what advanced education can do for them and their families but as we have seen in places like the Gully there is often little accurate and reliable guidance given to young people about a range of options including lives that can be lived well in an environment of extremely high youth unemployment, without a tertiary qualification. 


\section{Utilising vs. Occupying Place}

Taiohi Māori from the Gully are spending time 'all over the motu' [Ekin, Focus group hui]. Their journeys span suburbs in the Gully and Beeton, another urban centre nearby but their focus is more related to who these participants choose to socialise with, rather than where they go and what they do there. This is evident in the way that the Gully participants talked about places, for example, their discussions around places were focused on the people they were with, rather than the activities they carried out. Public spaces that Taiohi Māori do occupy, tend to be used as gathering places for friends and family from various areas to come together and socialise as opposed to intentionally going places with the purpose of utilising those specific spaces. Therefore, social and familial interaction is a more accurate measure of how the Gully participants establish a sense of belonging.

Of note here is that Taiohi Māori do not establish a sense of belonging in their own communities, but rather, they travel distances to socialise with their peers who live in various suburbs. The Taiohi Māori data shows that this group go to various places both in the Gully and also to Beeton. The cost of entertainment, such as going to the movies or going to public swimming pools or gyms, for example, was prohibitive for the Gully participants. As well, the lack of free public gathering spaces for young people in the Gully meant that time with friends often involved more risky forms of entertainment. Alcohol played a key role in their social activities and this often got them into trouble with the Police.

For the Gully participants to socialise freely, they had to navigate between the suburbs where they feel safe to gather. This required them to travel quite long distances which required some form of transport, either public transport or in cars owned by their friends. Relying on travel to get to and from the Gully and Beeton means they do not interact with the places in between. Without engaging in public spaces, especially in their own communities, Taiohi Māori struggle to connect with everyday place.

This was highlighted during a discussion about their lack of a sense of belonging in their own neighbourhoods. As they talked, Taiohi Māori reflected on a particular youth space that was once available to youth in the Gully area. This facility was situated in the Gully's central business district and offered various activities that attracted young people, such as, a pool table, computers for online activities and so on. The participants felt a strong sense of belonging in that environment because they could socialise with people their own age and participate in group activities. As a result they spent most of their time there. It had the advantage of being in an area that was central and was easily accessible to those who lived in other suburbs and in this respect, travel did not impact their use of this space. However, with the loss of this youth space communities of young people around the Gully dispersed and many of the social networks began to fragment.

In contrast, the Tümanako participant findings show that members of this group regularly utilise public spaces in their community. They spend several hours each day at places such as the basketball courts, rugby fields and parks. These spaces are within walking distance from their homes and they can access them easily. As well, most of the Pacific participants live in 
Te Ana Kore, and all of them live within Tümanako so they all lie in close proximity to each other and do not have to find ways of getting transport to see their friends, as is the case in the Gully. The Tūmanako participants are also able to walk around most places in the central city area and as such they are more exposed to public spaces.

Many of the Tūmanako participants also go to the same school and they are all part of a boxing membership, which strengthens their connection to their local community. Mynard et al. (2009) state that membership in sports establishes belonging in a team culture. The Pacific participants described their sport culture as a 'brotherhood' and spoke warmly about how they feel privileged to be members of their boxing gym where they feel a strong sense of solidarity and belonging.

McCreanor et al. (2006) argue that belonging is not necessarily limited to places and proximity to place users, but also, social factors should be equally considered. Socially, it is the connection to kinship and interaction in communities that influences place-belonging. Public spaces such as parks in Te Ana Kore are where these participants socialise with their friends. They play sports and carry out other activities, such as tag. Thus, this participant group spends time in many public spaces with the intention of utilising them for social purposes. Their ongoing use of these local public spaces anchors their sense of placebelonging.

It is clear that there is a range of factors that influence how Māori and Pacific youth from the Gully and Tūmanako establish place-belonging. These include having access to safe local gathering places near where young people live and the proximity between social peers' places of residence.

\section{Belonging and Connection to Place}

By taking a comparative approach to the two sites, patterns emerged that highlight differences in understanding the hopes that the participants hold for the future, future orientation, and place-belonging.

Belonging was established differently by the participant groups. In the Gully, there were few free or affordable youth spaces where unemployed young people could gather. At the same time, the participants in this city were members of households that struggled to secure basic resources for daily living, including having enough food and access to safe, affordable housing. These households were located in areas where people tend to stay only for relatively short periods of time - there are few families with long-term ties to the area and there is constant movement in and out of state-owned accommodation in their neighbourhoods. This has an impact on young people's ability to form long-term lasting friendships and enter into community networks and in this respect, they were considerably more isolated than the participants living in Tūmanako who had access to a wider range of longstanding relationships and structured gathering places in their immediate neighbourhood. 
Relationships with adults, such as parents and trainers differed between the two participant groups and this also had an influence on their sense of belonging and their hopes for the future. Participants in the Gully had difficult relationships with many of the adults around them. In some cases, their families were dealing with significant interpersonal conflict and this was a cause of anxiety and uncertainty for the young people. As well, adults in positions of authority such as the Police, teachers, court officials, child protection service representatives, truancy officers or WINZ workers (i.e. Work and Income or WINZ is the government ministry that handles welfare benefits and grants) tend to be drawn into their orbit only at times of crisis and they move on once the problem has an official or an administrative 'solution'. This leaves young people who need to navigate through some challenging situations with few avenues for support, guidance or positive role modelling.

By contrast, the participants in Tūmanako rely heavily on longstanding relationships with the adults around them, such as family members, church leaders, community leaders and trainers/coaches. These relationships connect them to their neighbourhood communities and provide a level of stability that was missing when I spoke to young people in the Gully. At the same time Tümanako offers a range of public and community spaces where young people on very low incomes are welcome. This allows youth in the area to forge long-standing connections and networks that they can turn to in times of crisis or need.

\section{Summary}

In this chapter I have discussed some of the main patterns that emerged from the findings gathered from young Māori and Pacific people from two different urban areas. The two urban cities, Tūmanako and the Gully provided a cross-site analysis between participants from the Gully and participants from Tūmanako. In the next chapter I conclude this thesis highlighting the limitations of this study and offering ideas for future research. 


\section{CHAPTER SEVEN:}

\section{CONCLUSION}

I began this study with the intention of understanding the hopes and fears that urban young people have about the future and how they establish a sense of place-belonging in economically marginalised communities. As part of a multi-site case study I conducted research conversations with Māori and Pacific youth in two cities. Hearing the stories that these young people shared has inspired me to continue working with youth and to continue my inquiry into the lives of young people who live on the social and economic peripheries of New Zealand society. In this final chapter, I identify some of the limitations of the study and offer ideas for future research.

The main questions that underpin this study are: What hopes and fears do young Māori and Pacific have for the future? And, how do they establish a sense of belonging in everyday place? To address these questions, the thesis was designed as a qualitative research project which drew on a combination of ethnographic and narrative designs. The ethnographic component of the study allowed me to explore how Māori and Pacific youth think about their future as members of neighbourhood or cultural communities of place while the narrative design provided insights into the way that individuals construct stories about the places they inhabit as well as their narratives about the future. Alongside advice from my thesis supervisor, I was guided by Dr Fiona Beals (WelTec), who helped me to develop some activity-based research methods that worked extremely well in this project and which will be used in the wider study of which this thesis is a part.

One of the key discoveries for this thesis has been the central importance of providing marginalised young people with urban spaces that welcome and value them as human beings. In environments where young people struggle to secure their basic needs not only for food and shelter and physical and emotional wellbeing but also education, health care, and legal protection when they enter into government systems like the Courts, the salience of long-term networks of trusted peers, adults and others cannot be under-estimated. One of the clear findings from this study is that economic deprivation is experienced in radically different ways by different groups of people and 'place' plays an important role in that. In this respect, there is not one kind of economic poverty in New Zealand - there are many - and they affect young people's hope, dreams and aspirations in radically different ways.

Young people need spaces where they feel connected. In cases where these spaces are offered and then taken away, as was the case in the Gully, the long term impact on their hopes and plans for the future can be devastating, especially if they have few people they can turn to who can act as a constant and guiding presence in their lives. In Tümanako, the participants who were involved with this study had access to structured social and cultural spaces where they were placed at the centre of their community's hopes and dreams and in this respect they were able to be part of a wider system of support and resources. At the same time, they had access to adults with whom they could build life-long relationships and connections that 
endorsed and valued their cultural and ethnic identities. This is a key finding in this study and one that will be explored further in the larger project to which this thesis contributes.

\section{Limitations}

By doing small-scale qualitative research, I sought to explore young people's hopes and fears and understand how they think about the future. I engaged with two relatively small participant groups in different cities and this provided rich data about the lives of young Māori and Pacific peoples living in economically marginalised urban areas. The participants had very different experiences of poverty, however, and this significantly affected the way they thought about the future as well as the way that the adults around them helped them to respond to the crises they experienced in the present. A larger sample group is needed in order to confidently make predictions about the multiple ways that poverty affects New Zealand young people's aspirations and future orientation. This limitation will be partially addressed in the wider project of which this thesis is part, as other sites in different parts of the country are brought on board.

\section{Future Research}

There are strong national narratives about the egalitarian nature of New Zealand society and importance of everyone having a 'fair go'. The reality for many Māori and Pacific young people who live precariously on the social and economic margins in communities where there is little work and high rates of long-term youth unemployment, however, is that a 'fair go' for everyone is increasingly out of reach. One of the key findings for this study is that young people experience poverty in different ways depending on the communities they are in and the level of access to reliable, well-informed adults who in turn have access to social and economic resources or information. Little is known about how young people in urban areas in New Zealand experience economic and social hardship, nor is much known about the experiences of young people in economically marginalised rural areas. This is where further research would provide useful information about young people's lives as they begin to think about their futures.

At the same time, much research about young people, at least in the field of education studies, is undertaken in schools. While this can provide important information, education researchers' dependence on schools as sites where young people gather and participants can be recruited can also miss out those who do not attend school or who do not have the resources to be part of school-based research projects. A far more difficult and time consuming approach would be to seek out young people in community or informal locations and ask them about their hopes and fears about the future. Marginalised or 'hard to reach' youth are not easily accessed by researchers who do not necessarily have the contacts or understand the social, cultural and ethnic codes that some of these groups live by. They may also be fairly transient which makes it difficult to include them in research projects that 
require a commitment of time over several days, weeks or months yet these are the groups that tend to be relatively invisible in youth research and their voices are important in their own right because they tell us something uncomfortable or disconcerting about the nation that often goes unheard.

In this thesis I have attempted to give a voice to young people who often fall below the radar of policy-makers, researchers and teachers. Sometimes we only hear their stories when they are in trouble or when adults who are committed to them find avenues where their stories can be told. The future for these young people, as they see it, is by turns, both tremendously exciting and utterly terrifying. As researchers, our job, I think, is to let them speak. And to listen to what they tell us. 


\section{REFERENCE LIST}

Allen, J. B. (2003). Social motivation in youth sport. Journal of Sport and Exercise Psychology, 25(4), 551-567.

Altrichter, H., Feldman, A., Posch, P. \& Somekh, B. (2008). Teachers investigate their work: An introduction to action research across the professions. London: Routledge.

Aronson, J. (1995). A pragmatic view of thematic analysis. The Qualitative Report, 2(1), 1-3.

Atkinson, P. \& Hammersley, M. (2007). Ethnography: Principles in practice. Oxon \& New York: Routledge.

Beck, U. (2015). Emancipatory catastrophism: What does it mean to climate change and risk society? Current Sociology, 63(1), 75-88.

Bennett, H. Jones, R., Keating, G., Woodward, A., Hales, S. \& Metcalfe, S. (2014). Health and equity impacts of climate change in Aotearoa New Zealand, and health gains from climate action. New Zealand Medical Journal, 127(1406), 16-31.

Bennett, A. Wood, D., Butterfield, R., Kraemer, D.F. \& Goldhagen, J. (2014). Finding hope in hopeless environments. International Journal of Child Health \& Human Development, 7(3), 313-324.

Berlant, L. (2006) Cruel optimism. Differences, 17(5), 20-36.

Berger, P.L. \& Luckmann, T. (1991). The social construction of reality. London: Penguin Books.

Bernburg, J. G. (2002). Anomie, social change and crime: A theoretical examination of institutional-anomie theory. The British Journal of Criminology, 42(4), 729-742.

Bessant, J. \& Watts, R.W. (2014). 'Cruel optimism': A southern theory perspective on the European Union's Youth Strategy, 2008-2012. International Journal of Adolescence and Youth, 19(Sup.1), 125-140.

Best Practice Journal. (2010). Te aukatinga o te whakamomoritanga o te Taiohi. Māori Suicide prevention in Māori youth report (issue 28). Retrieved from http://www.bpac.org.nz/BPJ/2010/June/docs/BPJ_28_suicideprevention_pages3643.pdf

Bishop, E.C. \& Wells, K. (2014). 'Without hope everything would be doom and gloom': Young people talk about the importance of hope in their lives. Journal of Youth Studies, 17(6), 778-793.

Black, R. \& Walsh, L. (2015). Educating the risky citizen: young people, vulnerability and schooling. In K. Te Riele \& R. Gorur (Eds.). Interrogating conceptions of 'vulnerable youth' in theory, policy and practice. (pp.181-194). Rotterdam: Sense Publishers. 
Brendtro, L. K., \& Du Toit, L. (2005). Response ability pathways: Restoring bonds of respect. Claremont, South Africa: Pretext Publishers.

Bryant, J. \& Ellard, J. (2015). Hope as a form of agency in the future thinking of disenfranchised young people. Journal of Youth Studies, 18(4), 485-499.

Bryman, A. (2008). Social research methods. 3rd Ed. Oxford: Oxford University Press.

Burke Johnson, R. (1997). Examining the validity structure of qualitative research. Education, 118 (2), 282-293.

Burns, W. (1999). The possible impacts of climate change on Pacific island state ecosystems. An occasional paper of the Pacific Institute for Studies in Development, Environment, and Security. Retrieved from http://pacinst.org/

Capital \& Coast District Health Board. (2016-2017). Māori health plan. Capital Coast District Health Board, NZ. Retrieved from http://www.ccdhb.org.nz/newspublications/publications-and-consultation-documents/ccdhb-Māori-health-plan-201617-final.pdf

Carpiano, R.M. (2009). Come take a walk with me: The go-along interview as a novel method for studying the implications of place for health and well-being. Health \& Place, 15, 263-272.

Chappell, D. \& Chappell, S.V. (2015). Stories of resistant play: Narrative construction as countercolonial methodology. Narrative Works: Issues, Investigations, \& Interventions, $5(1), 1-21$.

Chenhall, R. \& Senior, K. (2009). Those young people all crankybella. International Journal of Mental Health, 38(3), 28-43.

Claisse, F. \& Delvenne, P. (2015). Building on anticipation: Dystopia as empowerment. Current Sociology, 63(2), 155-169.

Cnaan, R. A., Gelles, R. J., \& Sinha, J. W. (2004). Youth and religion: The gameboy generation goes to "church". Social Indicators Research, 68(2), 175-200.

Cohen, N. \& Arieli, T. (2011). Field research in conflict environment: Methodological challenges and snowball sampling. Journal of Peace Research, 48(4), 423-435.

Cohen, G., \& Garcia, J. (2008). Identity, belonging, and achievement: A model, interventions, implications. Association for Psychological Science, 17(6), 365-369.

Core Education. (2014). 10 Things you need to know about Pasifika peoples in Aotearoa (Dispelling some common myths about the Pacific). Retrieved from http://blog.coreed.org/blog/2014/04/10-things-you-need-to-know-about-pasifika-peoples-in-aotearoadispelling-some-common-myths-about-the-pacific.html 
Côté, J. (2014). Youth studies: Fundamental issues and debates. New York: Palgrave Macmillan.

Crate, S. A., \& Nuttall, M. (Eds.). (2016). Anthropology and climate change: From encounters to actions. Oxon: Routledge.

Crath, R. (2012). Belonging as a mode of interpretive in-between: Image, place and space in the video works of racialised and homeless youth. British Journal of Social Work, $42(1), 42-57$.

Creswell, J. W. (2009). Research design: Qualitative, quantitative, and mixed methods approaches. Thousand Oaks, CA: Sage Publications.

Creswell, J. W. (2013). Research design: Qualitative, quantitative, and mixed methods approaches. Thousand Oaks, CA: Sage Publications.

Crivello, G. (2015). 'There's no future here': The time and place of children's aspirations in Peru. Geoforum, 62, 38-46.

Cuervo, H., Barakat, N. \& Turnbull, M. (2015). Youth, belonging and transitions: Identifying opportunities and barriers for indigenous young people in remote communities. Research Report 44. Youth Research Centre. University of Melbourne, Australia.

Denzin, N. K., \& Lincoln, Y. S. (Eds). (2005). Handbook of qualitative research. California: Sage Publications.

Duncan-Andrade, J. (2009). Note to educators: Hope required when growing roses in concrete. Harvard Educational Review, 79(2), 181-194.

Durkheim, E. (1951). Suicide: A study in sociology (J.A. Spaulding \& G. Simpson, trans.). Glencoe, IL: Free Press. (Original work published 1897).

Eichler, M. (2015). Raising children to cope with climate change? Canadian Review of Sociology/Revue Canadienne de Sociologie, 52(2), 232-240.

Faugier, J., \& Sargeant, M. (1997). Sampling hard to reach populations. Journal of Advanced Nursing, 26(4), 790-797.

Feagin, J. R., Orum, A. M., \& Sjoberg, G. (Eds.). (1991). A case for the case study. (n.p): University of North Carolina Press.

Freire, P., Shor, I. (1973). Education for critical consciousness. New York: Continuum.

Freire, P. (1987). A pedagogy for liberation: Dialogues on transforming education. London: Macmillan Education Ltd.

Freire, P. (1993). Pedagogy of the oppressed. New York: Continuum.

Freire, P. (2004). Pedagogy of hope: Reliving pedagogy of the oppressed. London and New York: Continuum. 
Fua, S. (2009). Ko hota fa'ungamotu'a ko hota kaha'u - A knowledge system for redesigning Tongan curriculum. In K. Sanga \& K. Thaman (Eds.). Re-thinking education curricula in the Pacific: Challenges and prospects. (pp.196-220). Wellington, NZ: He Pārekereke, Victoria University of Wellington.

Guba, E. G., \& Lincoln, Y. S. (1994). Competing paradigms in qualitative research. In N. K. Denzin \& Y. S. Lincoln (Eds.). Handbook of qualitative research. (pp.105-117). London: Sage Publications.

Hamilton, J. L., Connolly, S. L., Liu, R. T., Stange, J. P., Abramson, L. Y., \& Alloy, L. B. (2015). It gets better: Future orientation buffers the development of hopelessness and depressive symptoms following emotional victimization during early adolescence. Journal of Abnormal Child Psychology, 43(3), 465-474.

Hardgrove, A., Rootham, E. \& McDowell, L. (2015). Possible selves in a precarious labour market: Youth, imagined futures and transitions to work in the UK. Geoforum, 60, 163171.

Harris, A., Battle, J., Pastrana, A., \& Daniels, J. (2015). Feelings of belonging: An exploratory analysis of the sociopolitical involvement of Black, Latina, and Asian/Pacific Islander sexual minority women. Journal of Homosexuality, 62(10), 1374-1397. http://doi.org/10.1080/00918369.2015.1061360

Hohepa, M. K. (2013). Educational leadership and indigeneity: Doing things the same, differently. American Journal of Education, 119(4), 617-631.

Holmes, K., Murachver, T., \& Bayard, D. (2001). Accent, appearance, and ethnic stereotypes in New Zealand, New Zealand Journal of Psychology, 30 (2), 79-86

Hsieh, H. F., \& Shannon, S. E. (2005). Three approaches to qualitative content analysis. Qualitative Health Research, 15(9), 1277-1288.

Jackson, R., \& Sorensen, G. (2006). Social constructivism. In R. Sorenson \& G. Sorenson (Eds.). An introduction to international relations theories and approaches. (pp.161177). Oxford: Oxford University Press.

Jacobs, D. (2005). What's hope got to do with it? Toward a theory of hope and pedagogy. JAC: A Journal of Composition Theory, 25(4), 783- 802.

Kawharu, M. (2015). Aotearoa: Shine or shame? A critical examination of the sustainable development goals and the question of poverty and young Māori in New Zealand. Journal of Global Ethics, 11(1), 43-50.

Keelan, T. J. (2001). E tipu e rea: An indigenous theoretical framework for youth development. Development Bulletin, 56, 62-65. 
Khan, S \& VanWynsberghe, R. (2008). Cultivating the under-mined: Cross-case analysis as knowledge mobilization. Forum Qualitative Sozialforschung/Forum: Qualitative Social Research, 9(1), 1-26.

Kidman, J. (2012). The land remains: Māori youth and the politics of belonging. AlterNative: An International Journal of Indigenous Peoples. 8(2), 189-202.

Kidman, J., Chu, C., Fernandez, S. \& Abella, I. (2015). Maori scholars and the University. A Technical Report funded by Ngā Pae o te Māramatanga. Retrieved from http://www.maramatanga.co.nz/sites/default/files/projectreports/Kidman\%20Chu\%20Fernandez\%20Abella\%20Maori\%20Scholars\%20Final\%20report\%202015.pdf

King, D., Penny, G., Severne, C. 2010. The climate change matrix facing Maori society. In R. Nottage, D. Wratt, J. Bornman \& K. Jones (Eds.). Climate change adaptation in New Zealand: Future scenarios and some sectoral perspectives. (pp.100-111). Wellington, NZ: New Zealand Climate Change Centre. Retrieved from https://www.researchgate.net/publication/273737386_The_climate_change_matrix_faci ng_Maori_society

Knowles, J. G., \& Cole, A. L. (2008). Handbook of the arts in qualitative research: Perspectives, methodologies, examples, and issues. Thousand Oaks, CA: Sage Publications.

Kusenbach, M. (2003). Street phenomenology: The go-along as ethnographic research tool. Ethnography, 4(3), 455-485.

Kvale, S. (1996). Interviews: An introduction to qualitative research writing. Thousand Oaks, CA: Sage Publications.

Maannen, J. (2011). Tales of the field: On writing ethnography. $2^{\text {nd }}$ Ed. Chicago \& London: University of Chicago Press.

Mackley-Crump, J. (2015). The Pacific festivals of Aotearoa New Zealand: Negotiating place and identity in a new homeland. Honolulu: University of Hawai'i Press.

Manning, M., Lawrence, J., King, D.N. \& Chapman, R. (2015). Dealing with climate change: A New Zealand perspective on climate change adaptation. Regional Environmental Change, 15, 581-594.

Marvasti, A. (2011). Three aspects of writing qualitative research: practice, genre and audience. In D. Silverman (Ed.). Qualitative research: Theory, method and practice. $3^{\text {rd }}$ Edition. (pp.383-396). London: Sage Publications.

Mason, P. (2012). Why it's still kicking off everywhere: The new global revolutions. New York: Verso. 
Maxson, C. L., Whitlock, M. L., \& Klein, M. W. (1998). Vulnerability to street gang membership: Implications for practice. Social Service Review, 72(1), 70-91.

McCreanor, T., Penney, L., Jensen, V., Witten, K., Kearns, R., \& Moewaka-Barnes, H. (2006). 'This is like my comfort zone': Sense of place and belonging within Oruāmo/Beachhaven, New Zealand. New Zealnd Geographer, 62, 196-207.

McLeod, S. A. (2015). Simply psychology: Observation methods. Retrieved from www.simplypsychology.org/observation.html

Means, A.J. (2015). Generational precarity, education and the crisis of capitalism:

Conventional, Neo-Keynesian and Marxist perspectives, Critical Sociology, 1-16. DOI: $10.1177 / 0896920514564088$

Ministry of Health. (2013). NZDEP 2013 Census area unit data. Wellington, NZ. Retrieved from

http://www.otago.ac.nz/wellington/departments/publichealth/research/hirp/otago02019 4.html\#atlas

Ministry of Health. (2016). Suicide facts: 2014. Retrieved from http://www.health.govt.nz/publication/suicide-facts-2014-data

Mynard, L., Howie, L., \& Collister, L. (2009). Belonging to a community-based football team: An ethnographic study. Australian Occupational Therapy Journal, 56(4), 266274.

Nakhid, C. (2003). "Intercultural" perceptions, academic achievement, and the identifying process of Pacific Islands students in New Zealand schools. The Journal of Negro Education, 72 (3), 297-317.

Nakhid, C., Tanielu, T. R., \& Collins, E. (2009). Pacific families now and in the future: Pasifika Youth in South Auckland ( $2^{\text {nd }}$ report). Wellington, NZ: New Zealand Families Commission.

Nakhid, C., Shorter, L. T. (2014). Narratives of four Maori ex-inmates about their experiences and perspectives of rehabilitation programmes. International Journey of Offender Therapy and Comparative Criminology. 58(6), 697-717.

Newman, B. M., Lohman, B. J., \& Newman, P. R. (2007). Peer group membership and a sense of belonging: Their relationship to adolescent behaviour problems. Adolescence, 42(166), 241-263.

New Zealand Ministry of Education. (2015). Māori participation and attainment in NCEA. Retrieved from https://www.educationcounts.govt.nz/statistics/maori-education/maoriin-schooling/participation-and-attainment-of-maori-students-in-national-certificate-ofeducational-achievement 
Panelli, R., Nairn, K., \& McCormack, J. (2002). "We make our own fun": Reading the politics of youth with(in) community. European Society for Rural Sociology, 42(2), 106-130.

Pasifika Futures Ltd. (2015). Pacific people in New Zealand: How are we doing? Pasifika Futures Ltd, New Zealand. Retrieved from http://pasifikafutures.co.nz/wpcontent/uploads/2015/06/PAF0018-Pasifika-People-in-NZ.pdf

Rua, M.R. (2015). Māori men's positive and interconnected sense of self, being and place. (Unpublished doctoral thesis). The University of Waikato, Hamilton, New Zealand.

Ruth, M., Bernier, C., Jollands, N., \& Golubiewski, N. (2007). Adaptation of urban water supply infrastructure to impacts from climate and socioeconomic changes: The case of Hamilton, New Zealand. Water Resources Management, 21(6), 1031-1045.

Sanga, E. (2012). Pacific student success at university: Exploring what it is and how it is achieved. In K. Sanga, \& J. Kidman (Eds.). Harvesting ideas: Perspectives from a niu generation of Pacific leaders. (pp.134-146). Suva, Fiji: University of the South Pacific Press.

Seginer, R. (2008). Future orientation in times of threat and challenge: How resilient adolescents construct their future. International Journal of Behavioral Development, $32(4), 272-282$.

Statistics New Zealand. (2012). New Zealand's prison population. Retrieved from http://www.stats.govt.nz/browse_for_stats/snapshots-ofnz/yearbook/society/crime/corrections.aspx

Stewart-Withers, R. (2016). Edge walking ethics. New Zealand Sociology, 31(4), 28-42.

Te Pou o te Whakaaro Nui. (2015). Taiohi Māori workforce participation and health: Experiences and statistics. Retrieved from http://www.tepou.co.nz/uploads/files/resource-assets/Taiohi-maori-workforceparticipation-and-health-Experiences-and-statistics.pdf

Tesch, R. (1990). Qualitative research: Analysis types and software tools. New York: Falmer Press.

Tiatia-Seath, J. (2014). Pacific peoples, mental health service engagement and suicide prevention in Aotearoa New Zealand. Ethnicity and Inequalities in Health and Social Care, 7(3), 111-121.

Tupuola, A. (2004). Pasifika edgewalkers: Complicating the achieved identity status in youth research. Journal of Intercultural Studies, 25(1), 87-100.

Ulturgasheva, O. (2016). Spirit of the future: Movement, kinetic distribution, and personhood among Siberian Eveny. Social Analysis, 60(1), 56-73. 
Ulturgasheva, O. (2012). Narrating the future in Siberia: Childhood, adolescence and autobiography among the Eveny. Oxford \& New York: Berghahn Books.

Unluer, S. (2012). Being an insider researcher while conducting case study research. The Qualitative Report, 17(29), 1.

Van Hecke, L., Deforche, B., Van Dyck, D., De Bourdeaudhuij, I., Veitch, J., \& Van Cauwenberg, J. (2016). Social and physical environmental factors influencing adolescents' physical activity in urban public open spaces: A qualitative study using walk-along interviews. PLoS One, 11(5), DOI: 10.1371/journal.pone.0155686

Van Maannen, J. (2011). Tales of the field: On writing ethnography. $2^{\text {nd }}$ Ed. Chicago \& London: University of Chicago Press.

Webb, A. \& Radcliffe, S. (2015). Indigenous citizens in the making: Civic belonging and racialized schooling in Chile. Space and Polity, 19(3), 215-230.

Wexler, L. (2006). Inupiat youth suicide and culture loss: Changing community conversations for prevention. Social Science \& Medicine, 63, 2938-2948.

Wood, B. E. (2011). Citizenship in our place: Exploring New Zealand young people's everyday place-based perspectives on participation in society. Unpublished $\mathrm{PhD}$ thesis. Victoria University of Wellington, Wellington.

Woodman, D. (2011). Young people and the future: Multiple temporal orientations shaped in interaction with significant others. Young, 19(2), 111-128.

Yin, R. K. (2003). Case study research: Design and methods. $3^{\text {rd }}$ Ed. Thousand Oaks, CA: Sage Publications.

Yural-Davis, N. (2006). Belonging and the politics of belonging. Patterns of Prejudice, 40 (3), 197-214.

Zhao, R., \& Cao, L. (2010). Social change and anomie: A cross-national study. Social Forces, 88(3), 1209-1229. 
APPENDIX 1: Participant information for Taiohi Māori focus group in the Gully

\begin{tabular}{|l|l|l|}
\hline Age & $\begin{array}{l}\text { Suburb (By } \\
\text { pseudonym) }\end{array}$ & Iwi affiliation \\
\hline 16 & Rāwāhi & Ngāti Porou \\
\hline 17 & Pākā & Ngāti Porou/Tainui \\
\hline 16 & Rātā & Ngāti Porou/Tainui \\
\hline 16 & Reihi & $\begin{array}{l}\text { Participant wasn't } \\
\text { sure but a sibling in } \\
\text { attendance said Ngāti } \\
\text { Kahungunu }\end{array}$ \\
\hline 17 & Pākā & Unknown \\
\hline 17 & Pākā & Ngāti Porou \\
\hline
\end{tabular}


APPENDIX 2: Participant Information for Pacific Group in Tūmanako

\begin{tabular}{|l|l|l|}
\hline Ethnicity & Age & $\begin{array}{l}\text { Suburb (By } \\
\text { Pseudonym) }\end{array}$ \\
\hline Kiribati & 15 & Wairua \\
\hline Kiribati & 17 & Wairua \\
\hline Samoan & 13 & Wairua \\
\hline Tuvaluan & 17 & Te Ana Kore \\
\hline Tuvaluan & 15 & Te Ana Kore \\
\hline Tongan/Tokelauan & 16 & Te Ana Kore \\
\hline Samoan & 15 & Wairua \\
\hline Cook Island Maori & 14 & Te Ana Kore \\
\hline Tokelauan/Samoan & 14 & Te Ana Kore \\
\hline
\end{tabular}




\section{APPENDIX 3: Run sheet for Pacific Focus Group Hui}

\section{$\underline{\text { Research Topic: }}$}

Belonging in everyday places for young Màori and Pacific and their aspirations for the future.

\section{Research Questions:}

What aspirations do young Māori and Pacific boys have for the future?

How do young Māori and Pacific boys establish a sense of belonging in everyday places?

INTRO to whānau and reminder to participants:

Thank them, the issues, the rationale, their contribution, type of research, what will include today, consent forms for last min additions- tea/coffee and snacks for whanau

- $\quad$ Active interview

- $\quad$ Moving around

- Clear dialogue

- Use of paper and post its with initials so data sorting is already done

- Whanau may be there

- $\quad$ Have food available for whanau while waiting, coffee, tea, juice, biscuits, fruit

- Have pizza delivered at a certain time

\section{Resources required:}

- $\quad$ Notepad and pen

- $\quad$ Posters with activity questions

- Dictaphone

- Batteries

- Kete

- $\quad$ Spare paper

- Thick envelope

- $\quad$ Name stickers

- $\quad$ Red, yellow and green stickers

- $\quad$ Prompting questions sheet

- $\quad$ Multiple different coloured post it notes

- $\quad$ Poster/butcher paper

- 2 large maps of Tūmanako

- 2 large traffic light pictures

- Activity cars for the future

- Pens/markers

- Ball/gloves
- $\quad$ A clip or video that gives an example of a spoken word poetry

- Straws

- Tape

- Tray of eggs

- Timer

- $\quad$ Pizza (have delivered-meat and vegetarian, wedges, garlic bread- get own drinks)

- Plates

- $\quad$ Napkins

- Cups

- Cleaning products

- Cleaning cloths

- Rubbish bags

- $\quad$ Coffee plunger for the parents

- $\quad$ Fruit platter for parents 


\section{STARTER:}

Explain that it's only audio recorded, so will need to refer to their fight name and say it out loud. Hand out an individual coloured post it to each person 9-10 different colours.

Ask them to choose a fighter name that they would use eg: Rowdy Rhonda Rousey

Tell them that they need to write their fighter name on the post it

Activity One: (5-10mins)

Big map of Tūmanako as is. (all come up and add to it) Put your post its of ideas of the things that you can do in Tūmanako

Activity Two: (5-10mins) (make these)

2 groups (4-6) using the traffic light board, use your own personal post its:

Green light, add post its of things kids like to do in Tūmanako

Yellow light, things kids want to do but have to travel outside of Tūmanako for

Red light, things kids wouldn't like to do in Tümanako

And why?

Activity Three: (5-10mins) (make labels, Tūmanako 2016 and Tūmanako 2025)

(Have a second map of Tūmanako, labelled "Tūmanako 2025" and ask the, to imagine what their community would look like in the future.

Ask them to put post its of things they would like to see young people doing

\section{FUTURE:}

Activity One: Cards (5-10mins)

Lay out picture cards all over the floor facing up

Ask them to imagine their future, pick up a card that they think will be related to their future and explain what is happening in the picture and what they will be doing. 
Activity Two: Human Continuum (5 mins)

- How often would you consider your future?

\begin{tabular}{|c|c|c|c|}
\hline Never & rarely & sometimes & usually \\
\hline
\end{tabular}

Activity Three: Pass the glove (5 mins)

"what are your dreams for the future?"

In a big circle, making sure everyone gets a turn, state your fighter name, share your dream and throw to someone else to share.

Activity Four: Brainstorm (5-10 mins)

In your 2 groups, brainstorm concerns and fears you have for the future

Activity Five: Straw game (They will have (10) mins to brainstorm and (5) mins to build the support) (5 mins explain and intro)

Demonstrate the idea of an egg being faced with the concerns of the future and the need for support.

What happens if the egg is left to fall?

It cracks-we need to build a support system to catch the fall so the egg doesn't break. We can create this with straws and tape.

Task: in your 2 groups, have a note taker or all contribute:

Brainstorm as many ideas as you can for listing what kind of support you could use to achieve your dreams.

For each support listed, you earn a straw. The objective is to list a lot so you have a lot of straws.

Make a safety net to catch a falling egg

Each group will be given 1m of Duct Tape and however many straws they earn.

Activity Six: Te Kete (individual and anonymous) (5 mins)

Write your fighter name on your coloured post it and write your dreams for your family and place into the kete. 
- What dreams do you have for your families in the future?

\section{BELONGING:}

Activity One: Brainstorm belonging (what it means to you and young people) (5 mins)

Activity Two: Spoken word poem (5mins to prep, then each individually present) (present 30 mins)

Show a video of an example of using the 5 senses to describe what a concept means to someone.

Eg of hearing sense and Hope:

Do you hear the birds amidst the anarchy?

Muffled by our confronting reality

Grasp the flickers of light at all cost

Hope is what we fight with

When all else is lost

Eg of concept of pollution with all senses:

Smells like smoke in my lungs, shit in stream, just plain horrible

Looks like a mess everywhere, dying animals and dirty kids, you just don't want to go there

Sounds like noise on hyperdrive, the sub falling out of the car and into the tweeter, my ears are exploding

Tastes like rubbish, a piece of mouldy bread spread with the poison of others

Feels like walking in a slum in the middle of a dying forest, the soul being ripped out of the heart of the earth, dying

I know what pollution is to me

Explain the task of doing the same thing, with Belonging. (doesn't have to rhyme)- (put up a poster explaining this as a scaffold)

\section{Fighter name}

\section{Belonging}

Belonging looks like...

Belonging feels like... 
Belonging smells like...

Belonging tastes like...

Belonging sounds like...

This is belonging

Activity Three: Eco Map of Belonging (20mins)

Depending on the numbers, 3-4 concepts so 3-4 people plus the individual.

The individual stands in the middle and the other pillars are in other corners of the room.

The pillars will be: Home, School, Peers, community groups or other (stipulate)

(put signs on the corners so they each know their role and their pillar)

The individual will say their fighter name and one by one tell each pillar how close to stand next to them and explain their sense of belonging or not and why.

CONCLUSION: Pass the glove (in circle, everyone getting a turn) (5mins)

How important is belonging to achieve your dream?

\section{Anonymous kete}

- If you could travel ahead of time and see your future, what would you like to see?

\section{Time capsule:}

- What message would you give to the boys of this boxing gym in the year 2025 ?

- What would you tell about your community now?

On a piece of paper, write your fighter name and a message you'd give them. Anything at all. Read this out, including your fighter name to the recording.

We'll seal it in a courier envelope and lock away in a filer and is not to be open until 2025.

\section{Feedback:}

I hope you have had a lot of fun. 
I will go over this and keep in touch for the next phase where we walk around in small groups and discuss your community. I'm aware that people live all over, so if you can write down your suburb, area you live on this spare sheet then that would be very helpful.

\section{- What is one thing that you got out of this today?}

Thank you so much for being here and I hope you know how much I've learnt from you all! 


\section{Appendix 4: Run sheet for Taiohi Māori Focus Group Hui}

\section{$\underline{\text { Research Topic: }}$}

Belonging in everyday places for young Māori and their aspirations and fears for the future.

\section{$\underline{\text { Research Questions: }}$}

What aspirations do young Māori have for the future?

What concerns do young urban Maori have for the future?

How do young Māori establish a sense of belonging in everyday places?

\section{A bit about me:}

INTRO to whānau and reminder to participants:

Thank them, the issues, the rationale, their contribution, type of research, what will include today, consent forms for last min additions- tea/coffee and snacks for whanau

The aim of the project

- To find out what your hopes and aspirations are for the future

- To look at the things that make you feel a sense of belonging in your everyday places

- To explore the assets and great things in the community

- To give you a voice and speak out about your future and be the narrators of your own story

\section{The contribution they will have on the problem}

- You will be part of a ground breaking study that has never been done in this style or focus

- You will help speak up for others who are silenced and replaced as a number in statistics

- You will benefit your community by highlighting the assets in the community

- People all over the world will have access to your views. Youth workers, teachers, researchers and others can all learn from you.

- You will be the ripple effect that will eventually become a wave in the object of change

\section{What today will cover}

- Active interview

- Moving around

- Clear dialogue

- Use of paper and post its with initials so data sorting is already done 
- Whanau may be there

- Have food available for whanau while waiting, coffee, tea, juice, biscuits, fruit

- Have pizza delivered at a certain time

- Don't have Blade with me for this one

\section{Resources required:}

- Probing questions

- Notepad and pen

- Posters with activity questions

- Dictaphone

- Batteries

- Kete (bag)

- Spare paper

- Thick envelope

- Name stickers

- Red, yellow and green stickers

- Prompting questions sheet

- Multiple different coloured post it notes

- Poster/butcher paper

- 2 large maps of The Gully

- 2 large traffic light pictures

- Activity cards for the future

- Pens/markers

- Ball

- An example of a spoken word poetry

- Straws

- Tape

- Tray of eggs

- $\mathrm{KFC}$

- Plates/trays

- Napkins

- Cups

- Cleaning products

- Cleaning cloths

- Rubbish bags 


\section{STARTER:}

Describe the concept of a spirit animal:

Ask them to choose one. If they have the same, change it up a bit.

Eg: Wolf Queen

Explain that it's only audio recorded, so will need to refer to their spirit name for everything written and say it out loud. Hand out an individual coloured post it to each person 6-10 different colours.

\section{Activity One: (5-10mins)}

Big map of the Gully. (all come up and add to it) Put your post its of ideas of the things that you can do in the area (write initials or name on post it)

Probing Q: why do you like doing it?

What brings you there?

How do you get there?

Activity Two: (5-10mins) (make these)

2 groups (4-6) using the traffic light boards, write initials of name on stickers. Red, orange, green showing the places:

Green light, add post its of things kids like to do in the Gully.

Yellow light, things kids want to do but have to travel outside of the Gully for Red light, things kids wouldn't like to do in the Gully.

And why?

Activity Three: (5-10mins) (make labels, Tūmanako 2016 and Tūmanako 2025)

(Have a second map of Gully, labelled "The Gully 2025" and ask them, to imagine what their community would look like in the future.

Ask them to put post its of things they would like to see young people doing 


\section{FUTURE:}

Activity One: Cards (5-10mins)

Lay out picture cards all over the floor facing up

Ask them to imagine their future, pick up a card that they think will be related to their future and explain what is happening in the picture and what they will be doing.

Activity Two: Human Continuum (5 mins)

- How often would you consider your future?

\begin{tabular}{|c|c|c|c|c|}
\hline Never & rarely & sometimes & usually & always \\
\hline
\end{tabular}

Activity Three: Pass the ballo (5 mins)

"what are your dreams for the future?"

In a big circle, making sure everyone gets a turn, state your spirirt name, share your dream and throw to someone else to share.

Activity Four: Brainstorm (5-10 mins)

In your 2 groups, brainstorm concerns and fears you have for the future

Activity Five: Straw game (They will have (10) mins to brainstorm and (5) mins to build the support) (5 mins explain and intro)

Demonstrate the idea of an egg being faced with the concerns of the future and the need for support.

What happens if the egg is left to fall?

It cracks-we need to build a support system to catch the fall so the egg doesn't break. We can create this with straws and tape.

Task: in your 2 groups, all contribute and write your name next to your input.

Brainstorm as many ideas as you can for listing what kind of support you could use to achieve your dreams. 
For each support listed, you earn a straw. The objective is to list a lot so you have a lot of straws.

Make a safety net to catch a falling egg

Each group will be given $1 \mathrm{~m}$ of Tape and however many straws they earn.

Activity Six: Te Kete (individual and anonymous) (5 mins)

Write your spirit animal on your coloured post it and write your dreams for your family and place into the kete.

- What dreams do you have for your families in the future?

\section{BELONGING:}

Activity One: Brainstorm belonging (what it means to you and young people) (5 mins)

Activity Two: Spoken word poem (5mins to prep, then each individually present) (present 30 mins)

Eg of concept of pollution with all senses:

Smells like smoke in my lungs, shit in stream, just plain horrible

Looks like a mess everywhere, dying animals and dirty kids, you just don't want to go there

Sounds like noise on hyperdrive, the sub falling out of the car and into the tweeter, my ears are exploding

Tastes like rubbish, a piece of mouldy bread spread with the poison of others

Feels like walking in a slum in the middle of a dying forest, the soul being ripped out of the heart of the earth, dying

I know what pollution is to me

Explain the task of doing the same thing, with Belonging. (doesn't have to rhyme)- (put up a poster explaining this as a scaffold)

Fighter name

Belonging

Belonging looks like...

Belonging feels like...

Belonging smells like...

Belonging tastes like... 
Belonging sounds like...

This is belonging

Activity Three: Eco Map of Belonging (20mins)

Depending on the numbers, 3-4 concepts so 3-4 people plus the individual.

The individual stands in the middle and the other pillars are in other corners of the room.

The pillars will be: Home, School, Peers, community groups or other (stipulate)

(put signs on the corners so they each know their role and their pillar)

The individual will say their fighter name and one by one tell each pillar how close to stand next to them and explain their sense of belonging or not and why.

CONCLUSION: Pass the glove (in circle, everyone getting a turn) (5mins)

How important is belonging to achieve your dream?

\section{$\underline{\text { Anonymous kete }}$}

- $\quad$ If you could travel ahead of time and see your future, what would you like to see?

\section{Time capsule:}

- What message would you give to the next lot of young Maori in the Gully in $2025 ?$

- What would you tell about your community now?

On a piece of paper, write your animal and a message you'd give them. Anything at all.

It will be shared in the presentation of this research.

\section{Feedback:}

I hope you have had a lot of fun.

I will go over this and keep in touch for the next phase where we walk around in small groups and discuss your community. I'm aware that people live all over, so if you can write down your suburb, area you live on this spare sheet then that would be very helpful.

\section{- What is one thing that you got out of this today?}

Thank you so much for being here and I hope you know how much I've learnt from you all! 


\section{APPENDIX 5: Focus Group Hui-Prompt Questions}

\section{PROMPT QUESTIONS}

\section{Research Topic:}

Belonging in everyday places for young Māori and Pacific and their aspirations for the future.

\section{Research Questions:}

What aspirations do young Māori and Pacific boys have for the future?

How do young Māori and Pacific boys establish a sense of belonging in everyday places?

\section{Prompting Questions throughout the hui}

- When looking at the traffic lights: ask:

- How do you maintain connected to people?

- How long have you lived here?

- Have you moved from another town?

- Why do you think your community will be like that in the future?

- What drew you to the cards?

- Who would you normally turn to for support?

- Why?

- What is it about them that makes them supportive?

- Can schools and community places do this too? Do they already do this?

- Where do these concerns for the future come from?

- What influence do you think TV and social network has on these concerns?

- Who are your idols? 


\section{APPENDIX 6: Walk-Along Interviews- Additional Prompt Questions}

Belonging in everyday places for young Mäori and Pacific and their aspirations for the future.

\section{Research Questions:}

What aspirations do young Māori and Pacific boys have for the future?

How do young Māori and Pacific boys establish a sense of belonging in everyday places?

Refresh from the hui:

\section{Prompting Questions throughout the hui}

- When looking at the traffic lights: ask:

- How do you maintain connected to people?

- How long have you lived here?

- Have you moved from another town?

- Why do you think your community will be like that in the future?

- What drew you to the cards?

- Who would you normally turn to for support?

- Why?

- What is it about them that makes them supportive?

- Can schools and community places do this too? Do they already do this?

- Where do these concerns for the future come from?

- What influence do you think TV and social network has on these concerns?

- Who are your idols?

\section{Walk-along questions:}

1. Your name

2. You guys are going to lead this walk

3. Where's the best place to eat around here?

4. If we could fly and not have to walk, where would you guys take me?

5. What's great about it?

6. How do the owner/shop keepers treat you? 
7. Have you lived here long?

8. Moved from somewhere?

9. Do you know your neighbours?

10. Would you feel comfortable going to your neighbours to ask a favour?

11. Do you think you'd be living in the [Gully] as an adult?

12. Where do you go to school?

13. Take me to where you hang out?

14. What do you get up to? Tell me a story about where you hang out.

15. (ask each of them to share a story)

16. Can you remember the things you like to do that you added on the map activity?

17. What is it about those places that attract you?

18. How would you feel if that were gone?

19. What is it about everyday things that keeps you going?

20. What about the places you guys thought not to go, you know the red stickers. Why wouldn't you go there? 


\section{APPENDIX 7: Participant information sheet}

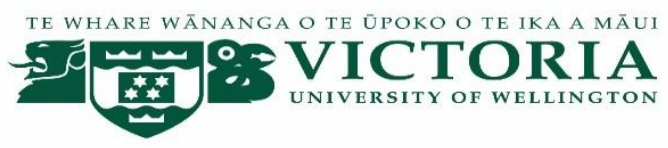

\section{Participant information sheet for a study about belonging and the hopes and fears of the future for young Māori and Pacific in Aotearoa New Zealand.}

Researcher: Hine Funaki

Supervisor: Associate Professor Joanna Kidman

Tēnā koe, Mālō ‘e lelei

I am a student in Te Kura Māori in the Faculty of Education at Victoria University of

Wellington and I am of Māori (Ngāpuhi, Ngāi Tahu) and Tongan descent. I am doing a study about Māori and Pacific young people's sense of belonging in their communities and how this influences their hopes, dreams and worries about the future. My thesis is part of a larger study about Māori and Pacific young people which is funded by Ngā Pae o te Māramatanga, the Māori Centre of Research Excellence at the University of Auckland. The leaders of the larger study are my supervisor, Dr Joanna Kidman (Ngāti Raukawa, Ngāti Maniapoto), Victoria University of Wellington; and, Professor Patricia Johnston, (Ngāi Te Rangi, Ngāti Ranginui, Te Arawa), Te Whare Wānanga o Awanuiārangi; and Professor Huia Jahnke (Ngāti Kahungunu, Ngāti Toa Rangatira, Ngāi Tahu, Ngāti Hine) Massey University.

I would like to invite you to be part of this study. If you agree to be involved, I will arrange a time to come and talk to you and other members of your gym as a group. During that time, I will ask the group questions about what it is like being a young person growing up in your neighbourhood and the hopes you and your whānau have for the future. I will ask you to tell me about the things that Māori and Pacific young people worry about as they grow older, and the kind of society you hope to be part of in the future. If you would like to bring whānau/family with you, they would be very welcome. This conversation will take approximately two hours and will be audio recorded.

When I have looked at the information you have given me, I would like to come back to the gym and arrange a time for the group to take a walk through the neighbourhood around the gym. We call these 'walk-along' interviews. If you are willing to join this group, we will take a one and a half hour walk through the area near the gym and I will ask you questions about the places in the neighbourhood where you feel a sense of belonging; places that you think are less welcoming to Māori and Pacific young people and what sorts of things you would like to see change in the area. You are welcome to bring whānau/family members with you if you wish. I will audio-record our conversation and take notes as we walk. 
It is up to you to decide if you want to be involved with the group conversation or the walkalong interview or both. Your participation is voluntary and we encourage you to talk to your whānau so they can help you to decide about this. If they would like more information, they can contact me or any of the other people listed at the end of this message.

Here is some information about the study:

- You will not be personally identified when I write about this study. That means that I will not use your name or give any information about you or your family that might lead others to recognise you. What you say to me will be confidential within the group. The transcriber and my thesis supervisor will see the information but all names and identifying information will be removed before the other researchers (Professor Patricia Johnston and Professor Huia Jahnke) involved with this study see it.

- The gym will not be identified. No one who reads about this study will recognise which gym was involved.

- Your participation in this project is voluntary. That means that you can decide whether you want to be involved. It is okay if you decide that you do not want to be involved. You can also decide which part of the study you want to be involved with, the group discussion, the walk-along interview or both.

- If you decide after the group discussion and/or the walk-along interview that you do not want me to use the information you have given to me, let me know in person, or by telephone or by email within four weeks of the interview taking place.

- If you would like a written report about my findings, please let me know when you sign the consent form.

- All data from this project will be destroyed 5 years after the conclusion of the research.

- The findings from this study will be discussed at conferences and published in academic journals.

If you have any concerns about any aspects of this study, you can contact the Victoria University of Wellington Human Ethics Committee: XXXXX

Ngā mihi nunui

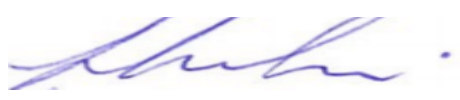

Hine Funaki 


\section{APPENDIX 8: Parent/Caregiver Consent form}

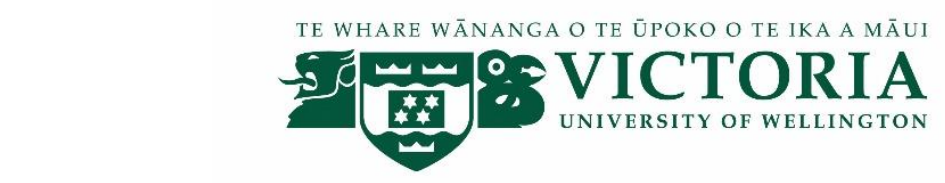

CONSENT FOR CHILD/REN TO PARTICIPATE IN RESEARCH

Belonging in everyday places for young Māori and Pacific and their aspirations and fears for the future.

I have read the Parent Information Sheet and I understand what this research involves. I have had an opportunity to ask questions and have them answered to my satisfaction.

I have been made aware that any information I provide will be kept confidential to the researcher, my supervisor and the person who transcribes the audio recordings of our discussions. I understand that discussions will be audio recorded and that my child/ren will have the opportunity to check the transcript of their discussion before publication of the results. I also understand that the published results will not include their name and they will not be made identifiable in any way.

I understand that my child/ren may withdraw from the study within 4 weeks of taking part in the group discussion without the need to provide any reason.

They will do this by calling or emailing Hine Funaki on

Email: $\underline{X X X X X X}$ or phone: $X X X X X X X$

I am happy for my child/ren to take part in the group discussion

Yes $\square \quad$ No

I am happy for my child/ren to take part in the walk-along discussion

Yes $\square \quad$ No

I wish to have a summary report of the findings in this research

Yes $\square \quad$ No

\section{Signed:}

Name of whānau member and participant:

Date: 


\section{APPENDIX 9: Information Sheet for Gym Provider}

\section{Gym provider information sheet for a study about belonging and the hopes and fears of the future for young Māori and Pacific in Aotearoa New Zealand.}

Researcher: Hine Funaki

Supervisor: Associate Professor Joanna Kidman

Tēnā koe, Mālō ‘e lelei

I am a student in Te Kura Māori in the Faculty of Education at Victoria University of Wellington and I am of Māori (Ngāpuhi, Ngāi Tahu) and Tongan descent. I am doing a study about Māori and Pacific young people and their sense of belonging, or not belonging, in their communities and how this influences their hopes, dreams and fears about the future. My thesis is part of a larger study about Māori and Pacific young people which is funded by Ngā Pae o te Māramatanga, the Māori Centre of Research Excellence. The leaders of the larger study are my supervisor, Dr Joanna Kidman (Ngāti Raukawa, Ngāti Maniapoto), Victoria University of Wellington; Professor Patricia Johnston, (Ngāi Te Rangi, Ngāti Ranginui, Te Arawa), Te Whare Wānanga o Awanuiārangi; and Professor Huia Jahnke (Ngāti Kahungunu, Ngāti Toa Rangatira, Ngāi Tahu, Ngāti Hine) Massey University.

I would like to invite members of your gym to take part of this study. If they are willing to be involved, I will arrange a time to come and talk to the members of your gym as a group. During that time, I will ask the group questions about what it is like being a young person growing up in their neighbourhood and the hopes they and their whānau have for the future. I will ask them to tell me about the things that Māori and Pacific young people worry about as they grow older, and the kind of society they hope to be part of as an adult. If they would like to bring whānau/family along, they would be very welcome. This conversation will take approximately two hours and will be audio recorded.

When I have looked at the information they have given me, I would like to come back to the gym and arrange a time for the group to take a walk through the neighbourhood around the gym. We call these 'walk-along' interviews. If they are willing to join this group, we will take a one and a half hour walk through the area near the gym and I will ask questions about the places in the neighbourhood where they feel a sense of belonging; places that they think are less welcoming to Māori and Pacific young people and what sorts of things they would like to see change in the area. They are welcome to bring whānau/family members along if they wish. I will audio-record our conversation and take notes as we walk.

It is up to them to decide if they want to be involved with the group conversation or the walkalong interview or both. Their participation is voluntary and we encourage them to talk to 
their whānau so they can help them to decide about this. If they would like more information, they can contact me or any of the other people listed at the end of this message.

Here is some information about the study:

- Members will not be personally identified when I write about this study. That means that I will not use their name or give any information about them or your family that might lead others to recognise them. What they say to me will be confidential within the group. The transcriber and my thesis supervisor will see the information but all names and identifying information will be removed before the other researchers (Professor Patricia Johnston and Professor Huia Jahnke) involved with this study see it.

- The gym will not be identified.

- Member's participation in this project is voluntary. That means that they get to decide whether they want to be involved. It is okay if they decide that they do not want to be involved. Members also get to decide which part of the study they want to be involved with, the group discussion, the walk-along interview or both.

- If members decide after the group discussion and/or the walk-along interview that they do not want me to use the information they have given to me, let me know in person, by telephone or by email within four weeks of the interview taking place.

- If members/whānau would like a written report about my findings, they are asked to let me know when they sign the consent form.

- All data from this project will be destroyed 5 years after the conclusion of the research.

- The findings from this study will be discussed at conferences and published in academic journals.

If you have any concerns about any aspects of this study, you can contact the Victoria

University of Wellington Human Ethics Committee, email: XXXXXX or Associate Professor XXXX, the convener of the committee at: (ph) XXXX or email XXXXX

If you have any other questions about this study, you can also contact me directly either by email or telephone: Hine Funaki,XXXXX (ph) XXXXX or my thesis supervisor Dr Joanna Kidman at: (ph) XXXXX or email $\underline{X X X X X X}$.

Ngā mihi nunui

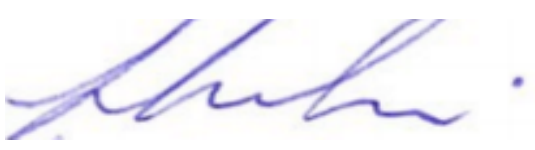

Hine Funaki 


\section{Appendix 10: Participant Consent Form}

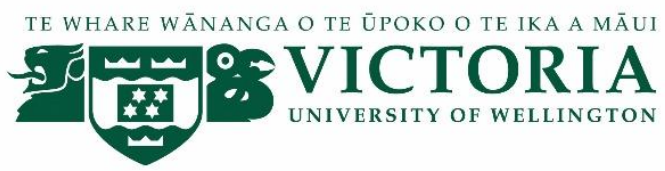

\section{CONSENT TO PARTICIPATE IN RESEARCH}

\section{Belonging in everyday places for young Māori and Pacific and their aspirations and fears for the future.}

\section{This consent form will be held for a period of 5 years}

I have read the Information Sheet and I understand what this research involves. I have had an opportunity to ask questions and have them answered to my satisfaction.

I have been made aware that any information I provide will be kept confidential to the researcher and the person who transcribes the audio recordings of our interview. I understand that interviews will be audio recorded and that I will have the opportunity to check the transcript of my interview before publication of the results. I also understand that the published results will not include my name and I will not be made identifiable in any way. I understand that I may withdraw from the study within 4 weeks of completing the interview without the need to provide any reason.

I will do this by calling or emailing Hine Funaki on Email: $\underline{X X X X X}$ or phone: $X X X X X X$

I agree to take part in this research.

I wish to have a copy of the transcript of my interview

I wish to have a copy of the thesis and any articles

which may result from this research project

Signed:

\section{Name of participant:}

Date:
Yes $\square \quad$ No

Yes $\square \quad$ No 


\section{APPENDIX 11: Gym Consent Form}

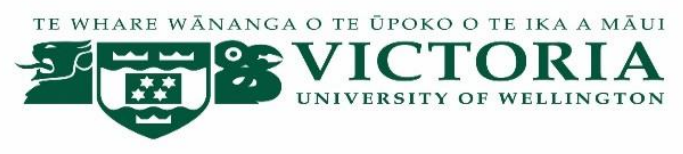

GYM CONSENT FORM

\section{Belonging in everyday places for young Māori and Pacific and their aspirations and fears for the future.}

I agree to provide the gym venue as a location for the initial hui with members and their whānau. I have read the Information Sheet and I understand what this research involves. I am aware that each participant and their whānau has their own individual Consent Form and Participation Information Sheet. I have had an opportunity to ask questions and have them answered to my satisfaction.

I have been made aware that any information that is provided by the gym members and their whānau will be kept confidential to the researcher, the supervisor and the person who transcribes the audio recordings of discussions. I understand that discussions between members/whānau and the researcher will be audio recorded and that they will have the opportunity to check the transcript of their discussions before publication of the results. I also understand that the published results will not include any names and will not be made identifiable in any way.

I understand that members may withdraw from the study within 4 weeks of the initial group discussion without the need to provide any reason. They will do this by calling or emailing Hine Funaki on

Email: hine.funaki@vuw.ac.nz or phone:022 1062067

\section{Signed:}

Date: 